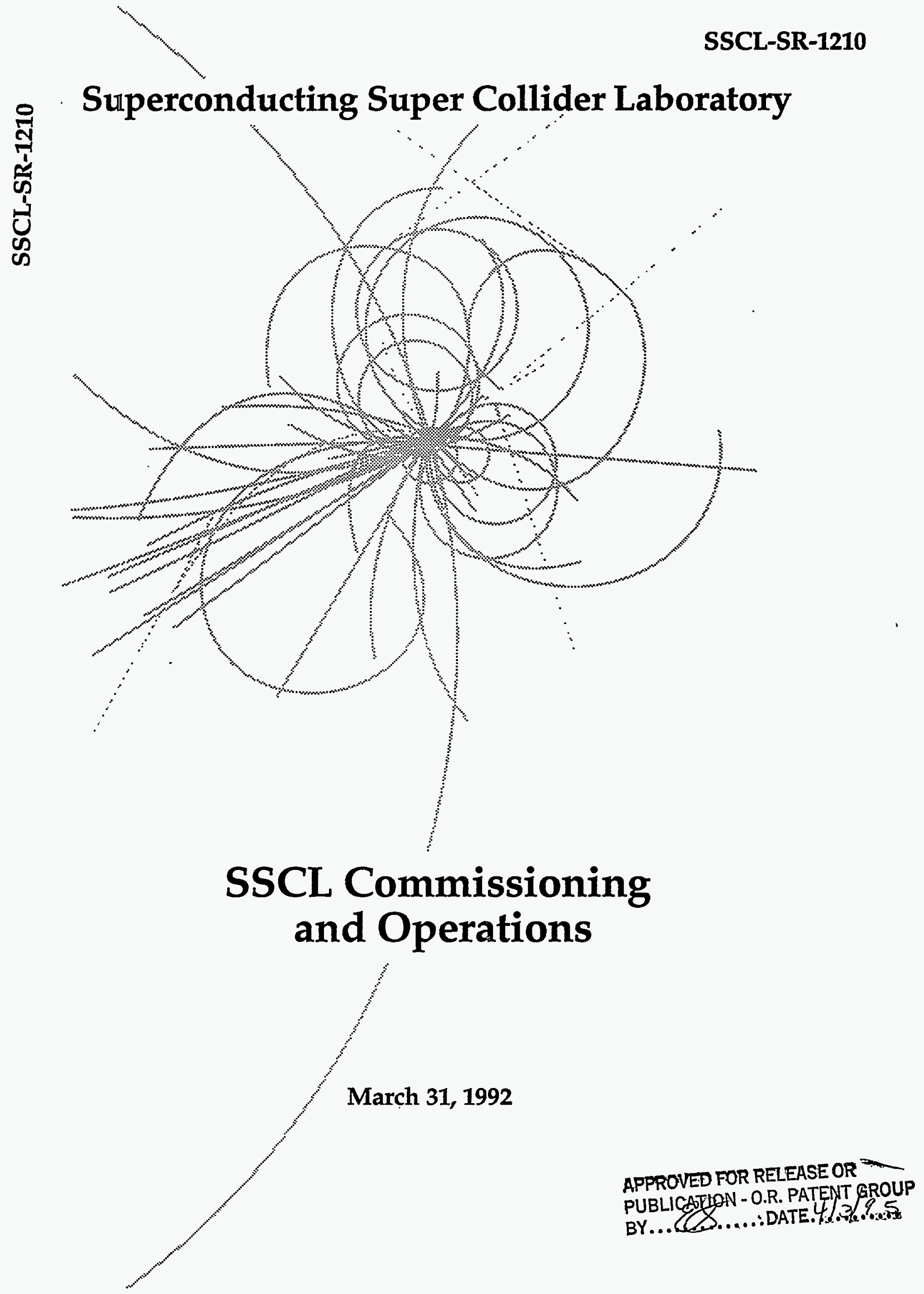


SSCL-SR-1210

\title{
SSCL Commissioning and Operations
}

\author{
Superconducting Super Collider Laboratory ${ }^{\dagger}$ \\ 2550 Beckleymeade Avenue \\ Dallas, Texas 75237
}

March 31, 1992

\section{DISCLAIMER}

\begin{abstract}
This report was prepared as an account of work sponsored by an agency of the United States Government. Neither the United States Government nor any agency thereof, nor any of their employees, makes any warranty, express or implied, or assumes any legal liability or responsibility for the accuracy, completeness, or usefulness of any information, apparatus, product, or process disclosed, or represents that its use would not infringe privately owned rights. Reference herein to any specific commercial product, process, or service by trade name, trademark, manufacturer, or otherwise does not necessarily constitute or imply its endorsement, recommendation, or favoring by the United States Government or any agency thereof. The views and opinions of authors expressed herein do not necessarily state or reflect those of the United States Government or any agency thereof.
\end{abstract}

TOperated by the Universities Research Association, Inc., for the U.S. Department of Energy under Contract No. DE-AC35-89ER40486.

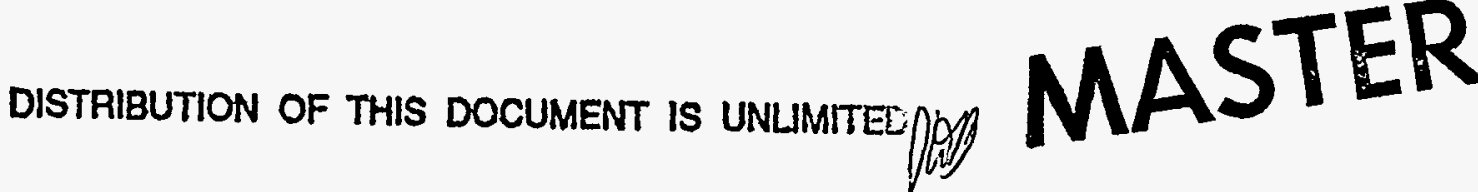




\section{DISCLAIMER}

Portions of this document may be illegible in electronic image products. Images are produced from the best available original document. 


\section{Table of Contents}

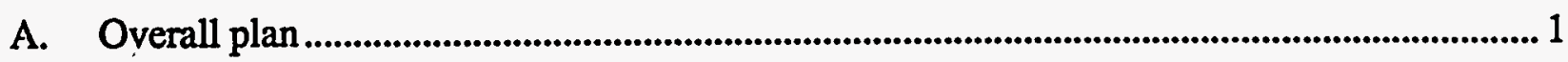

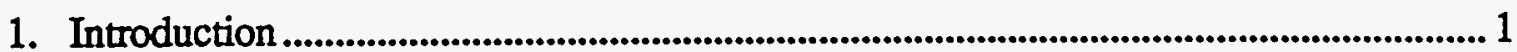

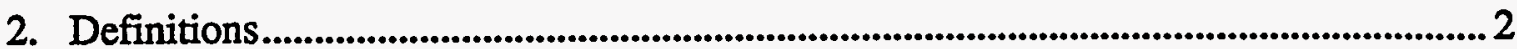

a) Construction Completion ......................................................................................... 2

b) Pre-Operations......................................................................................................... 2

c) Commissioning ................................................................................................. 2

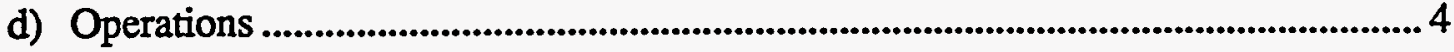

3. Types of Funds ...................................................................................................................... 4

a) SSC Funds ............................................................................................................ 4

b) High Energy Physics (HEP) Funds ............................................................................ 4

4. Injector Accelerators ............................................................................................................ 4

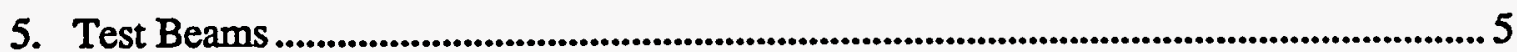

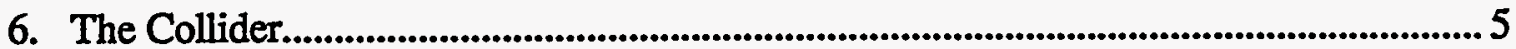

7. Magnet Test and Development Facilities....................................................................6 6

8. Experimental Facilities...................................................................................................... 6

9. Physics Research ...................................................................................................................... 6

B. Commissioning and Operations ........................................................................................

1. General Features and Assumptions................................................................................ 7

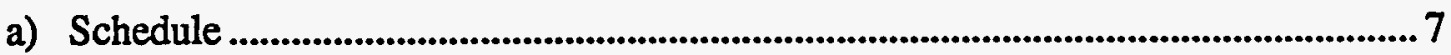

b) Labor Categories and Rates.........................................................................................

c) Model for Operations Shifts ......................................................................................

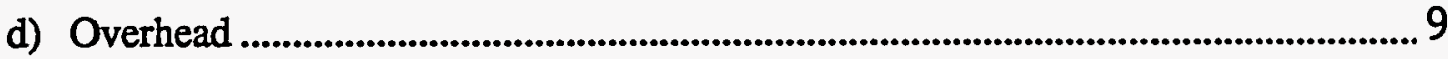

2. The Commissioning Program............................................................................................. 11

a) Injector Accelerators ...................................................................................................... 11

b) Collider Sectors.......................................................................................................... 24

c) Experimental Facilities.................................................................................................... 42

d) Magnet Research Laboratory .....................................................................................53

e) Physics Program...........................................................................................................5

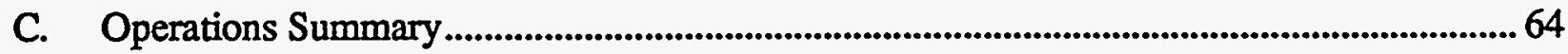

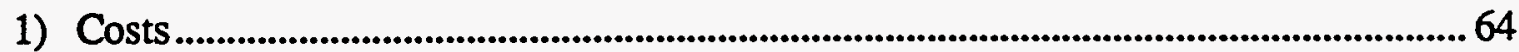

2) Manpower........................................................................................................................... 69 


\section{List of Figures and Tables}

Figure 1.0 Example Accelerator Schedule .......................................................................... 3

Table 1.0

Table 2.0

Table 3.0

Table 4.0

Figure 2.0

Table 5.0A

Table 5.0B

Table 6.1

Table 6.2

Table 6.3

Table 6.4

Table 6.5

Table 6.6

Figure 3.1

Figure 3.2

Figure 3.3

Figure 3.4

Figure 3.5

Figure 3.6

Figure 4.0

Table 7.0

Table 8.1

Table 8.2

Table 8.3

Table 8.4

Table 8.5

Table 8.6

Table 8.7

Table 8.8

Table 8.9

Table 8.10

Table 8.11

Figure 5.1

Figure 5.2

Figure 5.3

Figure 5.4

Figure 5.5

Figure 5.6

Figure 5.7

Figure 5.8

Figure 5.9

Accelerator Design Parameters for Collider Operations...................................5

SSC Commissioning and Operations Schedule ................................................. 8

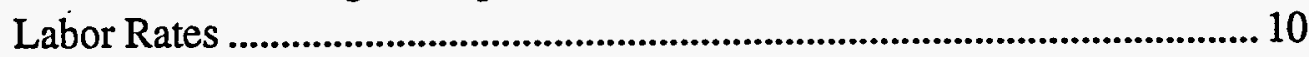

Projected Overhead Rates .................................................................................. 10

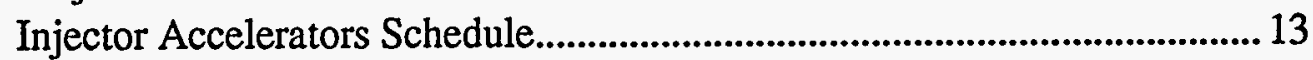

Injector Systems Cost for Pre-Operation ....................................................... 14

Injector Systems Cost for First Shift Operation .............................................. 15

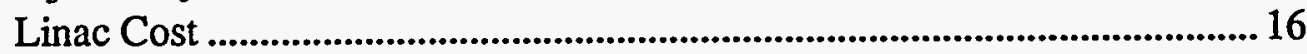

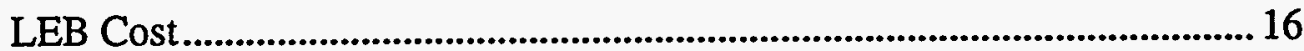

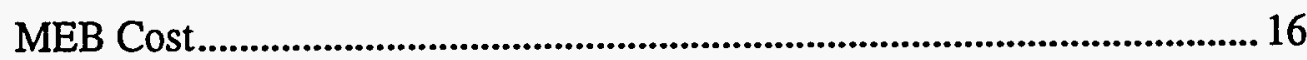

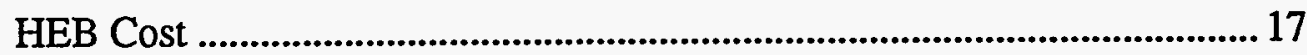

Injector Summary Cost....................................................................................... 17

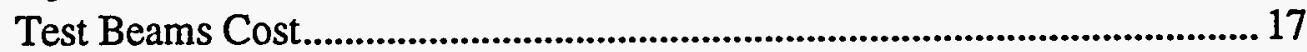

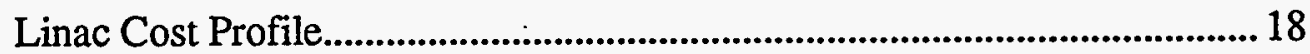

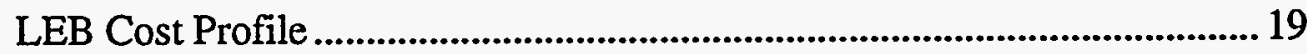

MEB Cost Profile ............................................................................................ 20

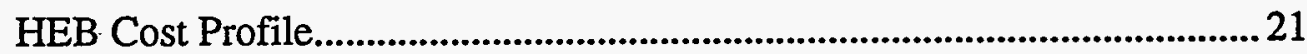

Injector Summary Cost Profile......................................................................... 22

Test Beams Cost Profile ................................................................................... 23

Collider Sector Commissioning Schedule....................................................... 25

Collider Sector Cost for First Shift Operations.............................................. 26

Collider Sector 1 Cost ....................................................................................... 27

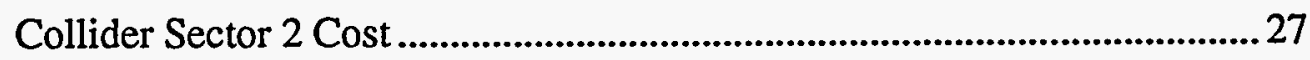

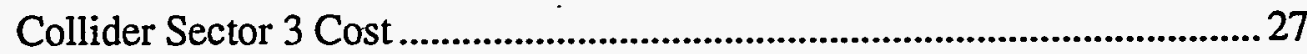

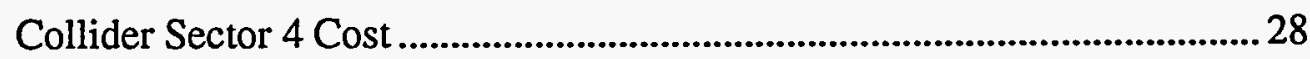

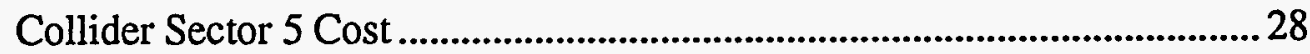

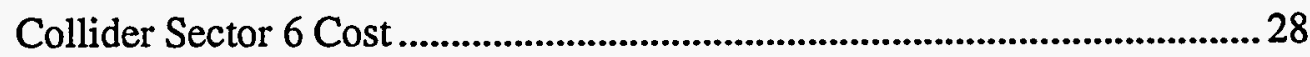

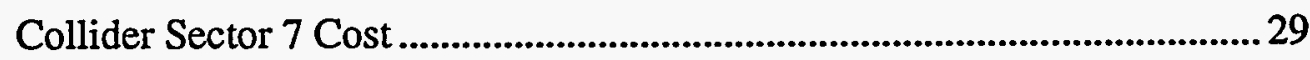

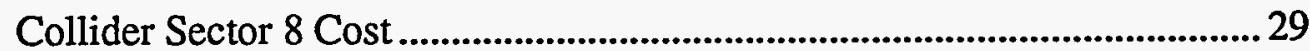

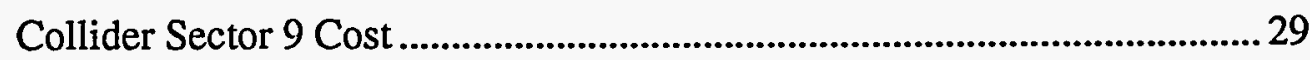

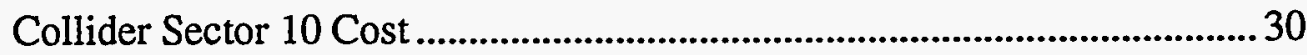

Summary Total Collider Sectors .......................................................................30

Collider Sector 1 Cost Profile ....................................................................... 31

Collider Sector 2 Cost Profile ..................................................................32

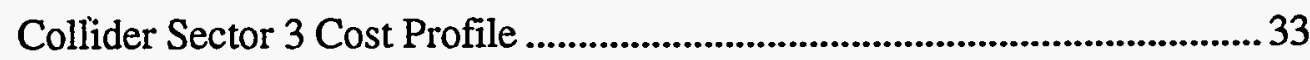

Collider Sector 4 Cost Profile ..................................................................34

Collider Sector 5 Cost Profile ........................................................................ 35

Collider Sector 6 Cost Profile ....................................................................36

Collider Sector 7 Cost Profile ........................................................................... 37

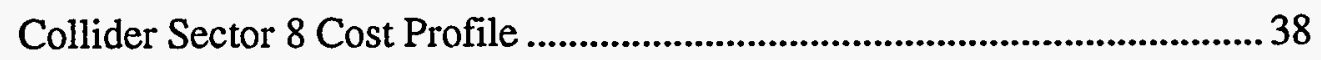

Collider Sector 9 Cost Profile .......................................................................... 39 
Figure 5.10 Collider Sector 10 Cost Profile ....................................................................... 40

Figure 5.11 Total Collider Sectors Cost Profile ............................................................. 41

Table 9.0

Experimental Facilities Cost for First Shift Operation..................................... 44

Table 10.0 Equipment, Power, and AIP for Experimental Areas ...................................45

Table $11.1 \quad$ Experimental Area 4 Cost ...................................................................................4 46

Table 11.2 Experimental Area 1 Cost ...............................................................................4 46

Table 11.3 Experimental Area 5 Cost ........................................................................4 46

Table 11.4 Experimental Area 8 Cost ...............................................................................4 47

Table 11.5 Total Experimental Areas Cost ......................................................................4 47

Figure $6.1 \quad$ Exp Area 4 Cost Profile ................................................................................. 48

Figure $6.2 \quad$ Exp Area 1 Cost Profile ............................................................................. 49

Figure 6.3 Exp Area 5 Cost Profile ......................................................................................50

Figure 6.4 Exp Area 8 Cost Profile ...................................................................................51

Figure 6.5 Total Exp Areas Cost Profile .....................................................................5 52

Table 12.0 Magnet Laboratory Direct Cost.......................................................................5

Table 13.0 Magnet Laboratory Total Costs.....................................................................55

Figure 7.0 Magnet Lab Cost Profile .................................................................................5

Figure 8.0 Total Physicists in SSC Experimental Program.............................................58

Figure 9.0 SSCL Physics Research Program Staff ...........................................................59

Table 14.0 Physics Operations \& Equipment Plan ............................................................6 61

Table 15.0 Physics Operations Cost Summary ...............................................................6 62

Figure 10.0 Physics Operations Cost Profile.............................................................6 63

Table 16.0 Summary of Integrated Operations Costs ...........................................................65

Figure 11.0A SSCL Total Operations Cost Profile (Cost/Month) ......................................66

Figure 11.0B SSCL Total Operations Cost Profile (Cost/Year) ...........................................6 67

Table 17.0

Annual Cost Summary ..............................................................................6 68

Table 18.0 SSCL Operations Staff Projection.................................................................. 70

Table 19.0 Staff Category Populations for FY2000........................................................70

Figure 12.0 Accelerator Operations Manpower Total - SSCL and FNAL......................71

Figure 13.0 Accelerator Operations Manpower Comparison- SSCL and FNAL............. 72 


\section{A. OVERALL PLAN}

\section{Introduction}

The SSC, with an energy of $20 \mathrm{TeV} / \mathrm{Beam}$, requires a sequence of individual accelerators of increasing energy in the injector chain. These are the Linac, Low Energy Booster (LEB), Medium Energy Booster (MEB), and High Energy Booster (HEB). Each accelerator system must be completed in sequence in order to provide beam to the next higher energy accelerator. The collider itself is comprised of ten sectors, each of which in terms of superconducting magnet bending strength, is equivalent to two HEB injectors. The completion of all injectors and collider sectors is required before stored beams can circulate in preparation for colliding beam operation.

Four experimental halls are planned for the detector systems. Each major detector will be assembled in one of the halls by a world-wide collaboration of scientists. In addition, above ground facilities provide shops and test facilities for accelerator technical systems, superconducting magnet and materials research and development, and for detector assembly and operations.

The purpose of this report is to present a plan for the sequential commissioning and operation of these individual accelerators and other technical facilities of the SSC. A central objective of this plan is to describe the activities at the SSCL that are not included as part of the construction project TPC, even though they occur during the overall project construction timeframe. Examples of such activities include the operation of general laboratory facilities and services not specifically related to construction, the operating costs for the individual accelerators in the injector chain once these facilities have been commissioned, and the costs of SSCL physics research groups. The Department of Energy has provided the following decision with regard to these operations categories for the SSCL. ${ }^{1}$

"It is the Department's conclusion that the funding for these operating costs, which are estimated to total approximately $\$ 460$ million (as-spent), should be provided outside the total project cost. These costs will begin at a low level in FY 1993, with a slow ramp-up during the remainder of the construction project. This is consistent with the approach used at other laboratories and is a logical decision since the costs are more endemic to operations after construction than to preparations for operations during construction. These funds for laboratory operations should be provided by additional appropriations for the high energy physics program which has the ultimate responsibility for operation of the SSC."

\footnotetext{
${ }^{1}$ Report on the Superconducting Super Collider Cost \& Schedule Baseline, U.S. Department of Energy, DOE-ER-0468P, January 1991
} 
The projected costs are provided in Section B for the operations of the following SSC Laboratory facilities and research Areas:

a) Injection Accelerators

b) Collider Sectors

c) Experimental Facilities

d) Magnet Research Laboratory

e) Physics Research

\section{Definitions}

An SSC Laboratory facility is defined as a major system of the overall laboratory complex that can achieve independently an operational status with regard to its initial mission. An example would be the Medium Energy Booster (MEB) and its associated support facilities.

For a given facility, the sequence of events leading to "operations" are "construction completion" followed by a "commissioning" phase. This final phase is used to test all systems and components together to insure that the facility functions properly. The time sequence of these phases is outlined in Figure 1.0. Dates and time durations are provided in Section B for each operations category. The definition of each phase is provided below.

\section{a) Construction Completion}

This is the time at which all major systems of a facility are in place and ready to operate together to provide the basic objective of that facility. In the case of an injector accelerator it is expected that each technical component (e.g., magnets, power supplies, if system, controls, etc.) will have been individually tested during the construction phase to insure that the performance requirement has been achieved.

\section{b) Pre-Operations}

This phase provides for the build-up and training of the technical staff who will help to commission and subsequently operate the facility. The operations crews may assist in the tests of individual components in the final construction phases noted above. The pre-operations phase starts before construction completion and includes the commissioning period below. The costs associated with pre-operations are included in the Total Project Costs (TPC).

\section{c) Commissioning}

This period follows construction completion. During commissioning all systems are tested and operated together to test and insure that the basic technical objective is achieved. In the case of an accelerator, this basic objective is accelerated beam. This period allows for tuning, timing, debugging, and perhaps minor modifications of individual components to optimize performance as well as reliability. Commissioning is complete when the basic objective is achieved, i.e., the facility can supply adequate beam for "start-up", and commissioning of the next higher-energy accelerator.

In addition to its own commissioning period, when an injector accelerator is used in the commissioning program for one of the higher energy accelerators or the collider, the costs of its operation is charged to pre-operations. We assume that the lower energy accelerators will be utilized half time in the commissioning of higher energy machines. For example, during the commissioning period of the MEB, the Linac and the LEB are charged half time to preoperations and half time to operations. 
Figure 1.0 Example Accelerator Schedule

Construction

Pre-Operations

Operations $\vdash$ Staffing $\mid$ Commissioning Training 


\section{d) Operations}

The start of operations is signalled by utilization of the facility following commissioning. In the case of injector accelerators, this includes operations for continued improvements, service to other accelerators (apart from commissioning), and operations for Test Beams and physics experiments.

For the Magnet Research Laboratory, the start of operations is signalled by the use of the facilities for future R\&D activities that are beyond the current program which is specific to the initial superconducting magnets of the HEB and Collider Rings.

\section{Types of Funds}

Funds are categorized by their supporting functions as defined in the previous section.

\section{a) SSC Funds}

SSC funds support the construction and pre-operations phases. "Construction Funds" support the construction phase within the Total Estimated Cost (TEC).

"Pre-Operations Funds" support the pre-operations activities including commissioning as defined above. These are included within the Total Project Cost (TPC).

\section{b) High Energy Physics (HEP) Funds}

HEP funds are expected to support the "Operations" phase which is outside of the TPC. Within these funds are included the funding categories of Operating, Equipment, Accelerator Improvement Projects (AIP) and General Plant Projects (GPP)

\section{Injector Accelerators}

There are four Injector accelerator systems, the Linac, LEB, MEB, and HEB, and associated beam transfer systems that deliver beam from one accelerator to the next. It is expected that the injectors will be constructed, tested and commissioned in sequence such that the collider can be commissioned with beam delivered from the HEB in FY99.

The conventional facility structures associated with each accelerator will nominally be complete before the installation start of the technical components. This will be indicated by the SSCL acceptance of these structures from the AE/CM. Other conventional systems including power and utilities are needed for component tests even before the start of commissioning. It is assumed that all relevant conventional systems will be complete before the start of the commissioning phase.

The performance goals for the SSC accelerator are described in the SSC Site-Specific Conceptual Design Report (Table 1.0). It is not possible to predict the exact time that each accelerator will operate at its maximum capability particularly with regard to luminosity. It is expected that after the commissioning period each accelerator will readily have the capability to commission the next higher energy machine. This means that the beam ejection system and beam transfer lines to the next accelerator are operational. In addition, the commissioning tests should provide evidence that the machine has the capability to reach maximum design performance and that the methods of achieving full design performance are understood. 


\section{Test Beams}

The test beam facilities are comprised of the beam transport lines and the associated experimental facilities. The commissioning of these facilities requires the operation of the Linac, LEB, and MEB accelerators. After commissioning it is expected that there will be a continuous utilization of these facilities by experimental physics groups for test and calibration of various detector systems and components. A daily three-shift operation is projected in order to meet the needs of the test and calibration programs associated with the various detectors.

Table 1.0 Accelerator Design Parameters for Collider Operations

\begin{tabular}{|c|c|c|c|c|c|}
\hline & Collider & HEB & MEB & LEB & Linac \\
\hline Kinetic energy & $20 \mathrm{TeV}$ & $2 \mathrm{TeV}$ & $200 \mathrm{GeV}$ & $11.1 \mathrm{GeV}$ & $0.6 \mathrm{GeV}$ \\
\hline Momentum & $20 \mathrm{TeV} / \mathrm{c}$ & $2 \mathrm{TeV} / \mathrm{c}$ & $200 \mathrm{GeV} / \mathrm{c}$ & $12 \mathrm{GeV} / \mathrm{c}$ & $1.2 \mathrm{GeV} / \mathrm{c}$ \\
\hline Superconducting/normal & SC & SC & normal & normal & normal \\
\hline Peak field (T) & 6.6 & 6.4 & 1.7 & 1.2 & - \\
\hline Circumference $(\mathrm{km})$ & 87.12 & 10.89 & 3.96 & 0.57 & - \\
\hline Bunch spacing (m) & 5 & 5 & 5 & 5 & - \\
\hline $\begin{array}{l}\text { Normalized emittance } \\
\text { ( } \pi \mathrm{mm} \text {-mrad, } \mathrm{rms} \text { ) }\end{array}$ & 1.0 & 0.8 & $0.7^{\circ}$ & 0.6 & $<0.5$ \\
\hline Protons per bunch $(\mathrm{N})$ & $0.75 \times 10^{10}$ & $1 \times 10^{10}$ & $1 \times 10^{10}$ & $1 \times 10^{10}$ & - \\
\hline$N_{\text {tot }}$ for collider operation & $1.3 \times 10^{14}$ & $2 \times 10^{13}$ & $8 \times 10^{12}$ & $1 \times 10^{12}$ & - \\
\hline Cycle time for collider oper. & - & $4.3 \mathrm{~min}$ & $8 \mathrm{~s}$ & $0.1 \mathrm{~s}$ & \\
\hline
\end{tabular}

\section{The Collider}

Each of the ten sectors of the collider is comprised of two superconducting magnet systems each of which is near the size of the HEB. There are almost 1,000 superconducting magnets in each sector. While each magnet will undergo testing procedures at room temperature, a large fraction will not have been tested at liquid helium temperatures.

The commissioning process represents the first time that the complete ensemble of all magnets in a sector will be cooled to $4^{\circ} \mathrm{K}$ and tested. The commissioning program is intended to filter out any remaining magnets which have marginal characteristics and to ensure that the complete ensemble will function according to design specifications.

The sequence of sector construction completions and subsequent sector commissionings is scheduled to extend over a 3-year period. The sequence and durations are detailed in Section B. All ten sectors of the collider are projected to be in operational readiness for the first circulating beam tests in the collider by March 1999. The period of commissioning the complete collider with circulating beam will extend to September 1999. After this period, full operations for experiments will be underway. Details of the projected physics utilization of the collider following commissioning are presented in a separate report. 


\section{Magnet Test and Development Facilities}

After the construction project mission of providing magnets for the initial installation in the HEB and the collider, the magnet Research and Development group will enter an operational phase to conduct research projects on superconducting magnets and materials as well to provide continuing support for accelerator operations. The operations support includes magnet repair, magnet replacement, and R\&D as required to resolve operational problems.

\section{Experimental Facilities}

When an experimental hall and its surface structures are ready for beneficial occupancy the operational procedures begin for the task of assembling the complex detectors. The detector design and fabrication is managed by each detector collaboration. Each major detector collaboration consists of more than 600 scientists from as many as 100 institutions from throughout the world. It is assumed that most of these scientists are not familiar with the details of the facility and its operational procedures. The assembly of the detector and its integration with the experimental facilities therefore require SSCL management and technical support.

An appropriate SSCL staff is planned for each experimental area. The staff will manage the facility, oversee the detector assembly program, and provide technical support. In general it will be the responsibility of the SSC staff to provide for all utility connections from the detector to established distribution points. This includes power, cryogenic lines, and control systems. The SSC group will provide experienced crane operators, riggers, and technicians to support the detector assembly program. The SSC staff will also act as a liaison group to assist the detector collaboration in obtaining other laboratory services, e.g. machine shops, electrical shops, special purchases, etc. A primary responsibility will be environmental health and safety. The SSC group must insure that all safety procedures are followed in both the assembly and operations of the detector systems.

\section{Physics Research}

A strong in-house physics group is planned at the SSC Laboratory in order to expeditiously carry out the design, construction, operations and data analysis for the SSC detectors. A unique role of this group is to facilitate the liaison between the experimental collaborations and the conventional construction as well as other SSCL Divisions. Such liaison is required in the design of the Experimental Facilities and the Collider design (beam pipes, IR Magnets, etc) in the vicinity of the Detectors. Another responsibility is the design and operations of test beam facilities. Finally the in-house group will carry out responsible roles in the design, fabrication, integration, installation, and commissioning of detector subsystems and components including controls, on-line and off-line computing and overall networking. Additional details of this effort are presented in section B2e and in the Physics Research Proposal of 4/1/92. 


\section{B. COMMISSIONING AND OPERATIONS}

\section{General Features and Assumptions}

In this section we provide the current schedule dates for the construction completion of major SSC components. The start dates for commissioning and operations are based on this schedule. In addition, labor categories and associated rates are provided together with an assumed annual overhead rate for the SSC laboratory. These are applicable to all of the operations categories in Section B2.

\section{a) Schedule}

By the definitions established in section $\mathrm{A}$, the end of the commissioning period for a given technical facility marks the beginning of the operation period. This is true for all of the injector accelerators and for the interaction halls. As a result of the schedule for magnet installation, the collider requires a three year period for commissioning each of its ten sectors followed by a beam commissioning period. The start of operations for the collider occurs after the beam commissioning period. The dates for commissioning and operations are provided in Table 2.0.

\section{b) Labor Categories and Rates}

While there are many disciplines at the SSCL that are required in the operations of technical systems and facilities, we have reduced the number of staff categories to eight disciplines for the estimates of this report. It is believed that most of the personnel associated with accelerator operations and physics research can be placed in one of the staff categories provided in Table 3.0. The number of personnel in each category is estimated for the various laboratory functions described in subsequent sections of this report.

In Table 3.0, the direct rate for each labor category is based on average FY91 rates at the SSCL for the technical divisions. The current burden rate of $43 \%$ is used to obtain the total cost per FTE in each category.

\section{c) Model for Operations Shifts}

A simplified shift model is used. The estimated staff for a one-shift/day operation is the operating staff necessary to run the operations of a given accelerator 7 days/week. Thus on any given day, only $5 / 7$ or $(-71 \%)$ of the staff indicated in subsequent tables for "first shift operations" are required to operate the accelerator. The same model applies to the second and third shift operations noted below.

The costs for the manpower and $M \& S$ in the second shift of operation is estimated at $70 \%$ of shift \#1 cost. The cost for the Manpower and M \& S on the third shift is assumed to be $50 \%$ of shift \#1 cost. As noted above the three-shift model assumed here covers 24-hour operations for a seven day week. 
Table 2.0

SSC Commissioning and Operations Schedule

\begin{tabular}{lccc}
\hline & $\begin{array}{c}\text { End } \\
\text { Construction }\end{array}$ & $\begin{array}{c}\text { End } \\
\text { Commissioning }\end{array}$ & Start Operations \\
\hline Linac & $10 / 94$ & $4 / 95$ & $4 / 95$ \\
LEB & $10 / 95$ & $4 / 96$ & $4 / 96$ \\
MEB & $7 / 96$ & $1 / 97$ & $1 / 97$ \\
HEB & $8 / 98$ & $2 / 99$ & $2 / 99$ \\
Test Beams & $7 / 96$ & $1 / 97$ & $1 / 97$ \\
IR Hall \# 5 & $1 / 96$ & $1 / 96$ & $1 / 96$ \\
IR Hall \# 8 & $1 / 96$ & $1 / 96$ & $1 / 96$ \\
IR Hall \# 1 & $1 / 97$ & $1 / 97$ & $1 / 97$ \\
IR Hall \# 4 & $1 / 97$ & $1 / 97$ & $1 / 97$ \\
Collider Sector 1 & $12 / 95$ & $6 / 96$ & $10 / 99$ \\
Collider Sector 2 & $5 / 96$ & $11 / 96$ & $10 / 99$ \\
Collider Sector 3 & $9 / 96$ & $3 / 97$ & $10 / 99$ \\
Collider Sector 4 & $1 / 97$ & $7 / 97$ & $10 / 99$ \\
Collider Sector 5 & $5 / 97$ & $11 / 97$ & $10 / 99$ \\
Collider Sector 6 & $9 / 97$ & $3 / 98$ & $10 / 99$ \\
Collider Sector 7 & $12 / 97$ & $6 / 98$ & $10 / 99$ \\
Collider Sector 8 & $3 / 98$ & $9 / 98$ & $10 / 99$ \\
Collider Sector 9 & $6 / 98$ & $12 / 98$ & $10 / 99$ \\
Collider Sector 10 & $9 / 98$ & $3 / 99$ & $10 / 99$ \\
Magnet Laboratory & & & $6 / 97$ \\
\hline
\end{tabular}




\section{d) Overhead}

The overhead provides for support services to the technical divisions for the SSC project as well as to other programs at the SSC Laboratory. The service divisions include the Directorate, Administration Services, Laboratory Technical Services, and part of the General Manager's office. The Laboratory Indirect Cost Policy provides for a consistent and equitable approach in planning, recording and recovering the cost of support services.

Support services are categorized and recovered as follows:

\section{CATEGORY}

Recharge Centers

Print Services

Shops

Engineering Services

Centralized Services

Occupancy services

Material handling

Computer services

General \& Administrative Pool

URA/EG\&G Management Fee

Directorate Management

International Cóordination

Legal Counsel

Internal Audit

ES\&H Oversight

Planning

Users' Office

Education

External Affairs

Technology Transfer

Administrative Services Management

Finance

Human Resources

Central Files

Lab Technical Services Management

\section{RECOVERY METHOD}

Actual usage - per work order

Actual usage - on-site occupants, purchase orders placed, etc.

Modified total direct costs

For projection purposes, a simplified model for the overall rate is provided in table 4 based on recovery rates for FY91 and the projected staff for support services in the year 2000 . The actual recovery rates will be determined annually when the magnitude of all programs is determined and the required levels of support services are identified. 
Table 3.0 --- Labor Rates

\begin{tabular}{|ll|r|r|}
\hline \multirow{2}{*}{ Staff Categoriẹs } & \multicolumn{2}{|c|}{ Annual Rate (FY91 K\$) } \\
\cline { 3 - 4 } & & \multicolumn{2}{|c|}{ Direct } \\
\hline & & & \\
Management & E3 & 73.20 & 104.68 \\
Physicists & E2 & 46.50 & 66.50 \\
Engineers & E2 & 46.50 & 66.50 \\
Administration & (E1+E2)/2 & 38.20 & 54.63 \\
Accel. Operators & E1 & 30.00 & 42.90 \\
Techs & E1 & 30.00 & 42.90 \\
Crafts & N3 & 28.80 & 41.18 \\
Labor/Clerical & N2 & 22.70 & 32.46 \\
\hline
\end{tabular}

Table 4.0 -..- Projected Overhead Rates

\begin{tabular}{|l|l|}
\hline \multicolumn{2}{|c|}{ (Applies to Labor and M \& S) } \\
\hline FY91 & $32.0 \%$ \\
FY92 & $33.0 \%$ \\
FY93 & $34.0 \%$ \\
FY94 & $35.0 \%$ \\
FY95 & $36.0 \%$ \\
FY96 & $37.0 \%$ \\
FY97 & $38.0 \%$ \\
FY98 & $39.0 \%$ \\
FY99 & $40.0 \%$ \\
FY00 & $40.0 \%$ \\
FY01 & $40.0 \%$ \\
FY02 & $40.0 \%$ \\
FY03 & $40.0 \%$ \\
FY04 & $40.0 \%$ \\
FY05 & $40.0 \%$ \\
\hline
\end{tabular}




\section{The Commissioning Program}

\section{a) Injector Accelerators}

The model used for each of the major accelerators includes a pre-operation period of 18 months. Twelve months of this period occur prior to construction completion during which time the operations and support personnel are assembled and trained. They will observe and participate in individual systems tests that will occur during the final construction phase. The operations group will become familiar with the technical components and their maintenance. In particular they must understand all control systems with associated instrumentation and establish overall operations procedures together with the technical design groups. Other tasks include the establishment of safety rules and regulations as well as emergency procedures.

The latter six months of the pre-operations period consists of the commissioning process as illustrated in Figure 2.0. During this period the operations group works together with the design group to insure that all technical systems operate in concert according to the established design and performance goals. This program is geared to produce the first accelerated beam and subsequently to begin optimizing performance in terms of beam quality and intensity. During the commissioning program the equivalent of two full operating crews are utilized in order to both operate the accelerator and to make appropriate modifications to insure operational reliability and performance.

The post-commissioning operations effort will be devoted to continued improvement of operating software and hardware, optimization of machine performance and reliability, maintenance, and sharpening the skills of the operating staff. Experimental Accelerator R \& D personnel are included in the staff estimates. For the Linac, LEB, and MEB, an active program supporting test beam operation is forseen. Such activities go beyond what is required for commissioning and will primarily benefit the SSC experimental physics program. Repairs and maintenance are also part of the operations costs after commissioning.

After the commissioning of a given accelerator, it will become operational, as noted above, except when it is utilized to commission another accelerator. The model used here assumes that the lower energy accelerator(s) are required one-half time during the commissioning of the higher energy machines. For example during the commissioning of the MEB, the Linac and LEB will be used half-time to support the MEB. The associated costs for the Linac and LEB are charged to Pre-operations during this period.

All costs of test beams beyond commissioning (i.e., for detector calibration or for other experiments) are included in Operations. Facility users are not normally charged for the costs of operating the accelerator facility and the test beams. Such costs are covered by the host laboratory as part of its base operation funding.

The end of the commissioning period for a given accelerator is signaled by a determination that the accelerated beam is adequate such that it can be used for tests and commissioning of the next higher energy accelerator. This determination will be made and documented by the Project Manager. The projected schedule for pre-operations is shown in Figure 2.0.

Table 5.0A provides the staffing model and associated costs for the Injector accelerators and test beams during the pre-operations and commissioning period. Table $5.0 \mathrm{~B}$ provides the staffing for the Injector accelerators and test beams that is projected for a one-shift per day 
operations period. The cost for materials and supplies ( $M \& S$ ) power, and cryogens is also provided. The value of the $M \& S$ is extrapolated from FNAL experience.

The staffing model includes the crew that is required to operate and maintain each accelerator and its associated facilities. Technical staff are also included for detailed analysis of machine operations behavior and for continued improvements of the overall capability of the accelerator.

Tables 6.1 through 6.6 show the total annual cost for each injection accelerator and the test beam operations. Figures 3.1 through 3.6 provide detail of the total monthly cost. The figures show operations during commissioning with a subsequent build-up to 3 shifts/day after completion of commissioning and start of operations. In Tables 6.1 - 6.6, Equipment and AIP have been added to the total annual costs. Laboratory overhead is applied to the operations manpower and $M \& S$ that make up the total cost.

The equipment budget for each accelerator is $15 \%$ of the direct manpower costs and the AIP budget is $30 \%$ of the direct manpower cost. This is based primarily on experience at FNAL. 


\section{Figure 2.0 Injector Accelerators Schedule}

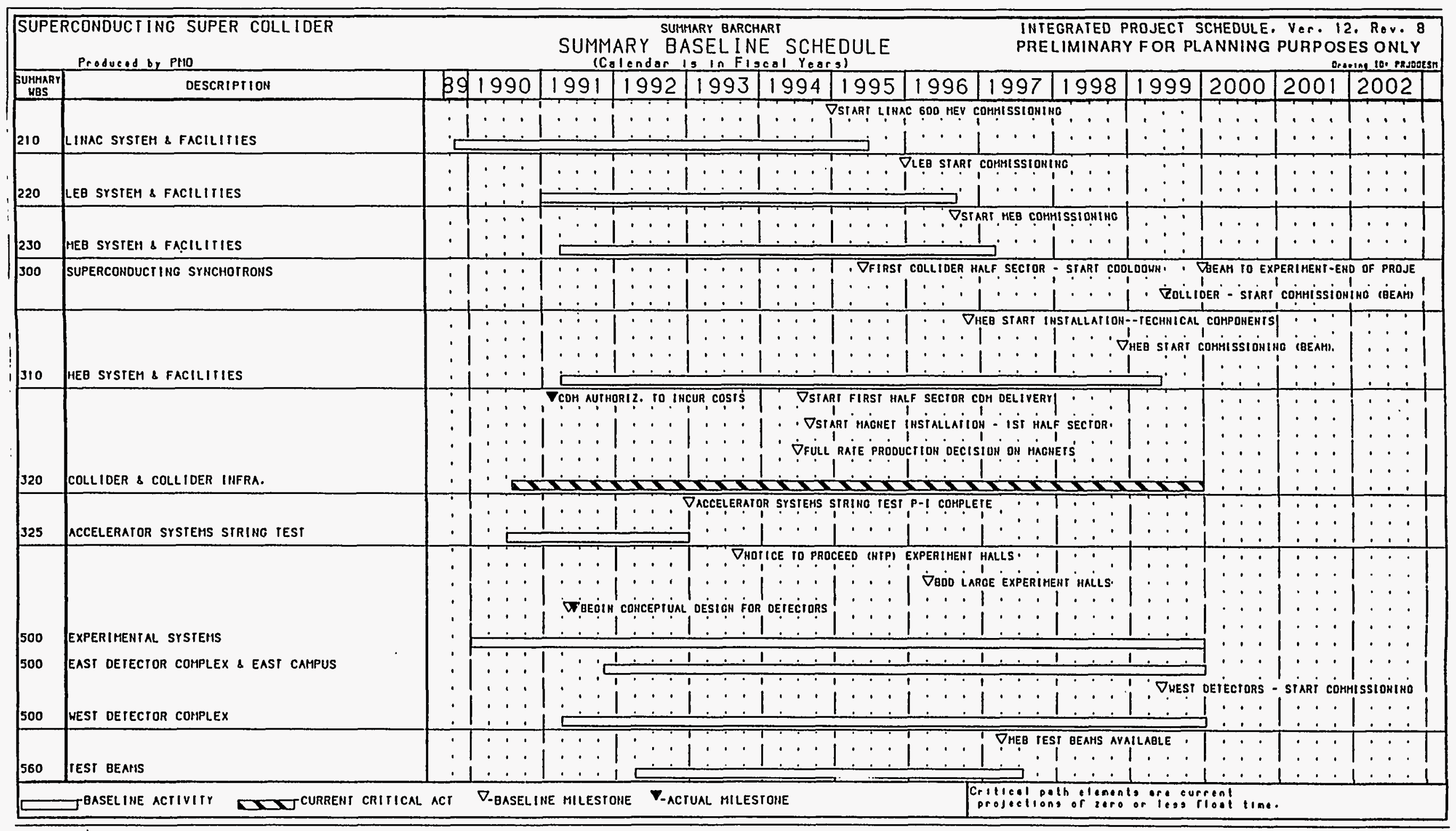


Table 5.0A --- Injector Systems Cost for Pre-Operation (FY91 K\$)

\begin{tabular}{|c|c|c|c|c|c|c|c|c|c|c|c|}
\hline \multirow[t]{2}{*}{ Staff } & \multirow[t]{2}{*}{$\begin{array}{r}\text { Annual Cost } \\
\text { Per FTE }\end{array}$} & \multicolumn{2}{|l|}{ Linac } & \multicolumn{2}{|l|}{ LEB } & \multicolumn{2}{|l|}{ MEB } & \multicolumn{2}{|l|}{ HEB } & \multicolumn{2}{|c|}{ Test Beams } \\
\hline & & \# FTE & Cost & \#FTE & Cost & \# FTE & Cost & \# FTE & Cost & \# FTE & Cost \\
\hline Management & 104.68 & 2.00 & 209.35 & 2.00 & 209.35 & 2.00 & 209.35 & 2.00 & 209.35 & 2.00 & 209.35 \\
\hline Physicists & 66.50 & 6.00 & 398.97 & 6.00 & 398.97 & 10.00 & 664.95 & 16.00 & 1063.92 & 4.00 & 265.98 \\
\hline Engineers & 66.50 & 8.00 & 531.96 & 10.00 & 664.95 & 14.00 & 930.93 & 24.00 & 1595.88 & 6.00 & 398.97 \\
\hline Administration & 54.63 & 2.00 & 109.25 & 2.00 & 109.25 & 2.00 & 109.25 & 4.00 & 218.50 & 2.00 & 109.25 \\
\hline Accel. Operators & 42.90 & 6.00 & 257.40 & 6.00 & 257.40 & 8.00 & 343.20 & 10.00 & 429.00 & 4.00 & 171.60 \\
\hline Techs & 42.90 & 20.00 & 858.00 & 24.00 & 1029.60 & 40.00 & 1716.00 & 56.00 & 2402.40 & 18.00 & 772.20 \\
\hline Crafts & 41.18 & 4.00 & 164.74 & 4.00 & 164.74 & 8.00 & 329.47 & 10.00 & 411.84 & 4.00 & 164.74 \\
\hline Labor/Clerical & 32.46 & 2.00 & 64.92 & 2.00 & 64.92 & 4.00 & 129.84 & 4.00 & 129.84 & 2.00 & 64.92 \\
\hline \multicolumn{2}{|l|}{ Total FTE } & 50.00 & & 56.00 & & 88.00 & & 126.00 & & 42.00 & \\
\hline \multirow{2}{*}{\multicolumn{2}{|c|}{$\begin{array}{l}\text { Total Staff Cost Per Shift } \\
\text { Total Staff Cost Per Annual }\end{array}$}} & & 10.38 & & 11.60 & & 17.73 & & 25.84 & & 8.63 \\
\hline & & & 2594.59 & & 2899.18 & & 4433.00 & & 6460.74 & & 2157.01 \\
\hline \multicolumn{2}{|l|}{ M \& S Per Shift } & & 6.23 & & 6.96 & & 10.64 & & 15.51 & & 5.18 \\
\hline \multicolumn{2}{|l|}{ M \& S Per Annual } & & 1556.76 & & 1739.51 & & 2659.80 & & 3876.44 & & 1294.21 \\
\hline \multicolumn{2}{|l|}{ Total Staff \& M \& S } & & 4151.35 & & 4638.69 & & 7092.80 & & 10337.18 & & 3451.22 \\
\hline \multicolumn{2}{|l|}{ Power Per Shift } & & 1.50 & & 1.06 & & 2.55 & & 8.10 & & 8.10 \\
\hline \multicolumn{2}{|l|}{ Power Per Annual } & & 374.00 & & 264.00 & & 638.00 & & 2024.00 & & 2024.00 \\
\hline \multicolumn{2}{|l|}{ Cryogenics Per Shift } & & & & & & & & 1.22 & & \\
\hline \multicolumn{2}{|l|}{ Cryogenics Per Annual } & & 0.00 & & 0.00 & & 0.00 & & & & 0.00 \\
\hline \multicolumn{2}{|c|}{ Total Pre-Operations (without $\mathrm{OH}$ ) } & & 4525.35 & & 4902.69 & & 7730.80 & & 12666.18 & & 5475.22 \\
\hline
\end{tabular}


Table 5.0B -.- Injector Systems Cost for First Shift Operation (FY91 K\$)

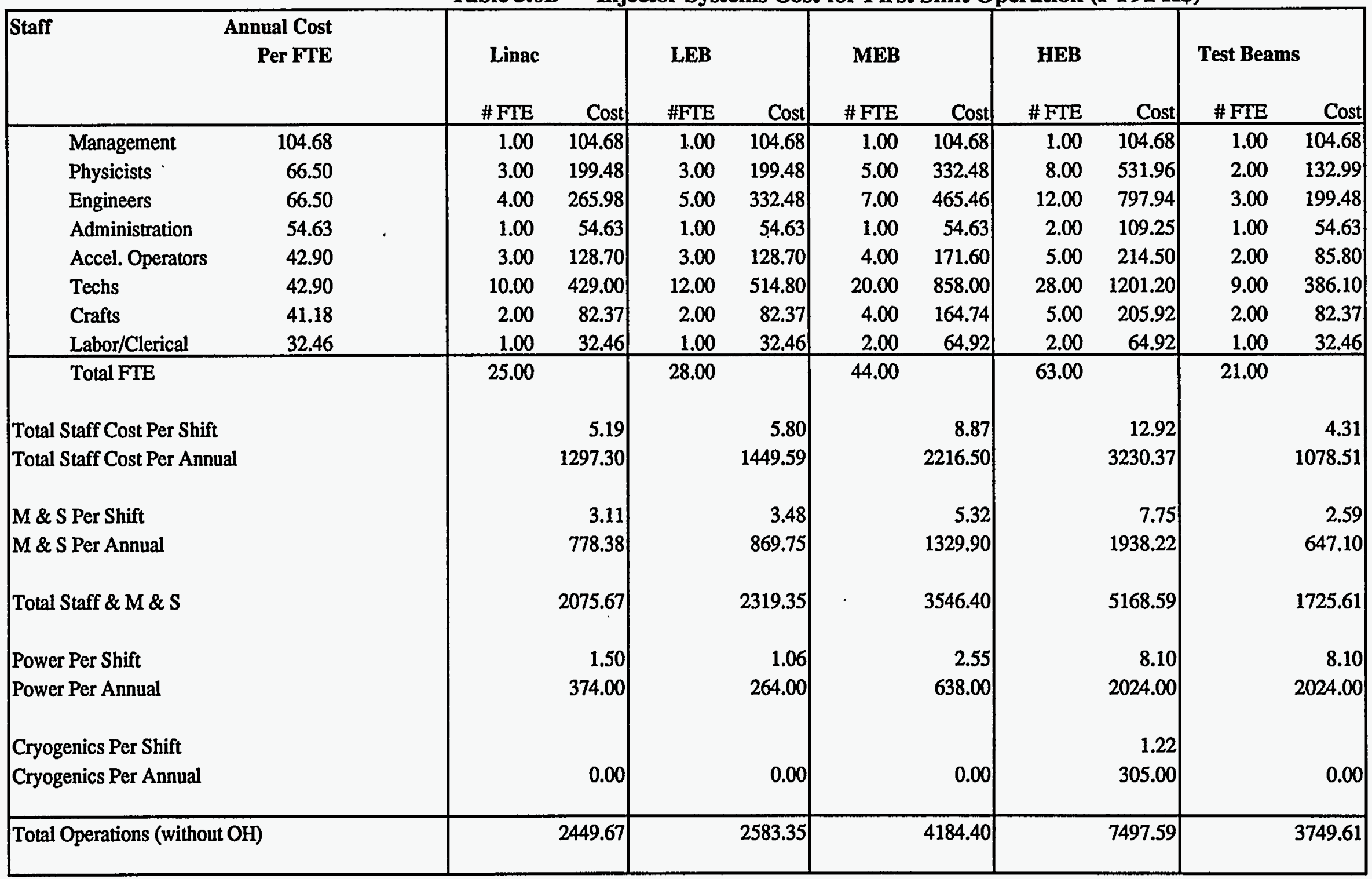


Table 6.1 ... Summary Linac Costs (FY91 K\$)

\begin{tabular}{|lr|rrrrr|}
\hline & & \multicolumn{2}{|c|}{ Operations } & & & \\
\cline { 3 - 7 } & Pre-Op & Direct & W/O.H. & Equip & AIP & Total \\
\hline FY93 & 0.00 & 0.00 & 0.00 & 0.00 & 0.00 & 0.00 \\
FY94 & 2074.12 & 0.00 & 0.00 & 0.00 & 0.00 & 0.00 \\
FY95 & 2262.67 & 2245.53 & 2930.51 & 178.38 & 356.76 & 3465.64 \\
FY96 & 2020.98 & 3368.30 & 4424.30 & 267.57 & 535.13 & 5227.00 \\
FY97 & 673.66 & 4715.62 & 6233.98 & 374.59 & 749.19 & 7357.76 \\
FY98 & 449.11 & 4940.18 & 6572.69 & 392.43 & 784.86 & 7749.99 \\
FY99 & 2245.53 & 3143.75 & 4209.26 & 249.73 & 499.46 & 4958.45 \\
& & & & & & \\
Subtotal & 9726.07 & 18413.38 & 24370.74 & 1462.70 & 2925.40 & 28758.84 \\
& & & & & & \\
FY00 & 0.00 & 5389.28 & 7215.87 & 428.11 & 856.22 & 8500.20 \\
\hline
\end{tabular}

Table 6.2 --- Summary LEB Costs (FY91 K\$)

\begin{tabular}{|lr|rrrrr|}
\hline & & \multicolumn{2}{|c}{ Operations } & & & \\
\cline { 3 - 7 } & Pre-Op & Direct & W/O.H. & Equip & AIP & Total \\
\hline FY93 & 0.00 & 0.00 & 0.00 & 0.00 & 0.00 & 0.00 \\
FY94 & 0.00 & 0.00 & 0.00 & 0.00 & 0.00 & 0.00 \\
FY95 & 2247.07 & 0.00 & 0.00 & 0.00 & 0.00 & 0.00 \\
FY96 & 3161.77 & 1657.65 & 2208.30 & 139.52 & 279.05 & 2626.87 \\
FY97 & 710.42 & 4972.94 & 6669.54 & 418.57 & 837.14 & 7925.25 \\
FY98 & 473.61 & 5209.75 & 7033.91 & 438.50 & 877.00 & 8349.42 \\
FY99 & 2368.07 & 3315.29 & 4505.89 & 279.05 & 558.09 & 5343.03 \\
& & & & & & \\
Subtotal & 8960.93 & 15155.63 & 20417.64 & 1275.64 & 2551.28 & 24244.56 \\
& & & & & & \\
FY00 & 0.00 & 5683.36 & 7724.38 & 478.37 & 956.73 & 9159.48 \\
\hline
\end{tabular}

Table 6.3 -.. Summary MEB Costs (FY91 K\$)

\begin{tabular}{|lr|rrrrr|}
\hline & & \multicolumn{2}{|c|}{ Operations } & & & AIP \\
\cline { 3 - 7 } & Pre-Op & Direct & W/O.H. & Equip & Total \\
\hline FY93 & 0.00 & 0.00 & 0.00 & 0.00 & 0.00 & 0.00 \\
FY94 & 0.00 & 0.00 & 0.00 & 0.00 & 0.00 & 0.00 \\
FY95 & 161.06 & 0.00 & 0.00 & 0.00 & 0.00 & 0.00 \\
FY96 & 5314.93 & 0.00 & 0.00 & 0.00 & 0.00 & 0.00 \\
FY97 & 1932.70 & 5718.68 & 7560.44 & 454.38 & 908.77 & 8923.59 \\
FY98 & 767.14 & 8438.54 & 11227.78 & 670.49 & 1340.98 & 13239.26 \\
FY99 & 3835.70 & 5369.98 & 7190.47 & 426.68 & 853.35 & 8470.49 \\
& & & & & & \\
Subtotal & 12011.52 & 19527.20 & 25978.69 & 1551.55 & 3103.10 & 30633.34 \\
& & & & & & \\
FY00 & 0.00 & 9205.68 & 12326.51 & 731.45 & 1462.89 & 14520.85 \\
\hline
\end{tabular}


Table 6.4 -.- Summary HEB Costs (FY91 K\$)

\begin{tabular}{|lr|rrrrr|}
\hline & & \multicolumn{2}{|c}{ Operations } & & & \\
\cline { 3 - 7 } & Pre-Op & Direct & W/O.H. & Equip & AIP & Total \\
\hline FY93 & 0.00 & 0.00 & 0.00 & 0.00 & 0.00 & 0.00 \\
FY94 & 0.00 & 0.00 & 0.00 & 0.00 & 0.00 & 0.00 \\
FY95 & 0.00 & 0.00 & 0.00 & 0.00 & 0.00 & 0.00 \\
FY96 & 0.00 & 0.00 & 0.00 & 0.00 & 0.00 & 0.00 \\
FY97 & 87.96 & 0.00 & 0.00 & 0.00 & 0.00 & 0.00 \\
FY98 & 7828.41 & 0.00 & 0.00 & 0.00 & 0.00 & 0.00 \\
FY99 & 8033.34 & 5060.87 & 6456.39 & 327.07 & 654.15 & 7437.62 \\
& & & & & & \\
Subtotal & 15949.70 & 5060.87 & 6456.39 & 327.07 & 654.15 & 7437.62 \\
FY00 & & & & & & \\
\hline
\end{tabular}

Table 6.5 --- Injector Systems Costs (FY91 K\$)

\begin{tabular}{|lr|rrrrr|}
\hline & & \multicolumn{3}{|c|}{ Operations } & & \\
\cline { 3 - 7 } & Pre-Op & Direct & W/O.H. & Equip & AIP & Total \\
\hline FY93 & 0.00 & 0.00 & 0.00 & 0.00 & 0.00 & 0.00 \\
FY94 & 2074.12 & 0.00 & 0.00 & 0.00 & 0.00 & 0.00 \\
FY95 & 4670.80 & 2245.53 & 2930.51 & 178.38 & 356.76 & 3465.64 \\
FY96 & 10497.67 & 5025.95 & 6632.60 & 407.09 & 814.18 & 7853.87 \\
FY97 & 3404.74 & 15407.24 & 20463.96 & 1247.55 & 2495.09 & 24206.60 \\
FY98 & 9518.27 & 18588.46 & 24834.39 & 1501.42 & 3002.85 & 29338.66 \\
FY99 & 16482.64 & 16889.90 & 22362.01 & 1282.53 & 2565.05 & 26209.59 \\
& & & & & & \\
Subtotal & 46648.23 & 58157.08 & 77223.47 & 4616.97 & 9233.93 & 91074.36 \\
& & & & & & \\
FY00 & 0.00 & 36773.02 & 48309.83 & 2703.94 & 5407.88 & 56421.65 \\
\hline
\end{tabular}

Table 6.6 -.- TEST BEAMS Costs (FY91 K\$)

\begin{tabular}{|lr|rrrrr|}
\hline & & \multicolumn{3}{|c|}{ Operations } & & \\
\cline { 3 - 7 } & Pre-Op & Direct & W/O.H. & Equip & AIP & Total \\
\hline FY93 & 0.00 & 0.00 & 0.00 & 0.00 & 0.00 & 0.00 \\
FY94 & 0.00 & 0.00 & 0.00 & 0.00 & 0.00 & 0.00 \\
FY95 & 114.07 & 0.00 & 0.00 & 0.00 & 0.00 & 0.00 \\
FY96 & 3764.21 & 0.00 & 0.00 & 0.00 & 0.00 & 0.00 \\
FY97 & 1368.80 & 5124.47 & 6020.63 & 221.09 & 442.19 & 6683.91 \\
FY98 & 0.00 & 8249.14 & 9729.71 & 355.91 & 711.81 & 10797.44 \\
FY99 & 0.00 & 8249.14 & 9767.68 & 355.91 & 711.81 & 10835.40 \\
& & & & & & \\
Subtotal & 5247.09 & 21622.75 & 25518.02 & 932.91 & 1865.82 & 28316.75 \\
& & & & & & \\
FY00 & 0.00 & 8249.14 & 9767.68 & 355.91 & 711.81 & 10835.40 \\
\hline
\end{tabular}




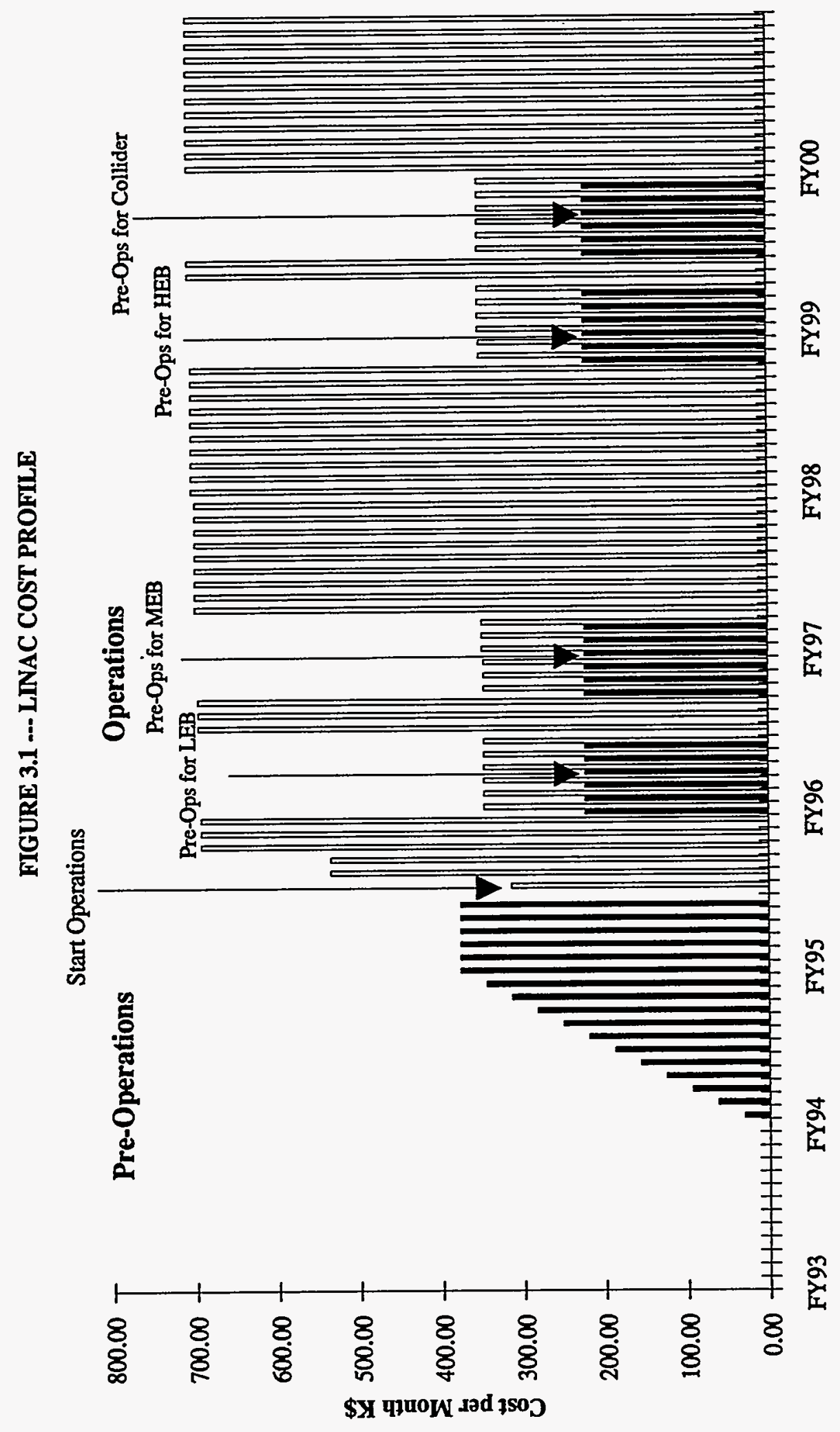




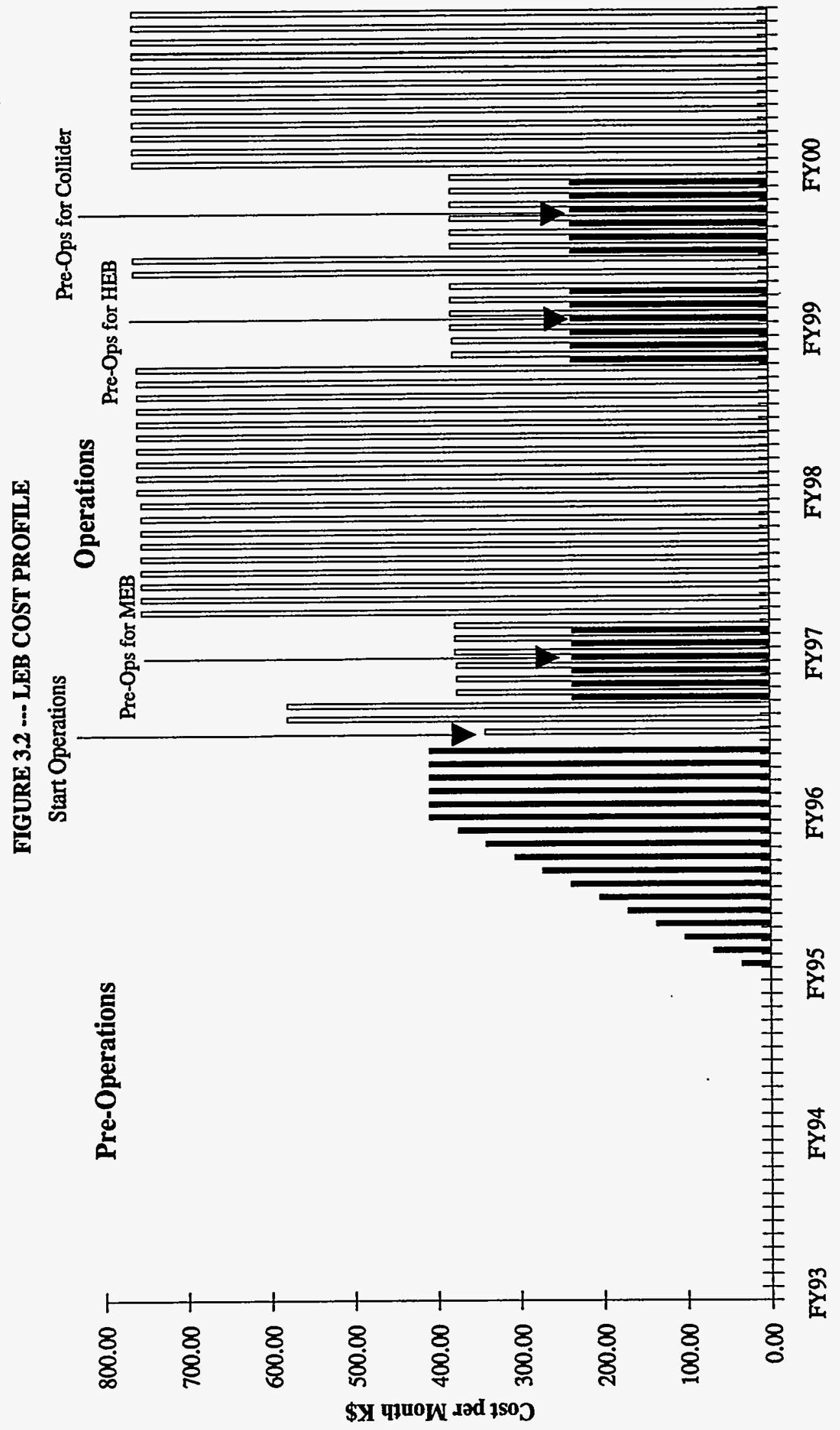




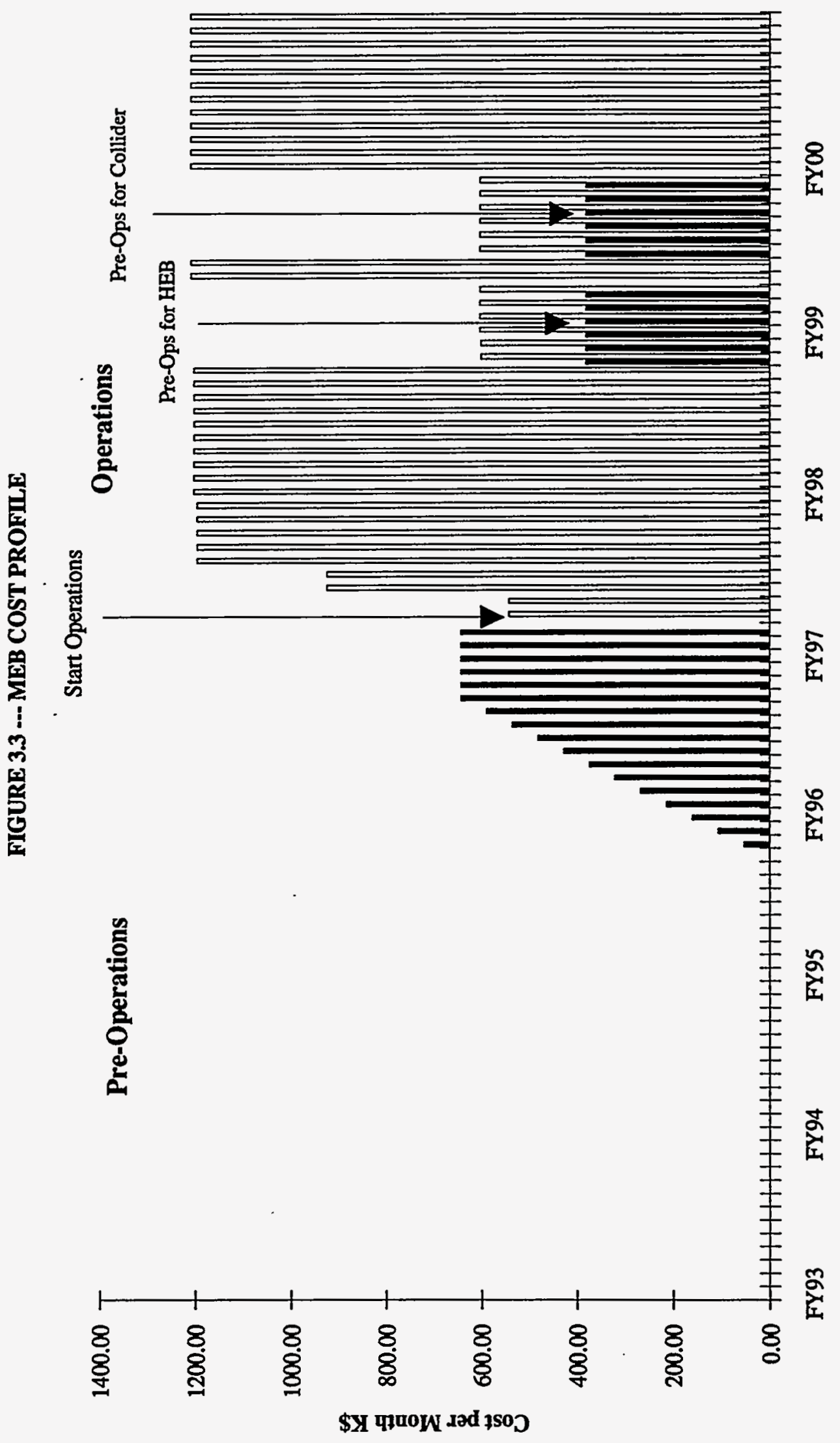




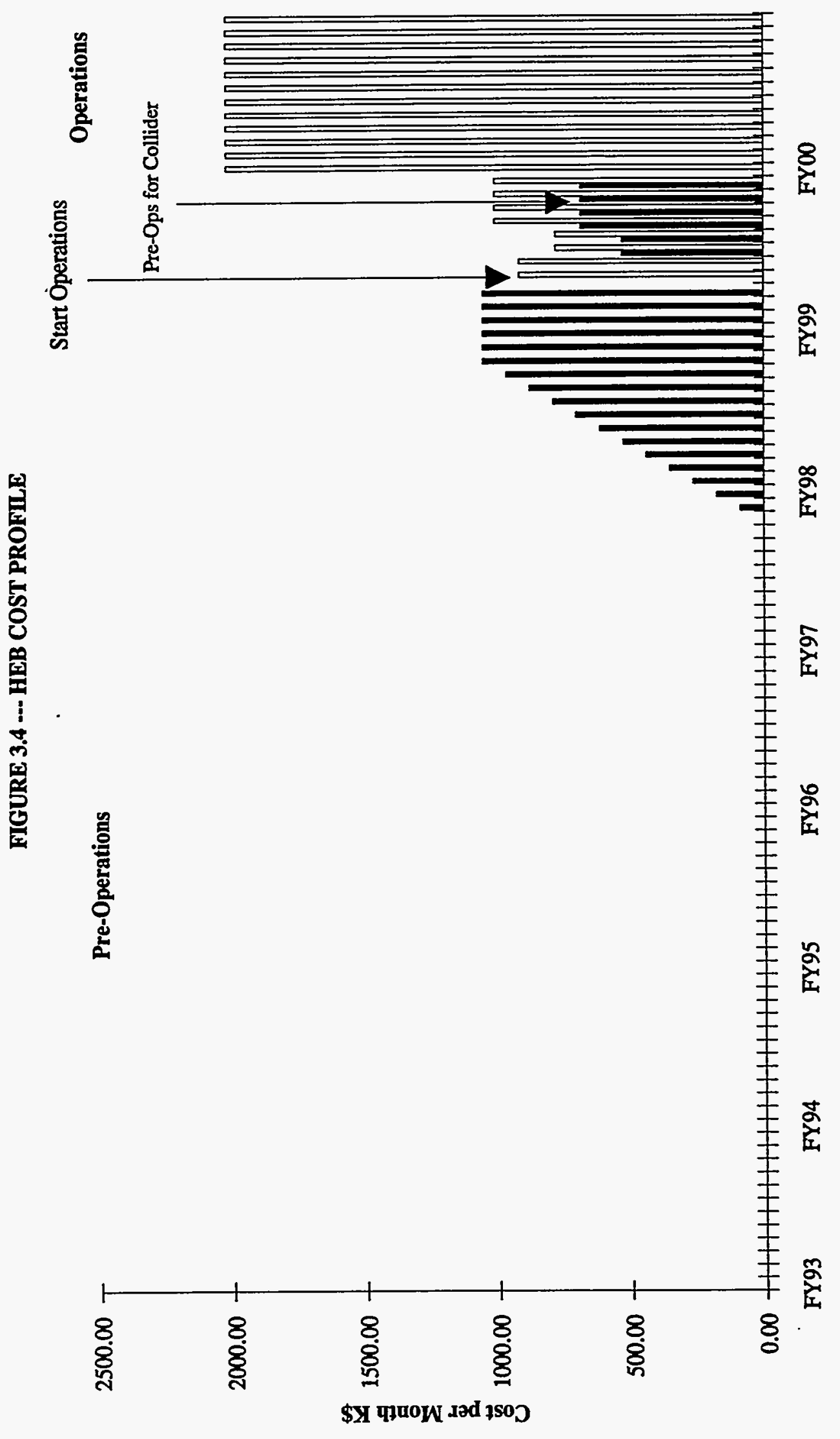




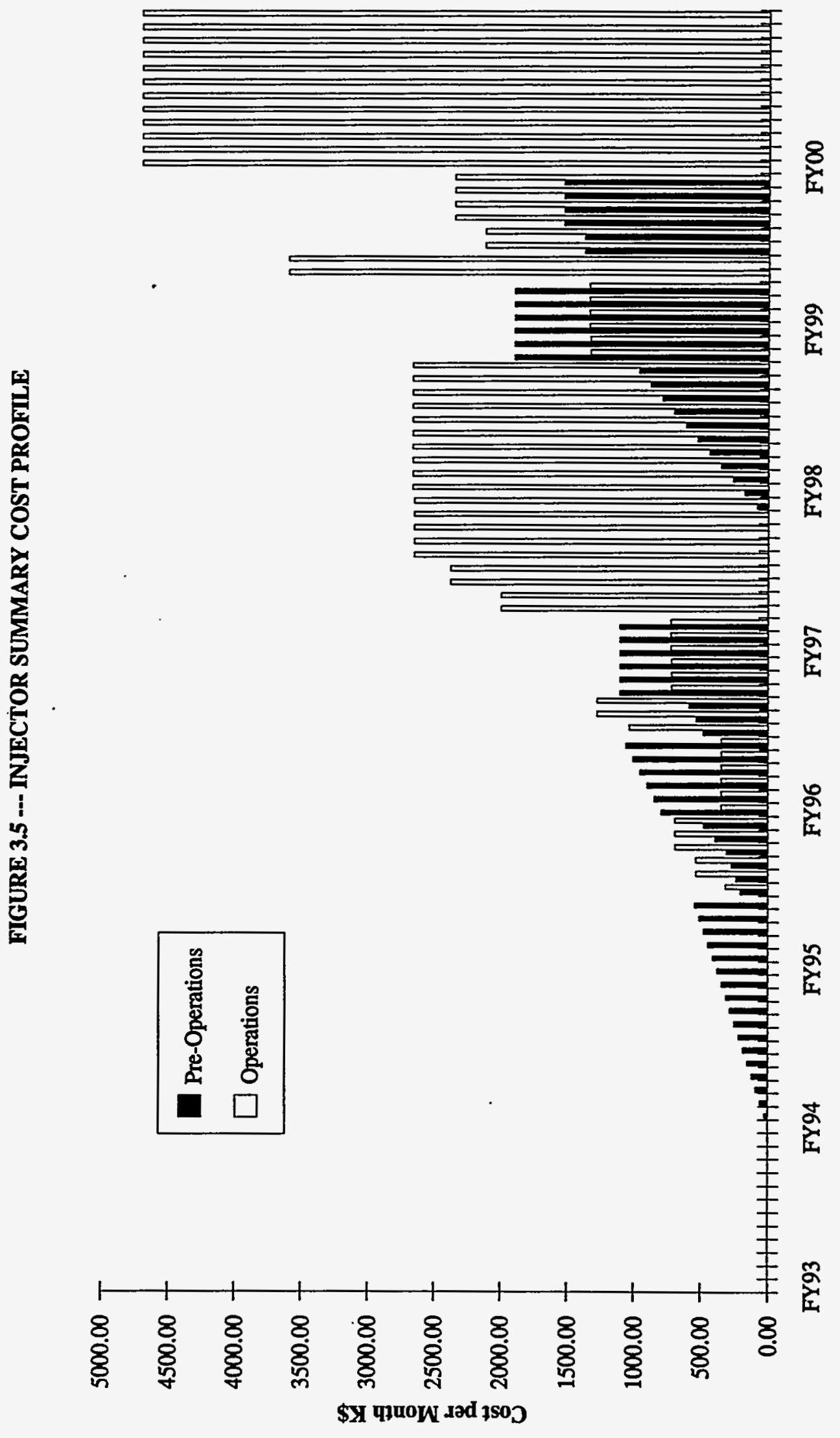




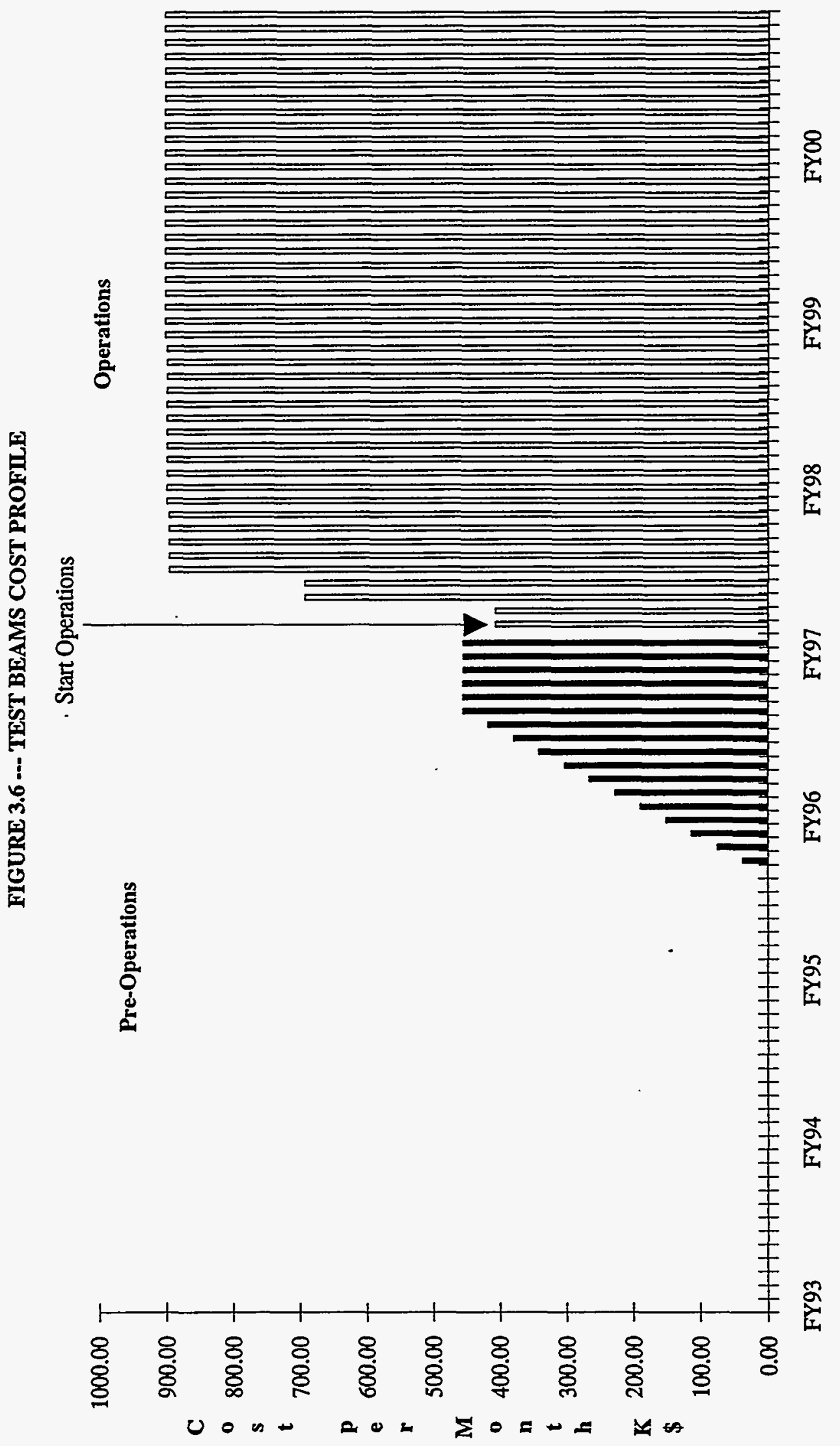




\section{b) Collider Sectors}

Section B1 provides the dates for the end of commissioning of each collider sector over a 33 month period. For each sector, a commissioning period of six months is allowed following construction completion of that sector. The overall pre-operations plan estimates three months of preparation and training of personnel prior to commissioning. The commissioning includes cooldown to liquid helium temperature, training procedures where necessary, check-out of power systems, pulsing tests to design current, and overall tests of diagnostics, instrumentation, and safety systems.

Figure 4.0 shows a schedule for the commissioning completion of each sector. In this model schedule, the first five sectors are "warmed-up" after commissioning and subsequently recooled beginning in mid-1998 in preparation for collider beam commissioning. The last five sectors remain at $4^{\circ} \mathrm{K}$ in preparation for the beam tests. A six month period is scheduled for the beam commissioning period which ends on or before October 1, 1999. After this date it is expected that all accelerator systems and the collider will be used primarily for the operations of experiments.

The operating costs for a single sector for first shift operations are provided in Table 7.0. The annual costs for each sector are summarized in Tables 8.1 through 8.10. A summary of the total annual costs for all sectors is given in Table 8.11. A full three shift operation is assumed at all times for the operation of collider sectors. The costs per month for each sector are plotted in Figures 5.1 through 5.11 . 
Figure 4

Collider Commissioning Schedule

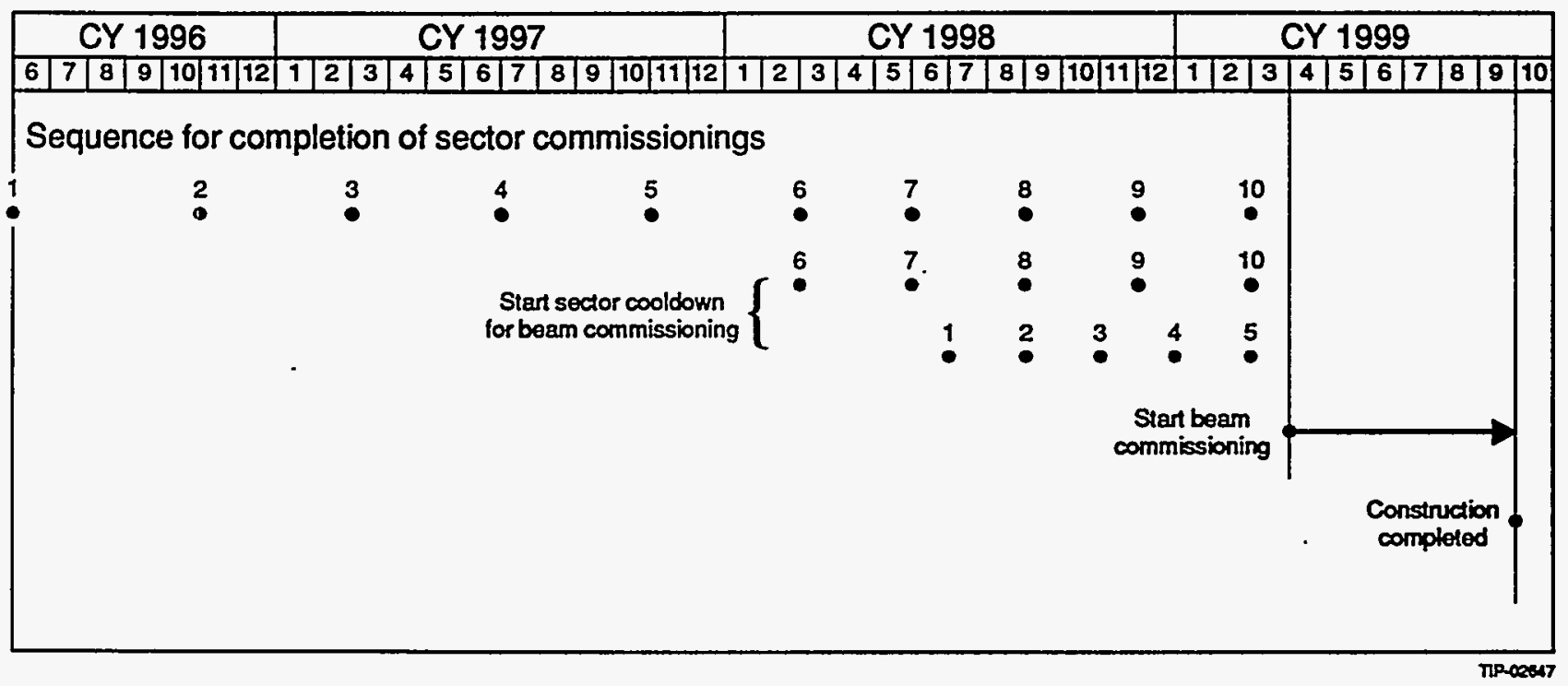


Table 7.0 -.. Collider Sector Cost for First Shift Operation (FY91 K\$)

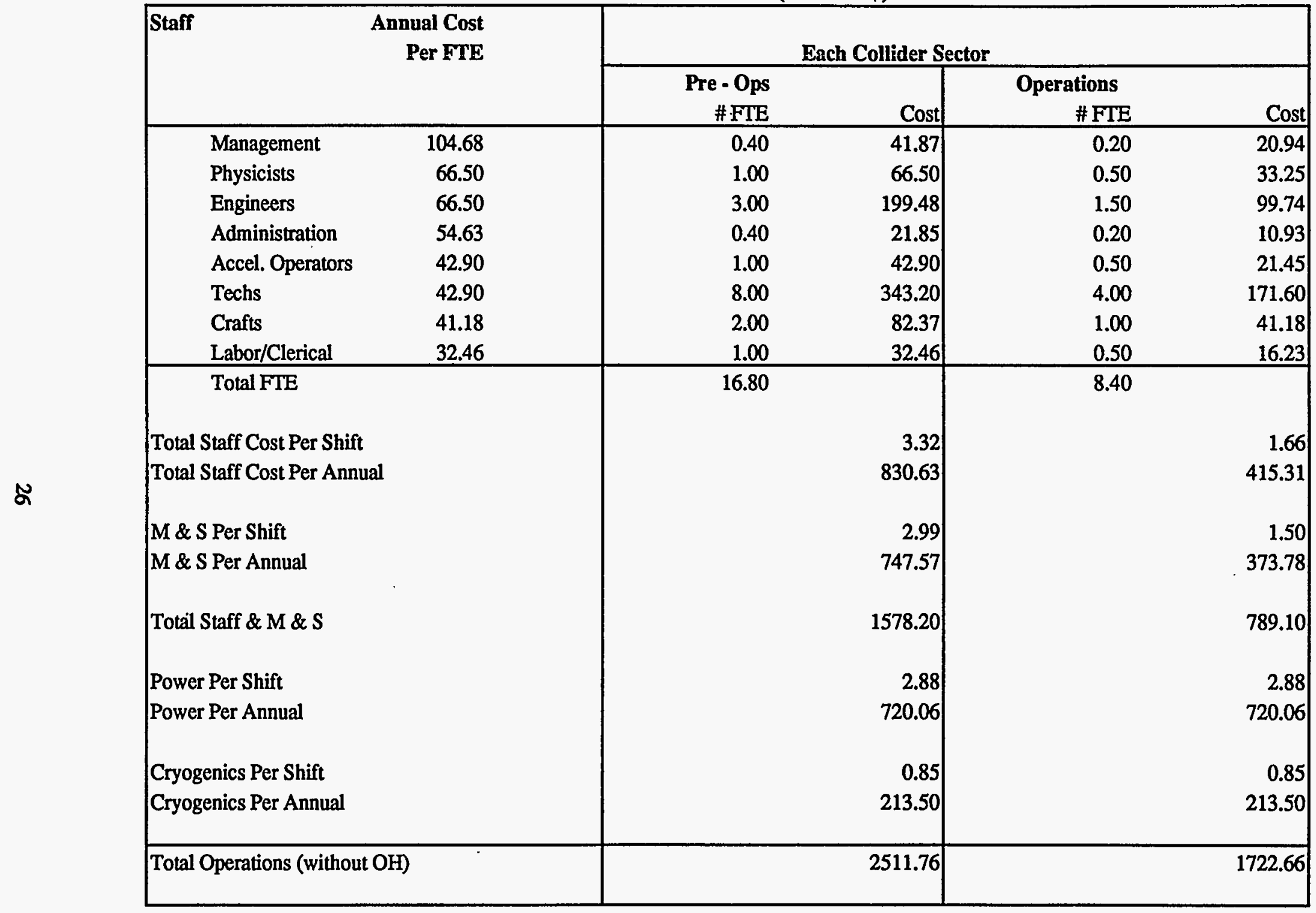


Table 8.1 --- Summary Collider Sector 1 (FY91 K\$)

\begin{tabular}{|c|c|c|c|c|c|c|}
\hline \multirow{2}{*}{\multicolumn{2}{|c|}{ Pre-Op }} & \multicolumn{2}{|c|}{ Operations } & \multirow[b]{2}{*}{ Equip } & \multirow[b]{2}{*}{ AIP } & \multirow[b]{2}{*}{ Total } \\
\hline & & Direct & W/O.H. & & & \\
\hline FY93 & 0.00 & 0.00 & 0.00 & 0.00 & 0.00 & 0.00 \\
\hline FY94 & 0.00 & 0.00 & 0.00 & 0.00 & 0.00 & 0.00 \\
\hline FY95 & 0.00 & 0.00 & 0.00 & 0.00 & 0.00 & 0.00 \\
\hline FY96 & 3223.42 & 0.00 & 0.00 & 0.00 & 0.00 & 0.00 \\
\hline FY97 & 0.00 & 0.00 & 0.00 & 0.00 & 0.00 & 0.00 \\
\hline FY98 & 947.46 & 0.00 & 0.00 & 0.00 & 0.00 & 0.00 \\
\hline FY99 & 3789.85 & 0.00 & 0.00 & 0.00 & 0.00 & 0.00 \\
\hline Subtotal & 7960.73 & 0.00 & 0.00 & 0.00 & 0.00 & 0.00 \\
\hline FYOO & 0.00 & 3789.85 & 4484.25 & 365.48 & 639.58 & 5489.32 \\
\hline
\end{tabular}

Table 8.2 --- Summary Collider Sector 2 (FY91 K\$)

\begin{tabular}{|lr|rrrrrr|}
\hline & & \multicolumn{3}{|c|}{ Operations } & & & \\
\cline { 3 - 7 } & Pre-Op & Direct & W/O.H. & Equip & AIP & Total \\
\hline FY93 & 0.00 & 0.00 & 0.00 & 0.00 & 0.00 & 0.00 \\
FY94 & 0.00 & 0.00 & 0.00 & 0.00 & 0.00 & 0.00 \\
FY95 & 0.00 & 0.00 & 0.00 & 0.00 & 0.00 & 0.00 \\
FY96 & 2762.93 & 0.00 & 0.00 & 0.00 & 0.00 & 0.00 \\
FY97 & 460.49 & 0.00 & 0.00 & 0.00 & 0.00 & 0.00 \\
FY98 & 315.82 & 0.00 & 0.00 & 0.00 & 0.00 & 0.00 \\
FY99 & 3789.85 & 0.00 & 0.00 & 0.00 & 0.00 & 0.00 \\
Subtotal & & & & & & 0.00 & 0.00 \\
& 7329.09 & & 0.00 & 0.00 & 0.00 & & \\
FY00 & & & & & & & \\
\end{tabular}

Table 8.3 --- Summary Collider Sector 3 (FY91 K\$)

\begin{tabular}{|c|c|c|c|c|c|c|}
\hline \multirow{2}{*}{\multicolumn{2}{|c|}{ Pre-Op }} & \multicolumn{2}{|c|}{ Operations } & \multirow[b]{2}{*}{ Equip } & \multirow[b]{2}{*}{ AIP } & \multirow[b]{2}{*}{ Total } \\
\hline & & Direct & W/O.H. & & & \\
\hline FY93 & 0.00 & 0.00 & 0.00 & 0.00 & 0.00 & 0.00 \\
\hline FY94 & 0.00 & 0.00 & 0.00 & 0.00 & 0.00 & 0.00 \\
\hline FY95 & 0.00 & 0.00 & 0.00 & 0.00 & 0.00 & 0.00 \\
\hline FY96 & 920.98 & 0.00 & 0.00 & 0.00 & 0.00 & 0.00 \\
\hline FY97 & 2302.44 & 0.00 & 0.00 & 0.00 & 0.00 & 0.00 \\
\hline FY98 & 0.00 & 0.00 & 0.00 & 0.00 & 0.00 & 0.00 \\
\hline FY99 & 3474.03 & 0.00 & 0.00 & 0.00 & 0.00 & 0.00 \\
\hline Subtotal & 6697.45 & 0.00 & 0.00 & 0.00 & 0.00 & 0.00 \\
\hline FYOO & 0.00 & 3789.85 & 4484.25 & 365.48 & 639.58 & 5489.32 \\
\hline
\end{tabular}


Table 8.4 --- Summary Collider Sector 4 (FY91 K\$)

\begin{tabular}{|c|c|c|c|c|c|c|}
\hline & & Operat & & & & \\
\hline & Pre-Op & Direct & W/O.H. & Equip & AIP & Total \\
\hline FY93 & 0.00 & 0.00 & 0.00 & 0.00 & 0.00 & 0.00 \\
\hline FY94 & 0.00 & 0.00 & 0.00 & 0.00 & 0.00 & 0.00 \\
\hline FY95 & 0.00 & 0.00 & 0.00 & 0.00 & 0.00 & 0.00 \\
\hline FY96 & 0.00 & 0.00 & 0.00 & 0.00 & 0.00 & 0.00 \\
\hline FY97 & 3223.42 & 0.00 & 0.00 & 0.00 & 0.00 & 0.00 \\
\hline FY98 & 0.00 & 0.00 & 0.00 & 0.00 & 0.00 & 0.00 \\
\hline FY99 & 2842.39 & 0.00 & 0.00 & 0.00 & 0.00 & 0.00 \\
\hline Subtotal & 6065.81 & 0.00 & 0.00 & 0.00 & 0.00 & 0.00 \\
\hline FYOO & 0.00 & 3789.85 & 4484.25 & 365.48 & 639.58 & 5489.32 \\
\hline
\end{tabular}

Table 8.5 ... Summary Collider Sector 5 (FY91 K\$)

\begin{tabular}{|c|c|c|c|c|c|c|}
\hline & \multirow[b]{2}{*}{ Pre-Opl } & \multicolumn{2}{|c|}{ Operations } & \multirow[b]{2}{*}{ Equip } & \multirow[b]{2}{*}{ AIP } & \multirow[b]{2}{*}{ Total } \\
\hline & & Direct & W/O.H. & & & \\
\hline FY93 & 0.00 & 0.00 & 0.00 & 0.00 & 0.00 & 0.00 \\
\hline FY94 & 0.00 & 0.00 & 0.00 & 0.00 & 0.00 & 0.00 \\
\hline FY95 & 0.00 & 0.00 & 0.00 & 0.00 & 0.00 & 0.00 \\
\hline FY96 & 0.00 & 0.00 & 0.00 & 0.00 & 0.00 & 0.00 \\
\hline FY97 & 2762.93 & 0.00 & 0.00 & 0.00 & 0.00 & 0.00 \\
\hline FY98 & 460.49 & 0.00 & 0.00 & 0.00 & 0.00 & 0.00 \\
\hline FY99 & 2210.74 & 0.00 & 0.00 & 0.00 & 0.00 & 0.00 \\
\hline Subtotal & 5434.17 & 0.00 & 0.00 & 0.00 & 0.00 & 0.00 \\
\hline FYOO & 0.00 & 3789.85 & 4484.25 & 365.48 & 639.58 & 5489.32 \\
\hline
\end{tabular}

Table 8.6 -.. Summary Collider Sector 6 (FY91 K\$)

\begin{tabular}{|c|c|c|c|c|c|c|}
\hline & \multirow[b]{2}{*}{ Pre-Op } & \multicolumn{2}{|c|}{ Operations } & \multirow[b]{2}{*}{ Equip } & \multirow[b]{2}{*}{ AIP } & \multirow[b]{2}{*}{ Total } \\
\hline & & Direct & W/O.H. & & & \\
\hline FY93 & 0.00 & 0.00 & 0.00 & 0.00 & 0.00 & 0.00 \\
\hline FY94 & 0.00 & 0.00 & 0.00 & 0.00 & 0.00 & 0.00 \\
\hline FY95 & 0.00 & 0.00 & 0.00 & 0.00 & 0.00 & 0.00 \\
\hline FY96 & 0.00 & 0.00 & 0.00 & 0.00 & 0.00 & 0.00 \\
\hline FY97 & 920.98 & 0.00 & 0.00 & 0.00 & 0.00 & 0.00 \\
\hline FY98 & 4513.19 & 0.00 & 0.00 & 0.00 & 0.00 & 0.00 \\
\hline FY99 & 3789.85 & 0.00 & 0.00 & 0.00 & 0.00 & 0.00 \\
\hline Subtotal & 9224.01 & 0.00 & 0.00 & 0.00 & 0.00 & 0.00 \\
\hline FYOO & 0.00 & 3789.85 & 4484.25 & 365.48 & 639.58 & 5489.32 \\
\hline
\end{tabular}


Table 8.7 --- Summary Collider Sector 7 (FY91 K\$)

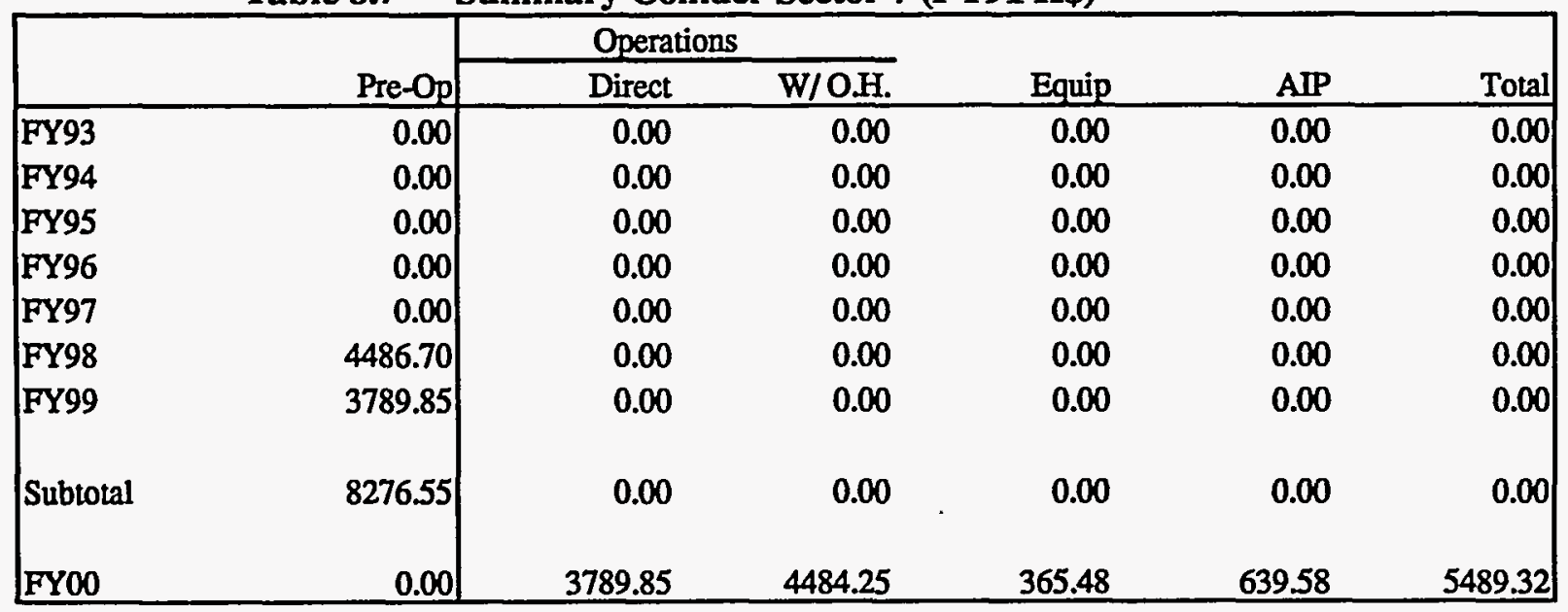

Table 8.8 -.- Summary Collider Sector 8 (FY91 K\$)

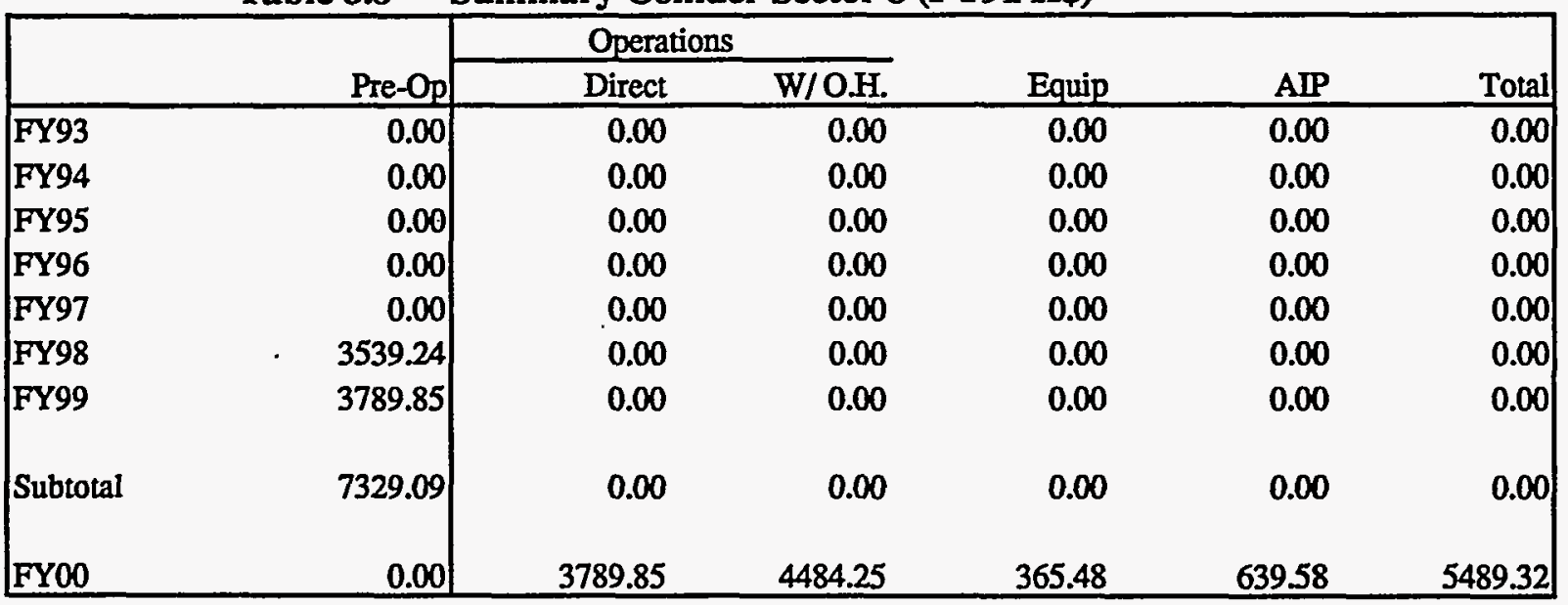

Table 8.9 -.-- Summary Collider Sector 9 (FT91 K\$)

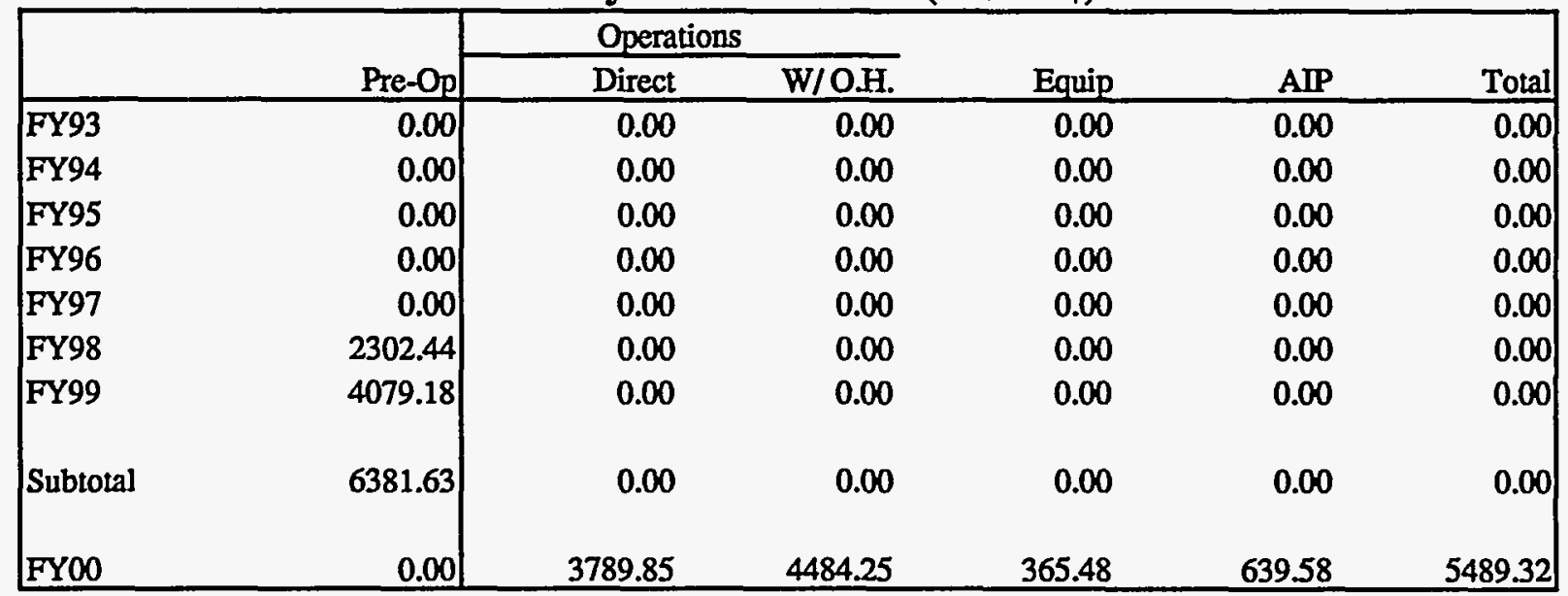


Table 8.10 Summary Collider Sector 10 (FY91 K\$)

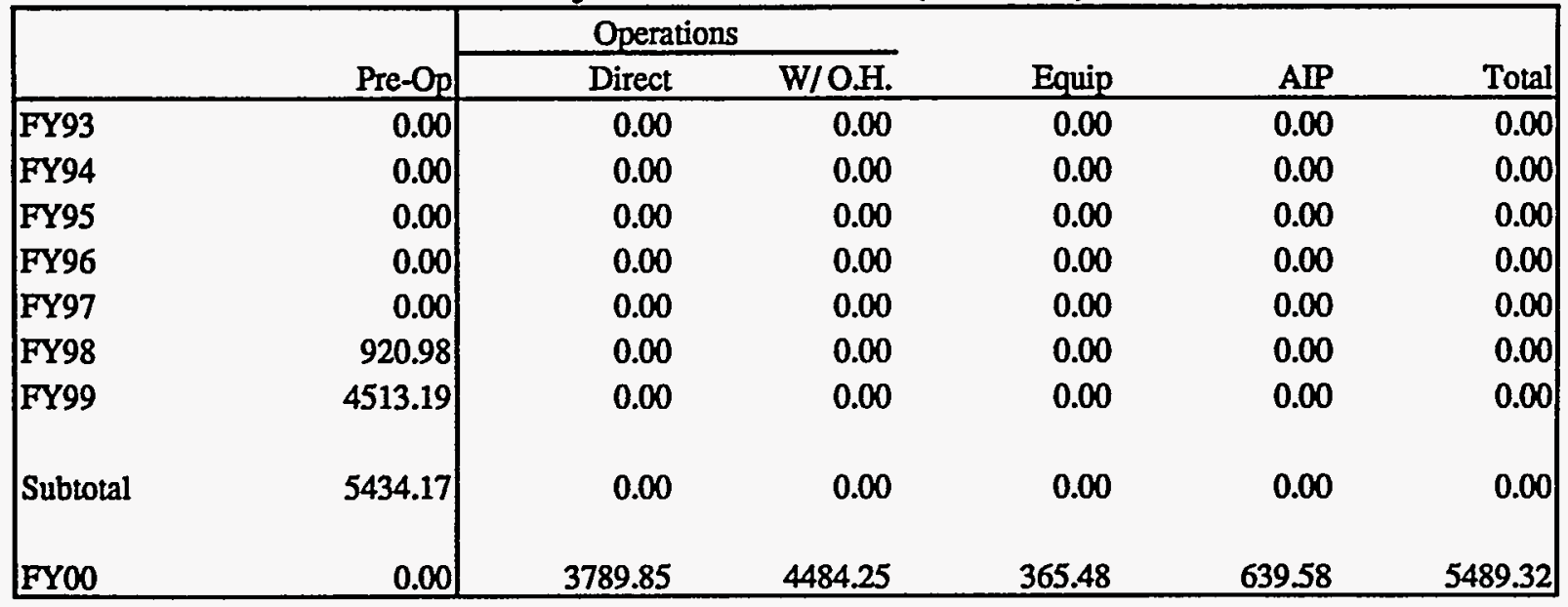

Table 8.11 -.. Total Collider Costs (FY91 K\$)

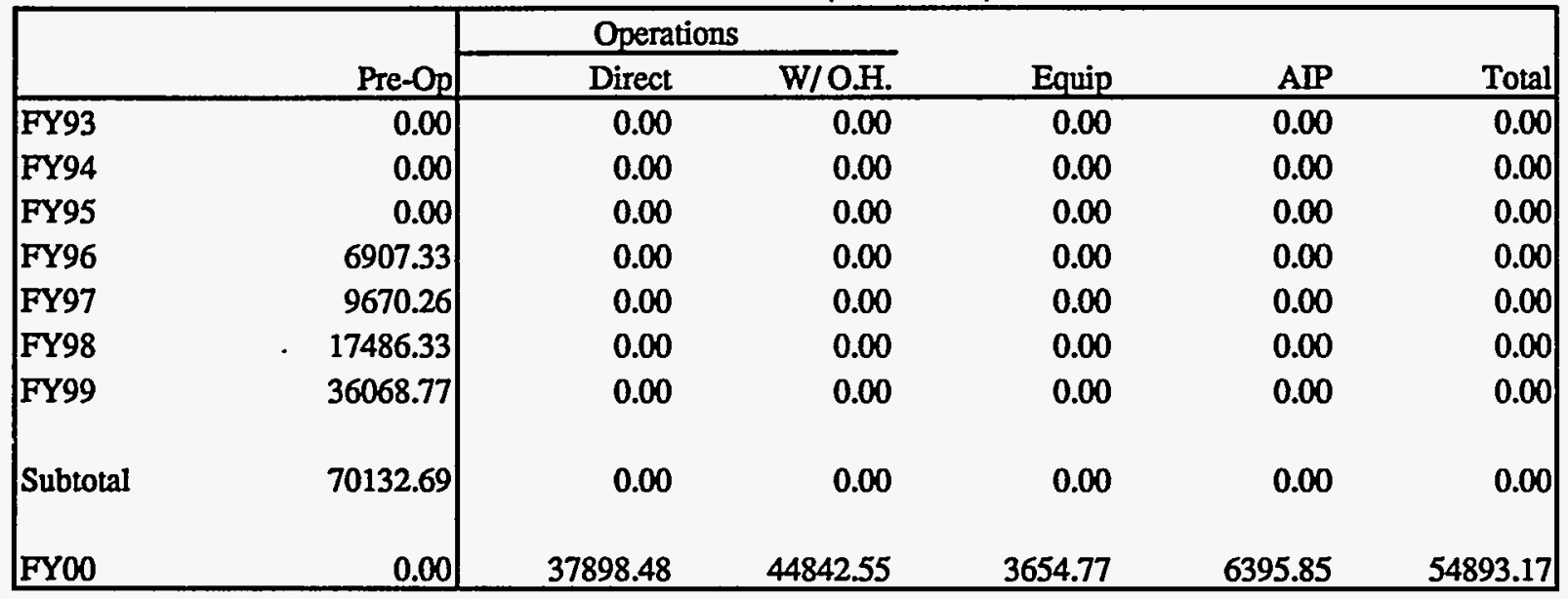




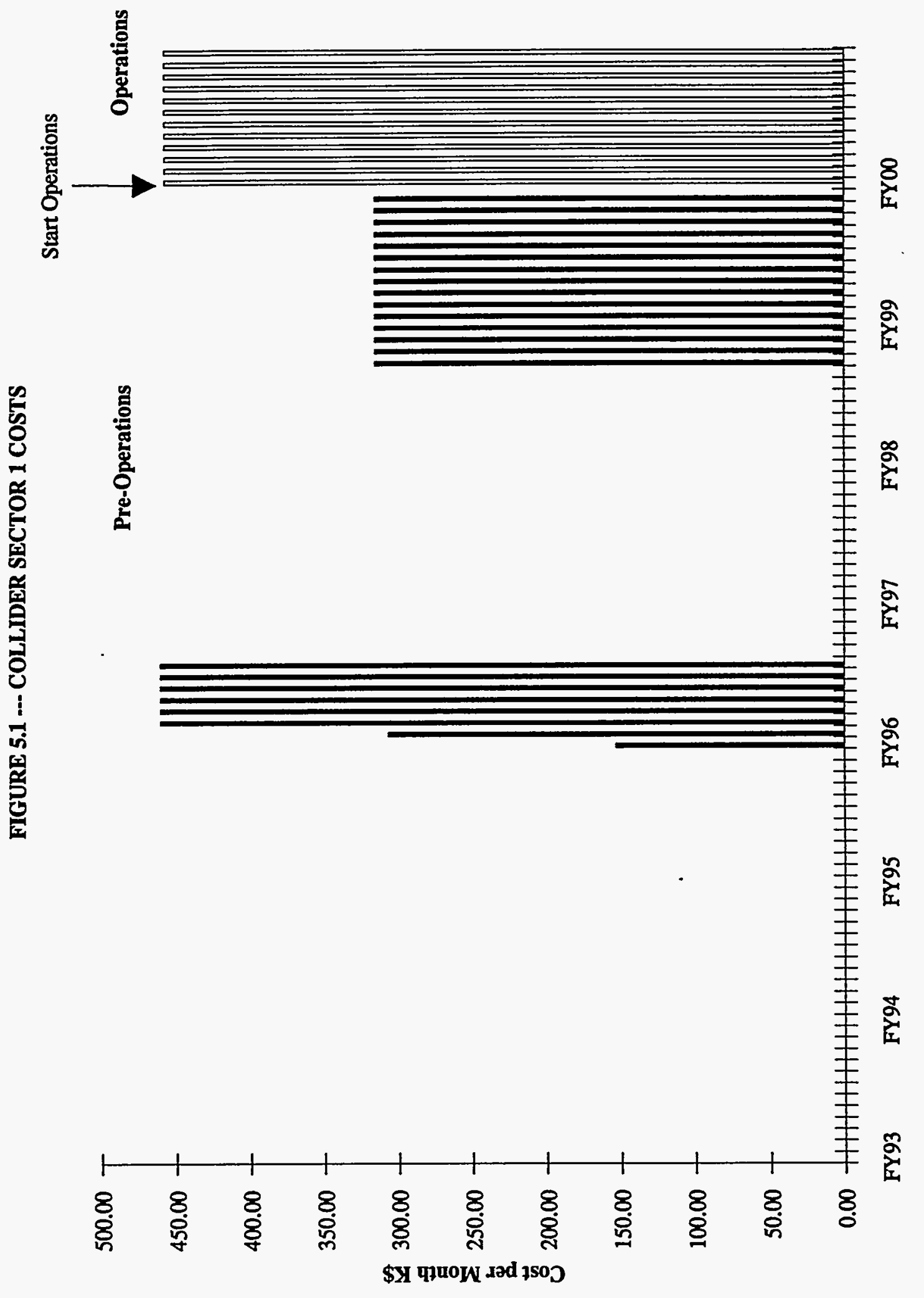




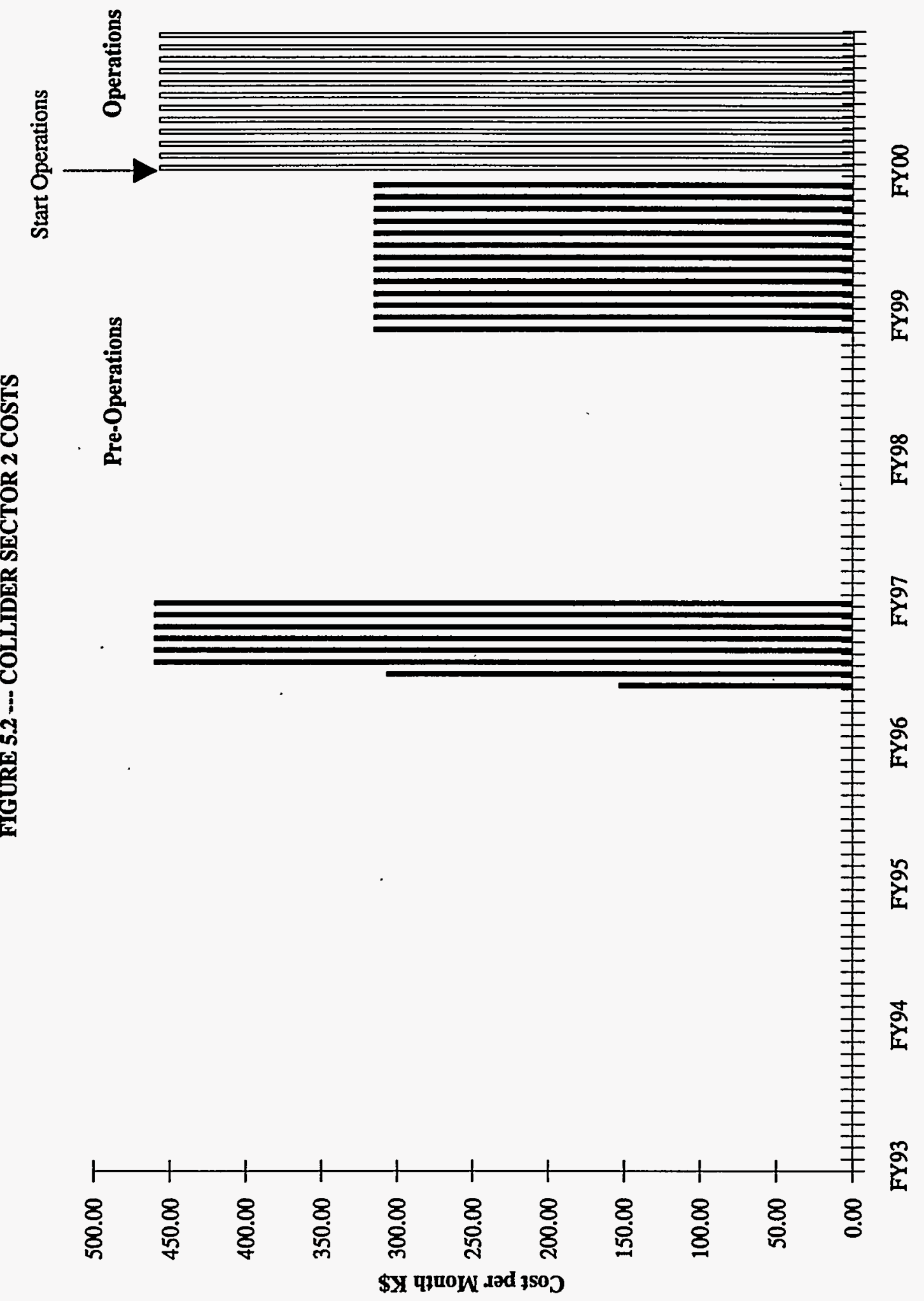




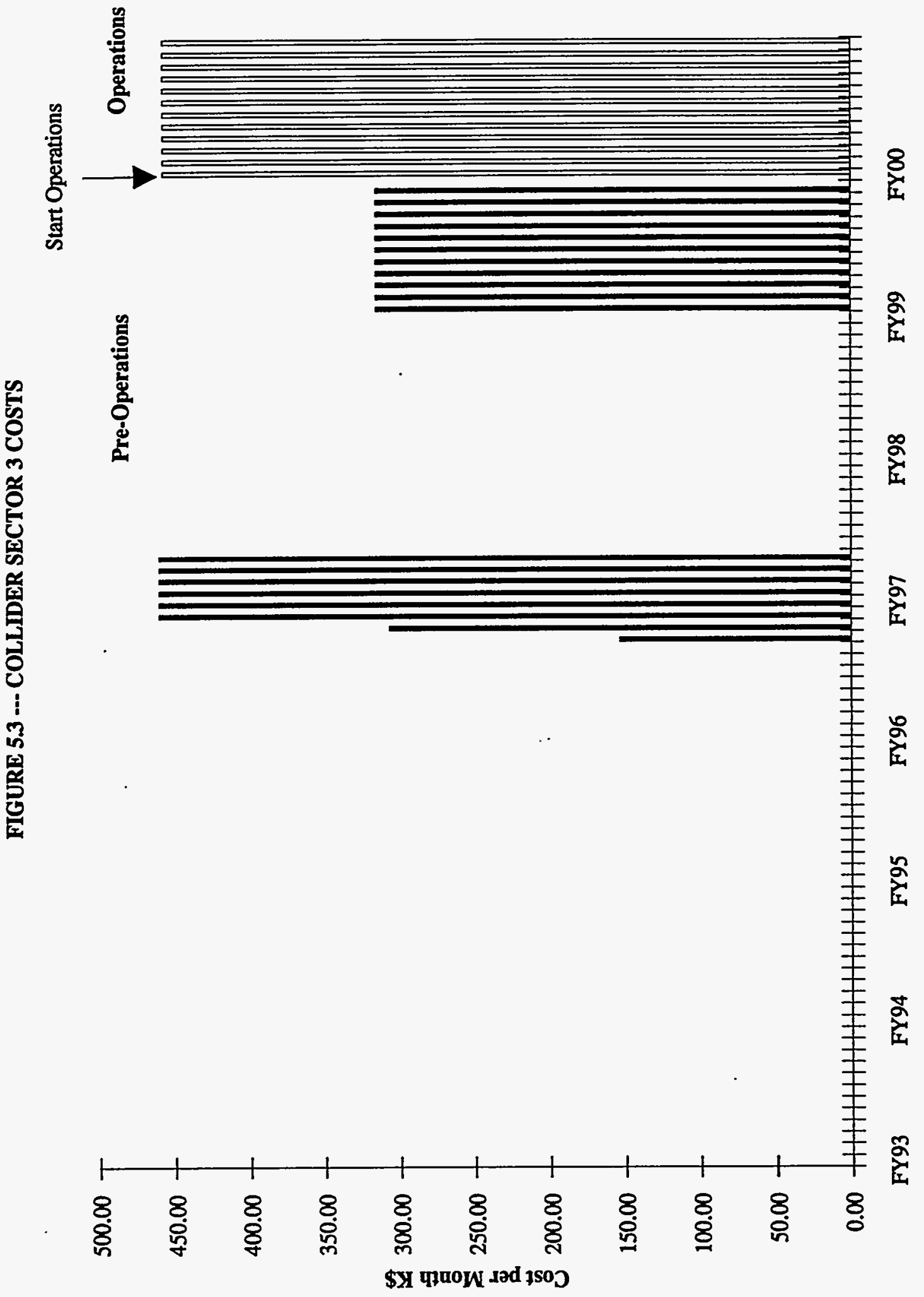




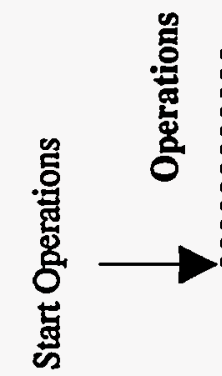

8

焉

.0.

\&

$\stackrel{\infty}{2}$

5

岳

$\sum_{1}^{\infty}$

an

\&્木

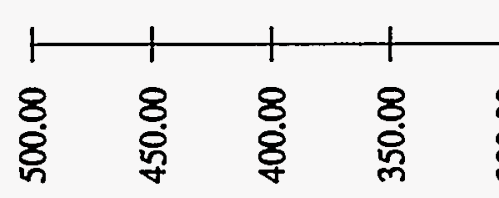

\&

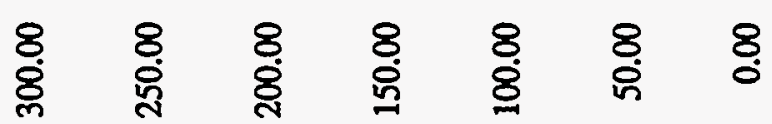

\$Y पนuOW dod 750 D 


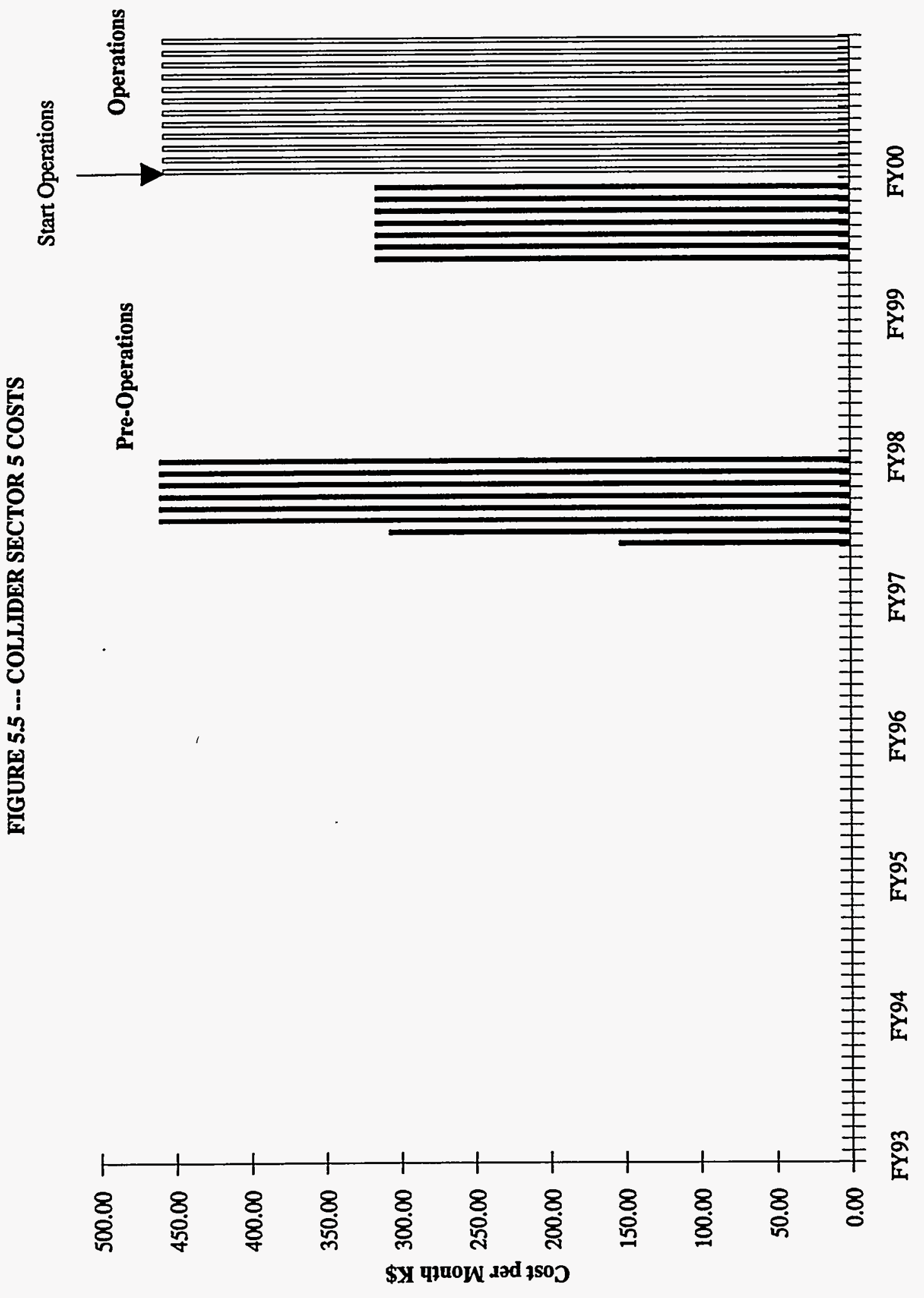




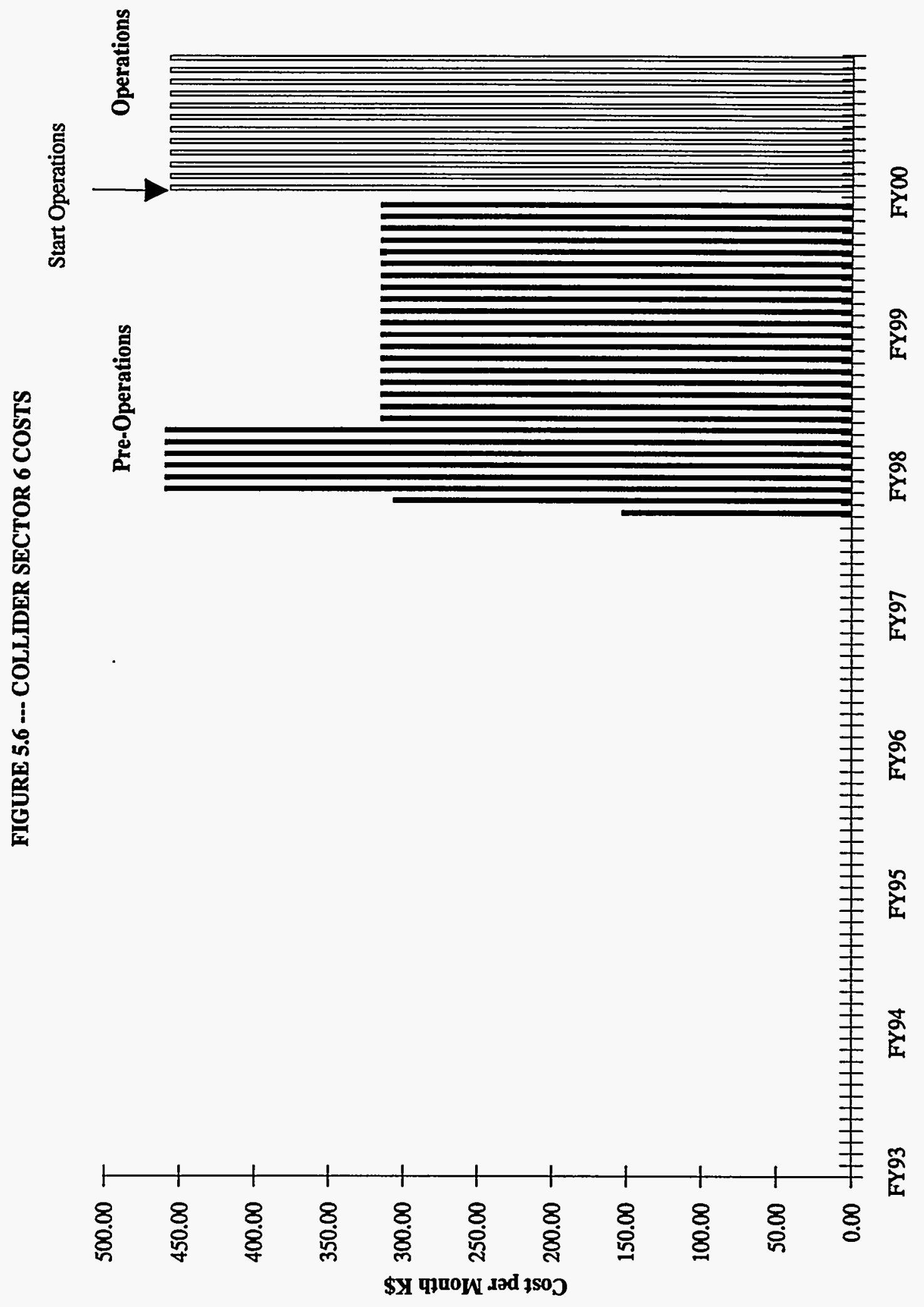




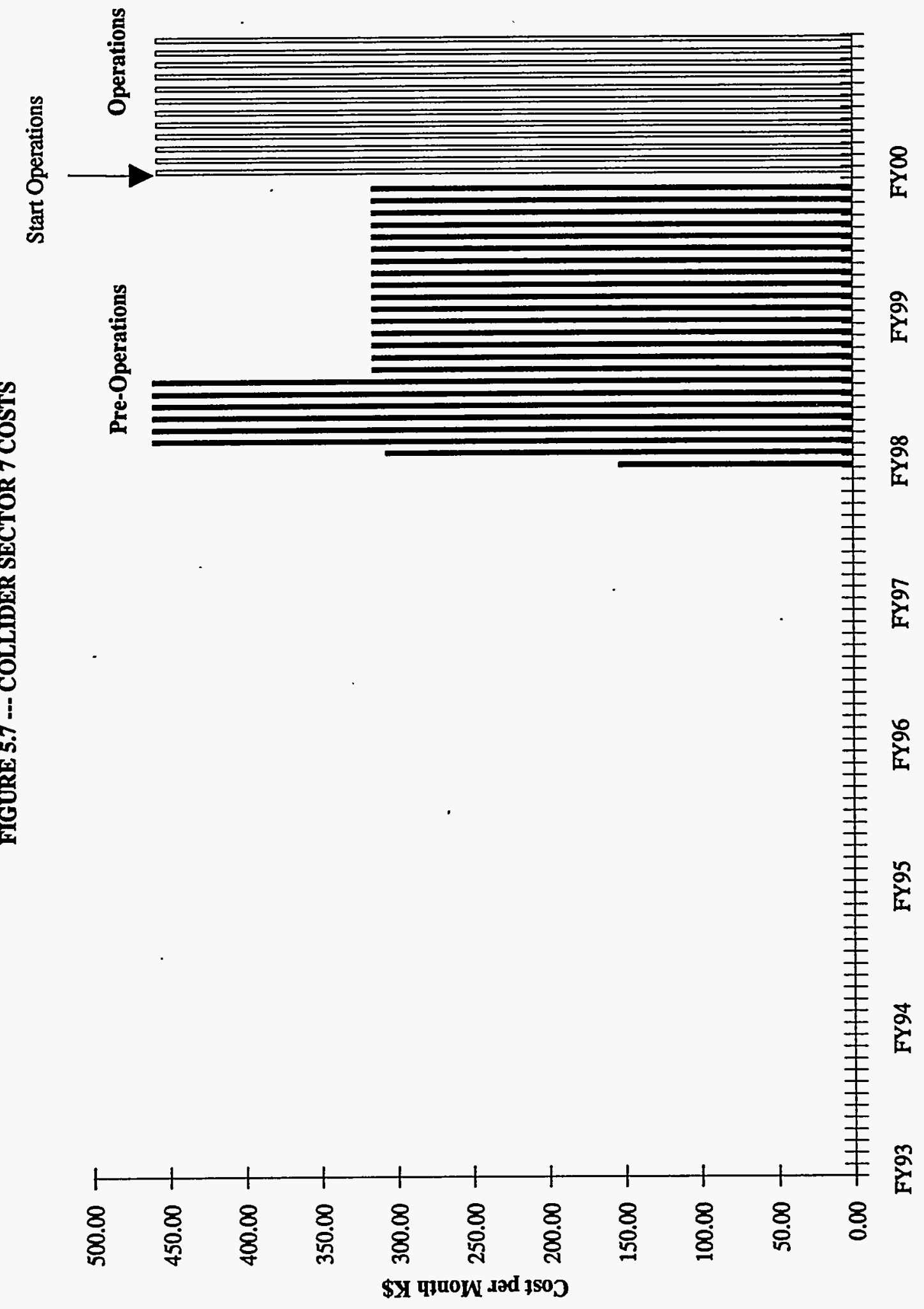




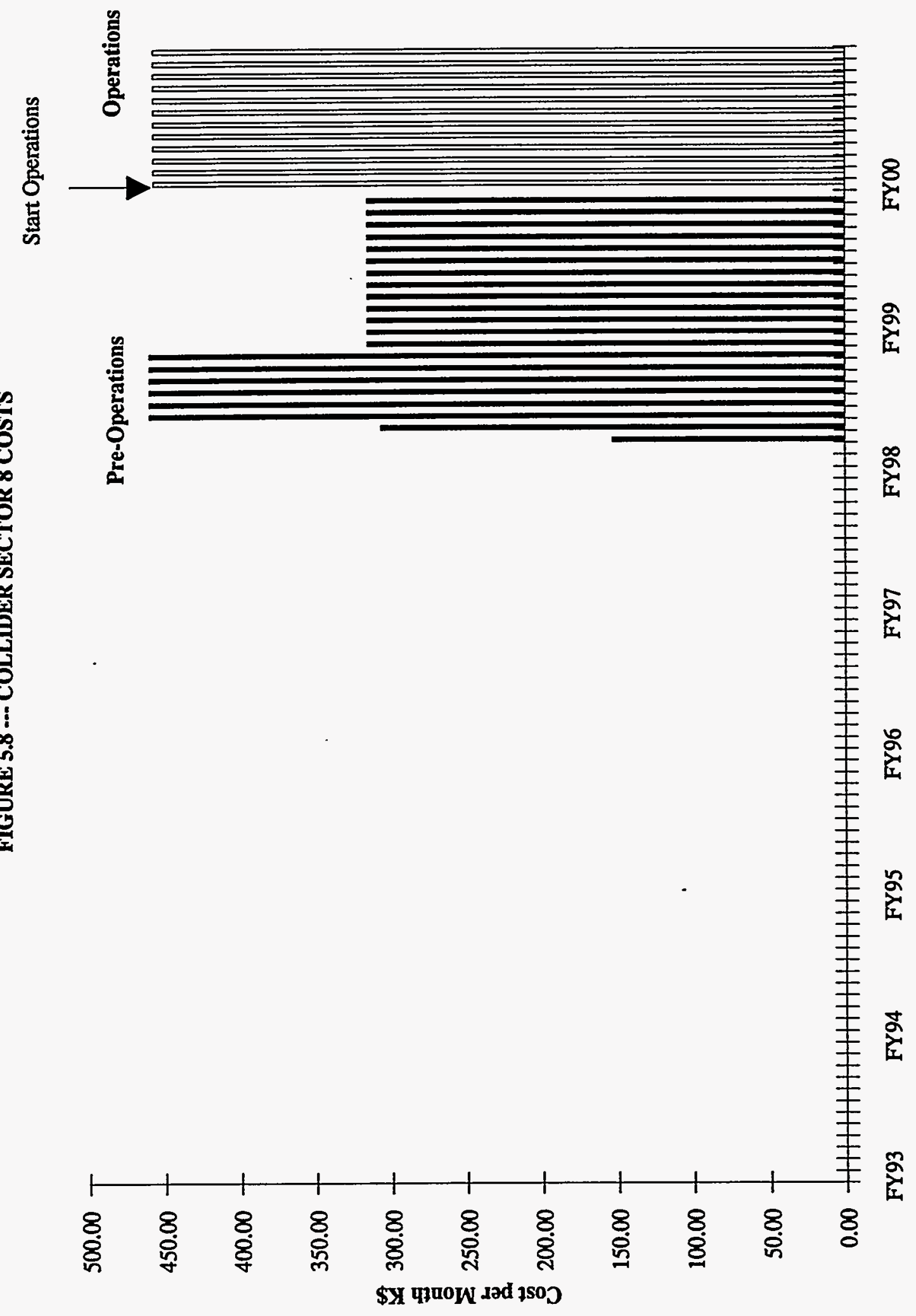




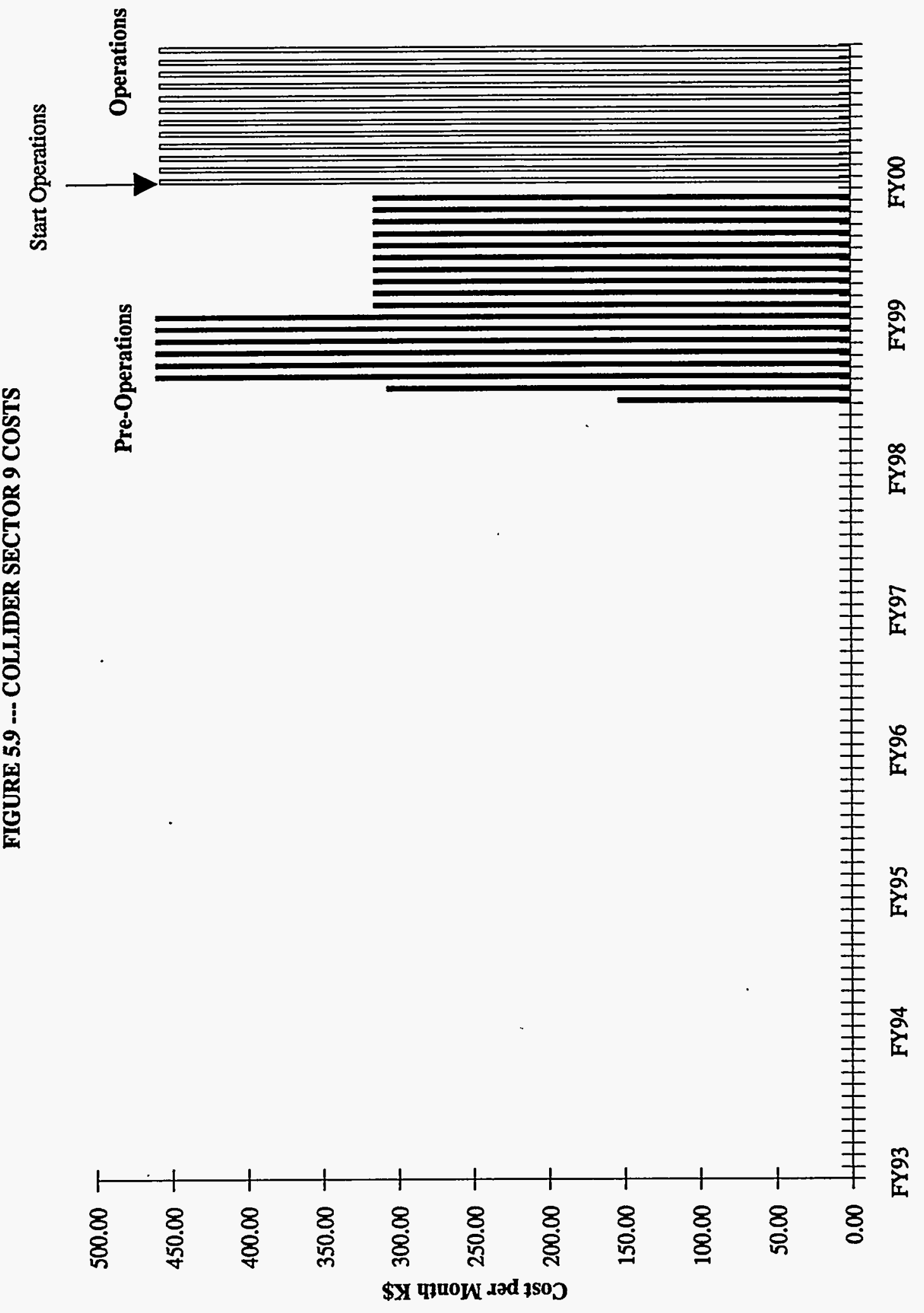




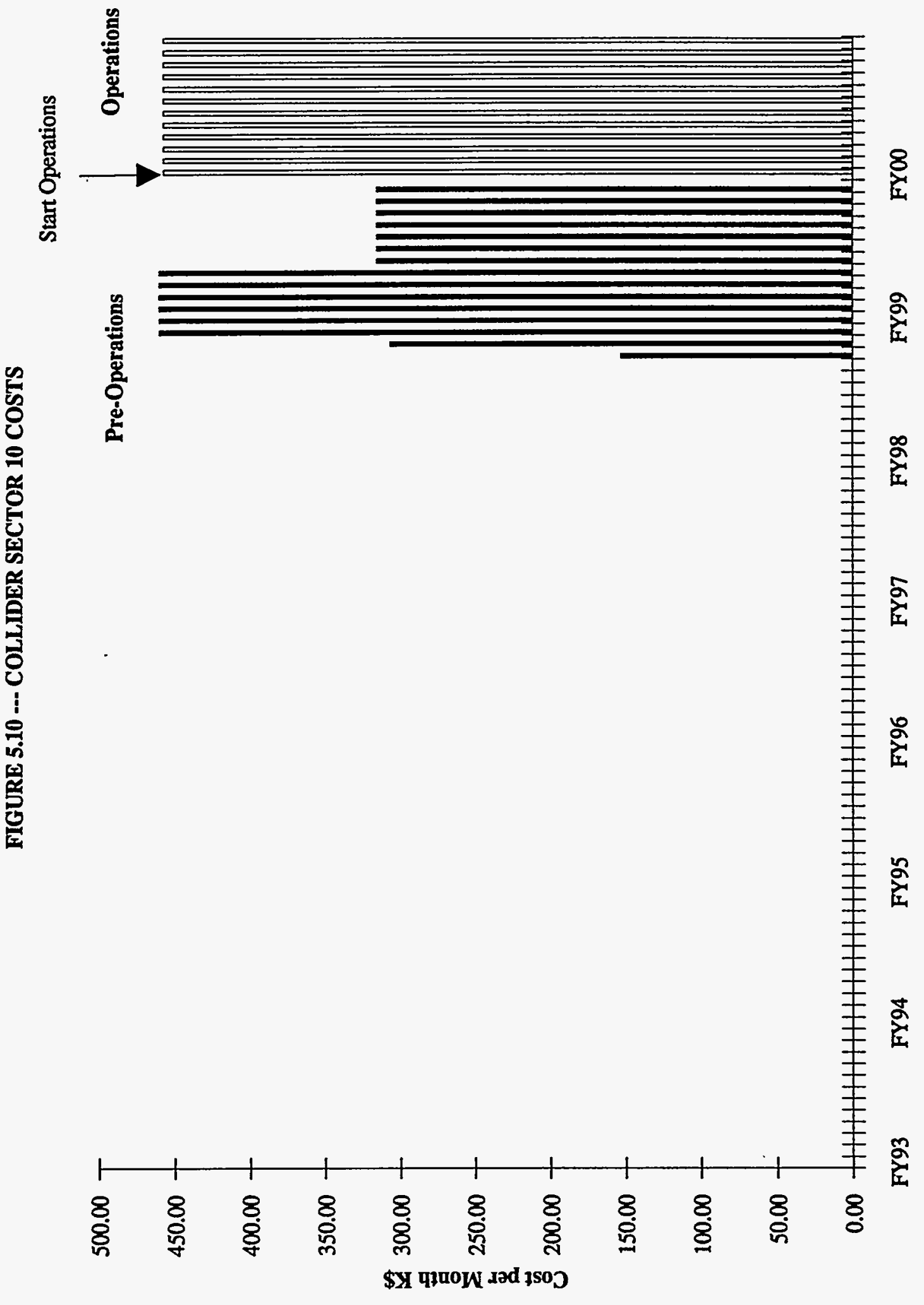


용
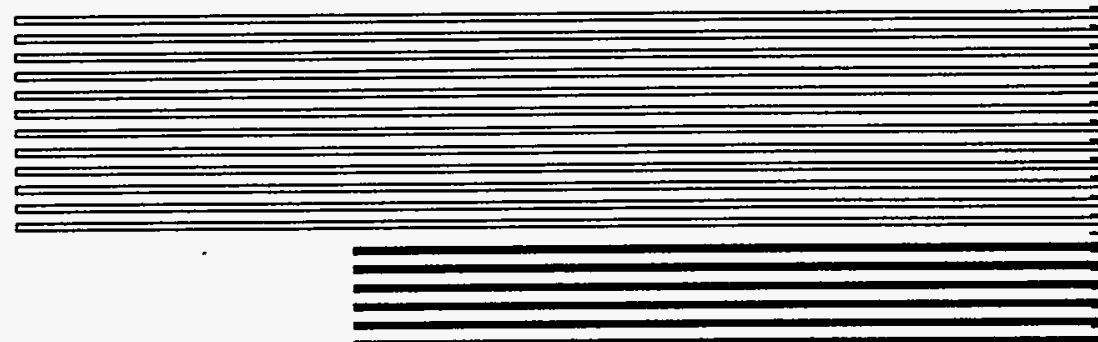

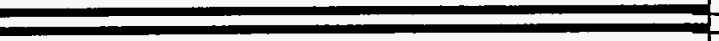

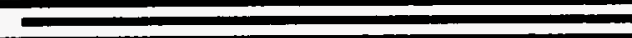

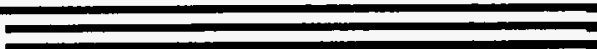

\&

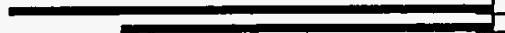

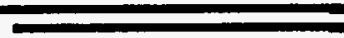

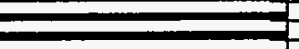

$\underset{5-\infty}{2} \infty$

$\stackrel{\infty}{\stackrel{1}{1}}$

-

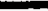

rarar

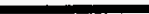

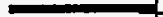

-

हิ
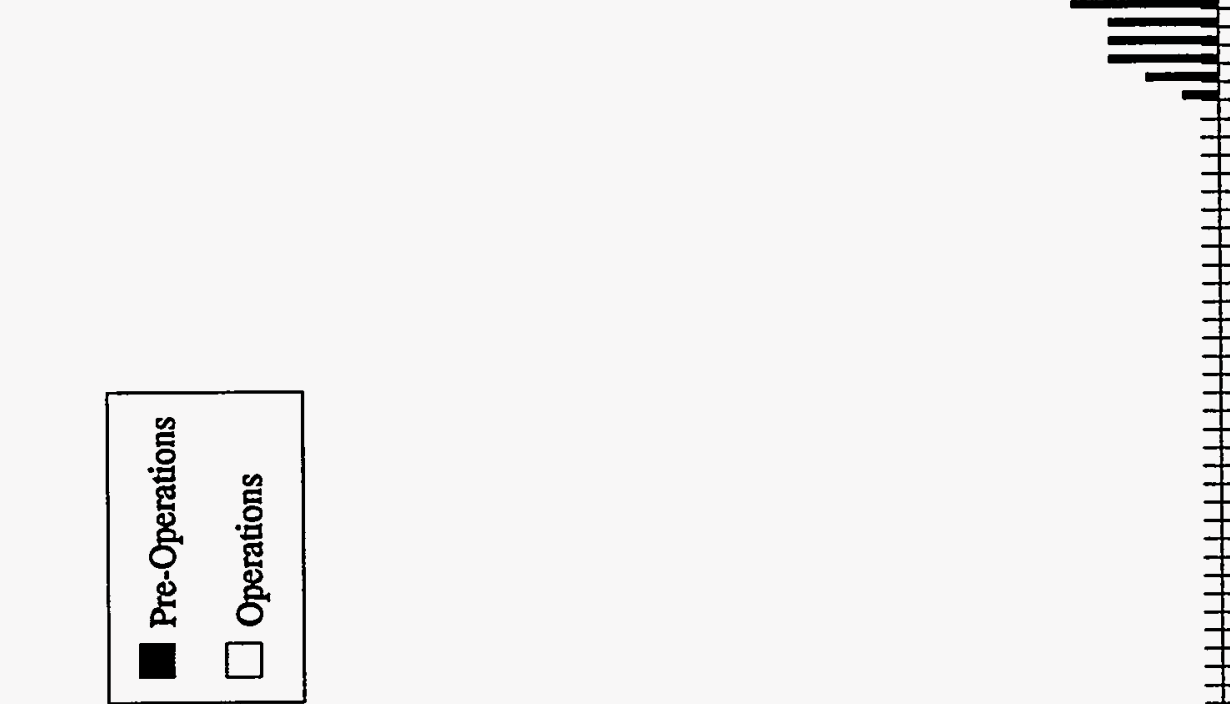

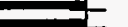

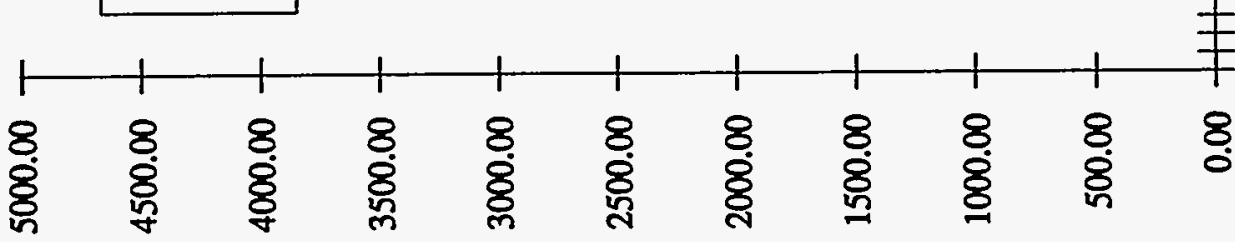

\$Y quLoW Jad yso 


\section{c) Experimental Facilities}

This section estimates the cost of the experimental facilities group that will operate and manage the facilities that support the operations of the SSCL detectors. This includes the underground halls which enclose the detectors, the surface structures which support the assembly, test, and operations, and the associated power and utilities for these operations.

Four experimental areas are planned at Interaction Regions 5 and 8 on the east side of the collider, and Regions 1 and 4 on the west side. Two large experimental halls (approximately 100 $\mathrm{m}$ long $\mathrm{x} 30 \mathrm{~m}$ wide $\mathrm{x} 40 \mathrm{~m}$ high) will be located at Regions $5 \& 8$. These will provide the underground enclosures for the Solenoidal Detector and the GEM detector. The designs for these detectors are underway.

An "intermediate" size detector is contemplated for IR 1 and a relatively "small" experiment is forecast for IR4. No detailed proposals for detectors have been accepted for these regions. For purposes of estimating the experimental facilities staff that will be required, we assume that the IR 1 and IR4 regions will require about $1 / 3$ and $1 / 9$ respectively of the manpower required by $\mathbf{R} 5$ and $\mathbb{R} 8$.

The large halls are scheduled for completion in FY96 and the smaller ones in FY97. These dates signal the availability of the halls for assembly of the detector systems. The transport of thousands of tons of detector components via crane from the surface facilities to the underground enclosure followed by assembly of components within the halls will be a complex and lengthy procedure.

As described in Section A, an operational management and support group will provide area supervision and technical support for the detector assembly process and the detector operations thereafter. It is projected that this group will rapidly build to a three-shift operation within one year of the Beneficial Occupancy of each experimental hall. At the end of this period the detector assembly program will become a 24 hour operation. During this time there will be considerable activity in the above-ground buildings with regard to detector component assembly and tests.

In the pre-operational period prior to acceptance of the experimental hall, the facilities group will be assembling and training staff. The staff will become knowledgeable with regard to the facilities (access, power, utilities, etc). The group will also become familiar with the detector requirements for assembly, crane utilization, special handling of components. and overall schedules for component delivery, test, and final assembly. A major responsibility of the facilities group will be to establish and enforce safety rules and procedures.

After beneficial occupancy the facilities group will supervise and approve procedures for detector assembly, particularly operations which require the handling of heavy components. General tasks include the operations and maintenance of buildings, power systems, cryogenics plants, and utilities. The operation of cranes, lifts and elevators will be the responsibility of this group.

The installation of the detectors will require operations of special devices assembled for this purpose. These devices will require trained operators, safety monitors, maintenance people, and management for their operation. Such devices will be needed as early as FY 1996. By FY 1998 , the detectors will be well along in their construction. As each subsystem is installed, it will be operated to make certain that it functions according to specifications. These tests will require that support facilities are available. Gas, cryogenic, water, and power systems will be required at this stage with a full technical support team. 
By FY97, the large magnets involved in the general purpose detectors will be undergoing current tests and field mapping. These tests will require operating support, including trained technical people available on a three-shift-a-day basis. The magnets will require operations support for cryogenic refrigeration systems, power supplies, safety systems, and magnet control systems. Researchers will be involved in carrying out field maps, and will require data management and computing support.

The facilities staff will monitor and enforce safety rules and regulations. This includes the establishment of emergency procedures, the maintenance of access and egress, and the assurance that procedures are enforced for fire protection, the handling of hazardous materials, and environmental protection.

Other responsibilities include the supervision of space utilization in the IR halls and above-ground buildings, the maintenance of tools and equipment that may be required for detector component assembly and tests, and the maintenance of records, drawings, logs, and reports with regard to the detectors and operation of the overall facility. In addition, if improvements or modifications are required to the facilities in order to accomplish and/or expedite the assembly and operations of the detector, the facilities group will be responsible for evaluating and implementing these changes.

The estimated manpower and M\&S associated with each area is given in Table 9.0. Table 10 provides the projections for Power, Equipment, and AIP. The resulting annual costs are provided in Tables 11.1 through 11.5. The associated profile of monthly costs are plotted in Figures 6.1 through 6.6. 
Table 9.0 --- Experimental Facilities Cost for First Shift Operations

(FY91 K\$)

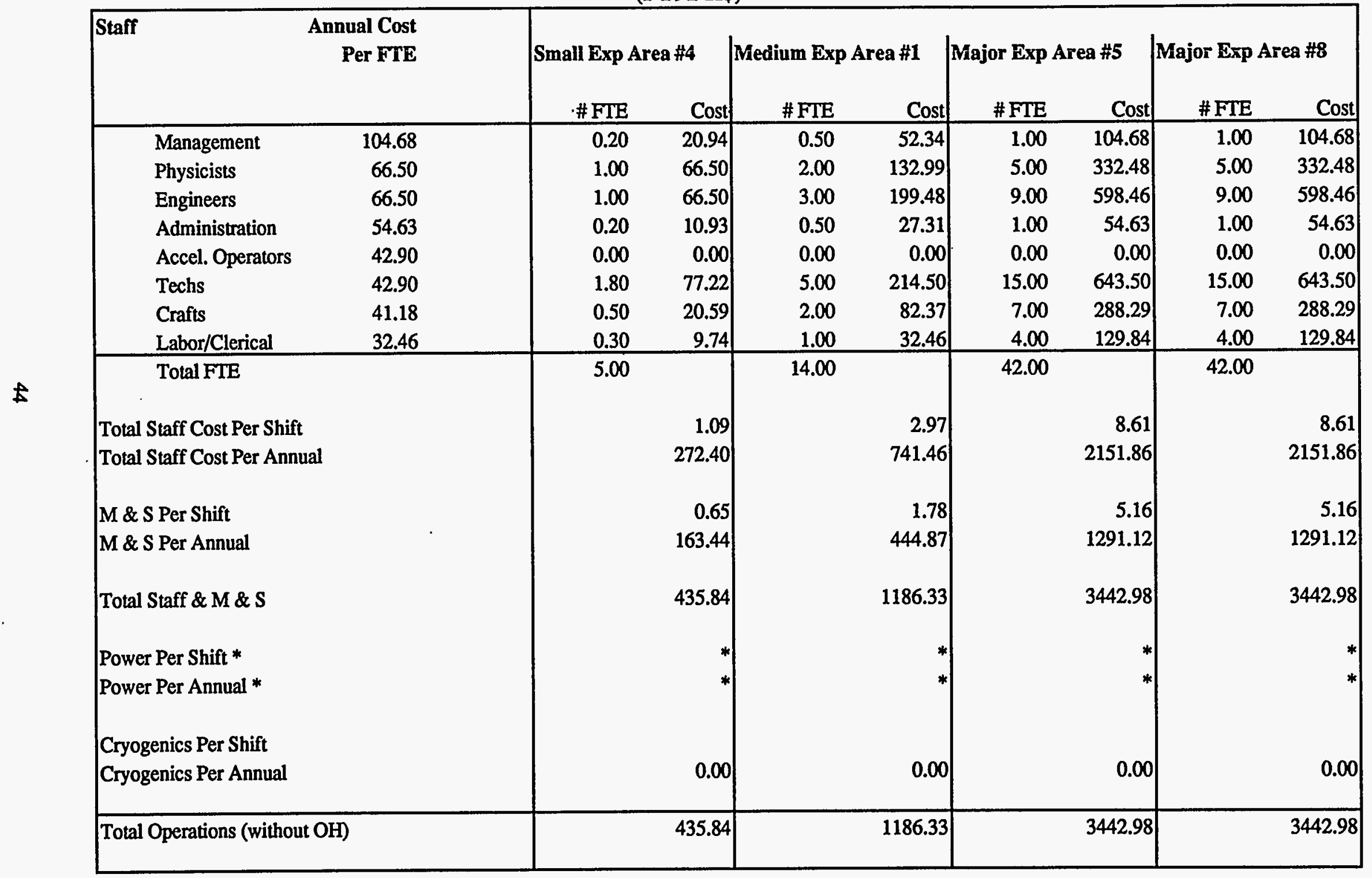

* See Table 10 
Table 10.0 --- Equipment, Power, and AIP for Experimental Areas and Detectors

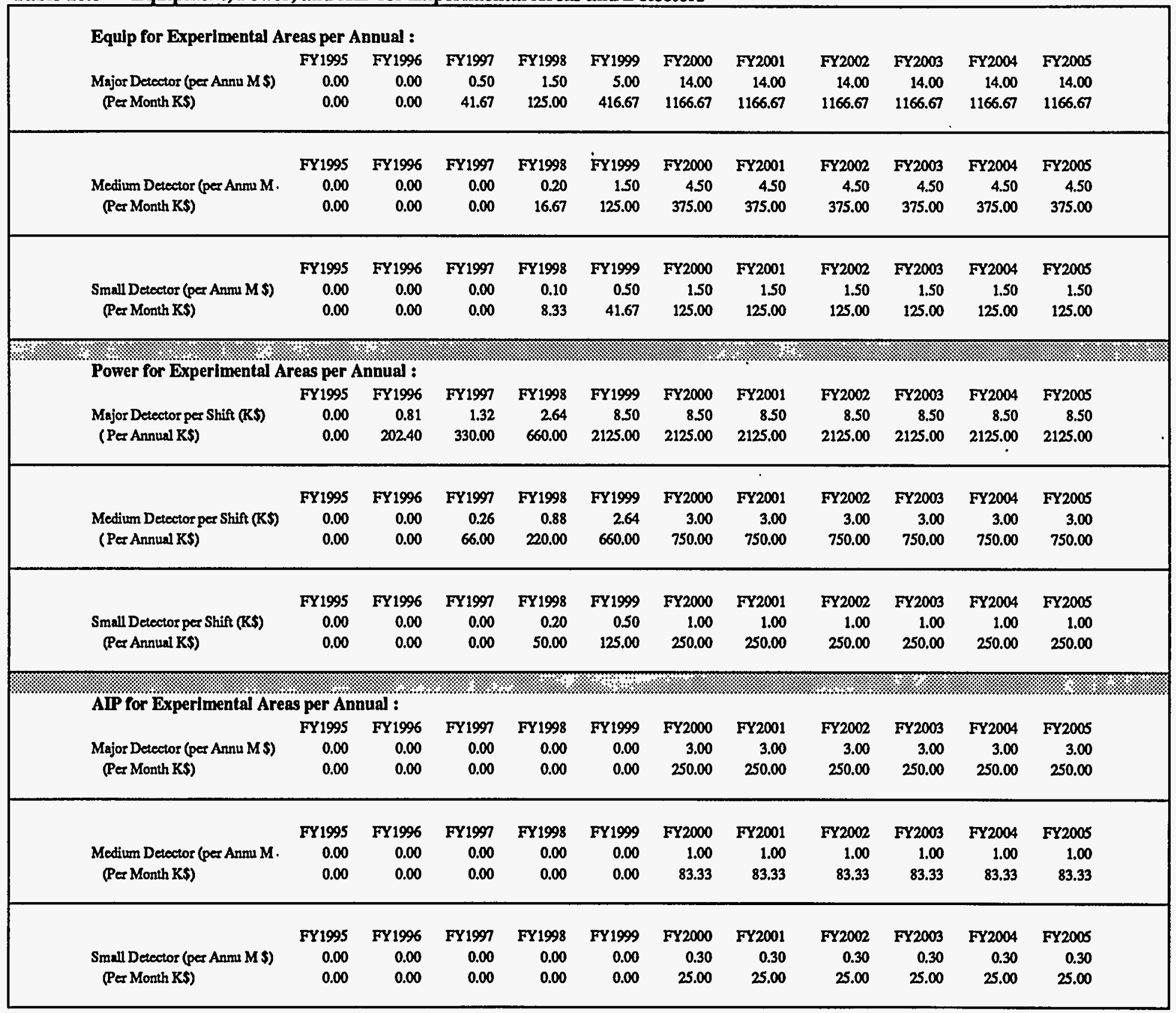


Table 11.1 -.. Exp Area 4 Costs (FY91K\$)

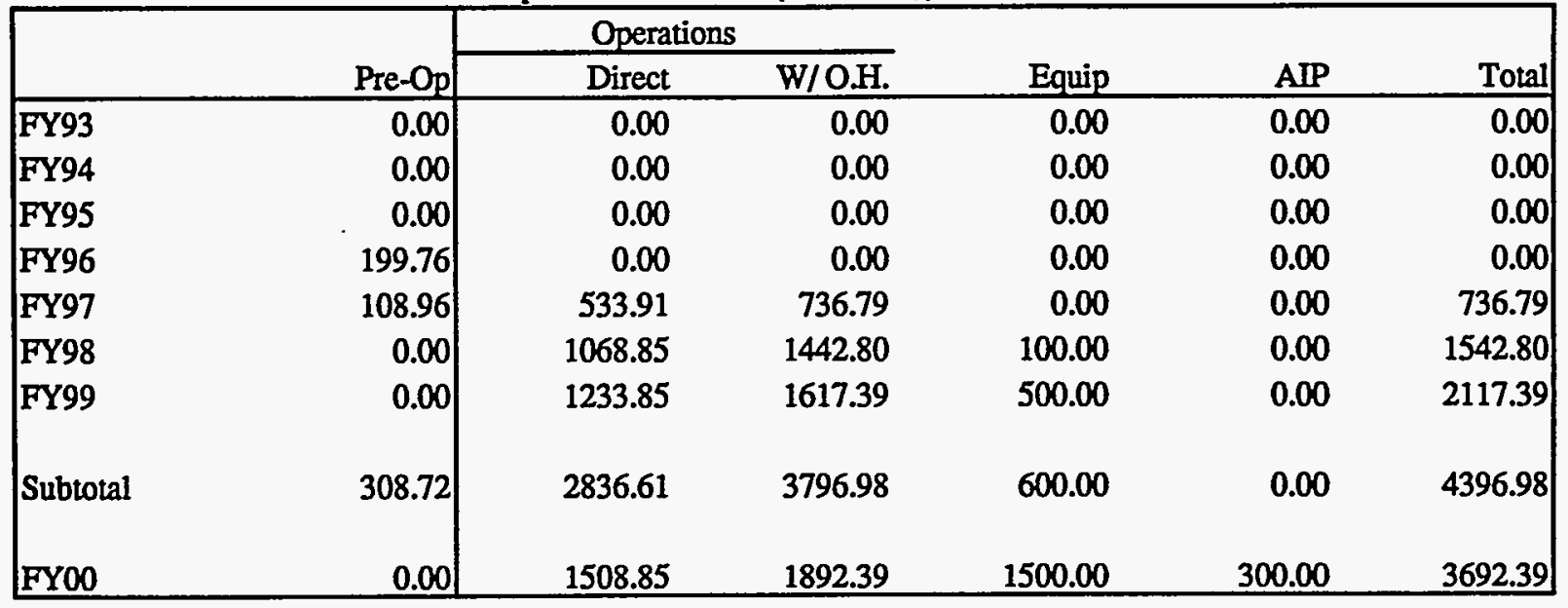

Table 11.2 -.. Exp Area 1 Costs (FY91K\$)

\begin{tabular}{|c|c|c|c|c|c|c|}
\hline & \multirow[b]{2}{*}{ Pre-Op } & \multicolumn{2}{|c|}{ Operations } & \multirow[b]{2}{*}{ Equip } & \multirow[b]{2}{*}{ AIP } & \multirow[b]{2}{*}{ Total } \\
\hline & & Direct & W/OH. & & & \\
\hline FY93 & 0.00 & 0.00 & 0.00 & 0.00 & 0.00 & 0.00 \\
\hline FY94 & 0.00 & 0.00 & 0.00 & 0.00 & 0.00 & 0.00 \\
\hline FY95 & 0.00 & 0.00 & 0.00 & 0.00 & 0.00 & 0.00 \\
\hline FY96 & 573.98 & 0.00 & 0.00 & 0.00 & 0.00 & 0.00 \\
\hline FY97 & 313.08 & 1534.10 & 2086.34 & 0.00 & 0.00 & 2086.34 \\
\hline FY98 & 0.00 & 3093.92 & 4111.79 & 200.00 & 0.00 & 4311.79 \\
\hline FY99 & 0.00 & 4061.92 & 5105.89 & 1500.00 & 0.00 & 6605.89 \\
\hline Subtotal & 887.07 & 8689.95 & 11304.02 & 1700.00 & 0.00 & 13004.02 \\
\hline FYOO & 0.00 & 4259.92 & 5303.89 & 4500.00 & 1000.00 & 10803.89 \\
\hline
\end{tabular}

Table 11.3 --- Exp Area 5 Costs (FY91 K\$)

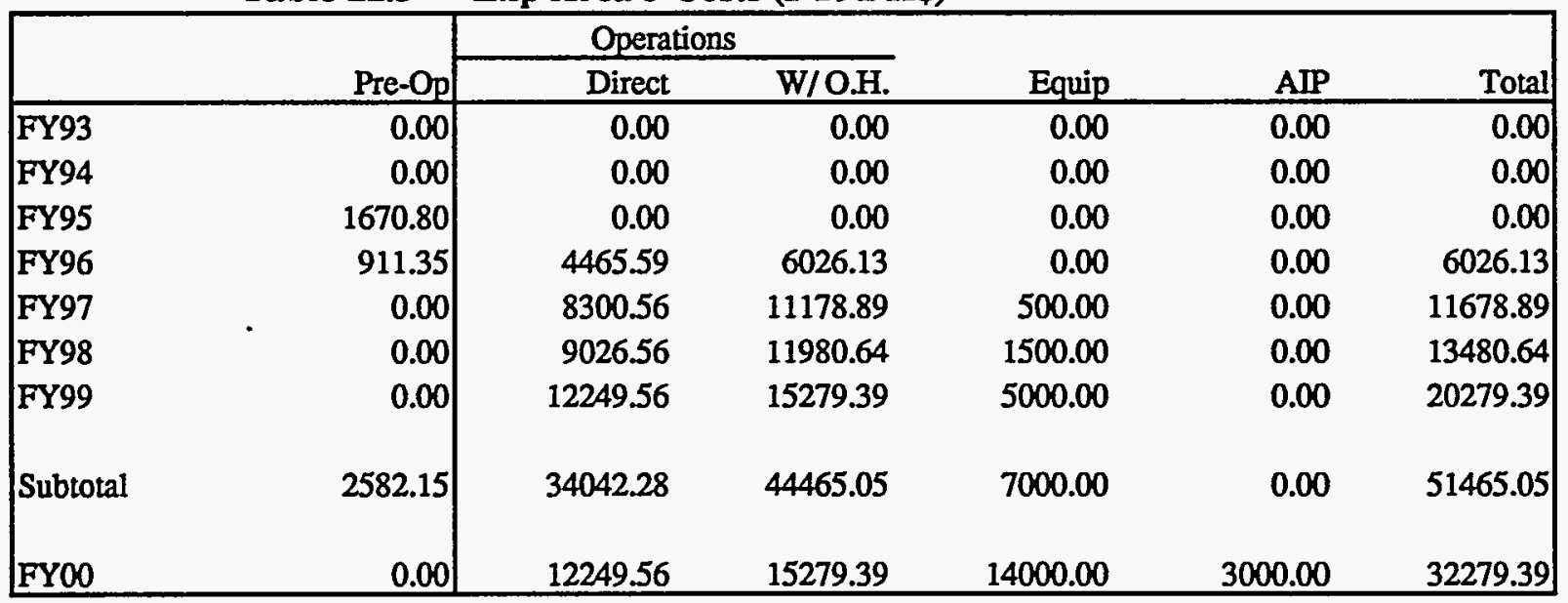


Table 11.4 --- Exp Area 8 Costs (FY91 K\$)

\begin{tabular}{|c|c|c|c|c|c|c|}
\hline & & Operat & & & & \\
\hline & Pre-Op & Direct & W/O.H. & Equip & AIP & Total \\
\hline FY93 & 0.00 & 0.00 & 0.00 & 0.00 & 0.00 & 0.00 \\
\hline FY94 & 0.00 & 0.00 & 0.00 & 0.00 & 0.00 & 0.00 \\
\hline FY95 & 1670.80 & 0.00 & 0.00 & 0.00 & 0.00 & 0.00 \\
\hline FY96 & 911.35 & 4465.59 & 6026.13 & 0.00 & 0.00 & 6026.13 \\
\hline FY97 & 0.00 & 8300.56 & 11178.89 & 500.00 & 0.00 & 11678.89 \\
\hline FY98 & 0.00 & 9026.56 & 11980.64 & 1500.00 & 0.00 & 13480.64 \\
\hline FY99 & 0.00 & 12249.56 & 15279.39 & 5000.00 & 0.00 & 20279.39 \\
\hline Subtotal & 2582.15 & 34042.28 & 44465.05 & 7000.00 & 0.00 & 51465.05 \\
\hline FYOO & 0.00 & 12249.56 & 15279.39 & 14000.00 & 3000.00 & 32279.39 \\
\hline
\end{tabular}

Table 11.5 --- Total Exp Areas Cost (FY91 K\$)

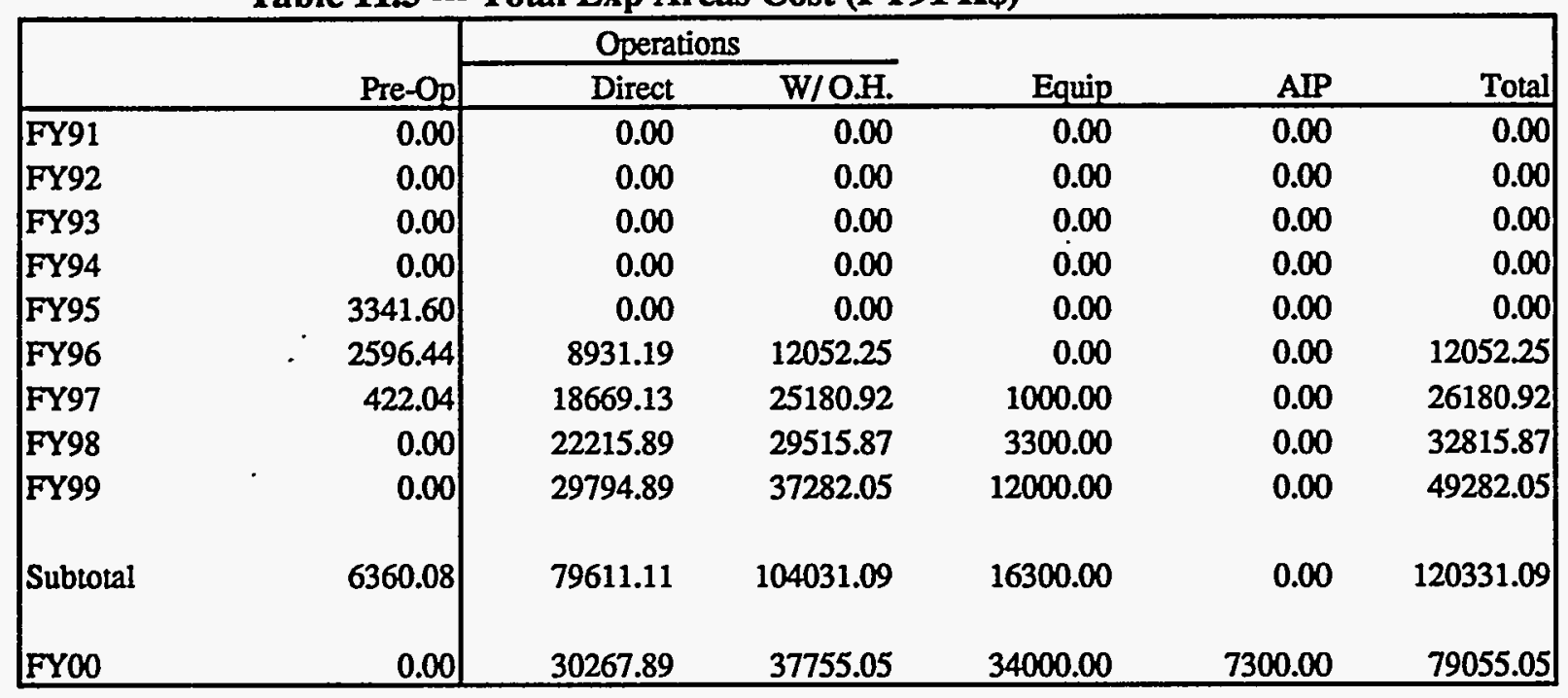




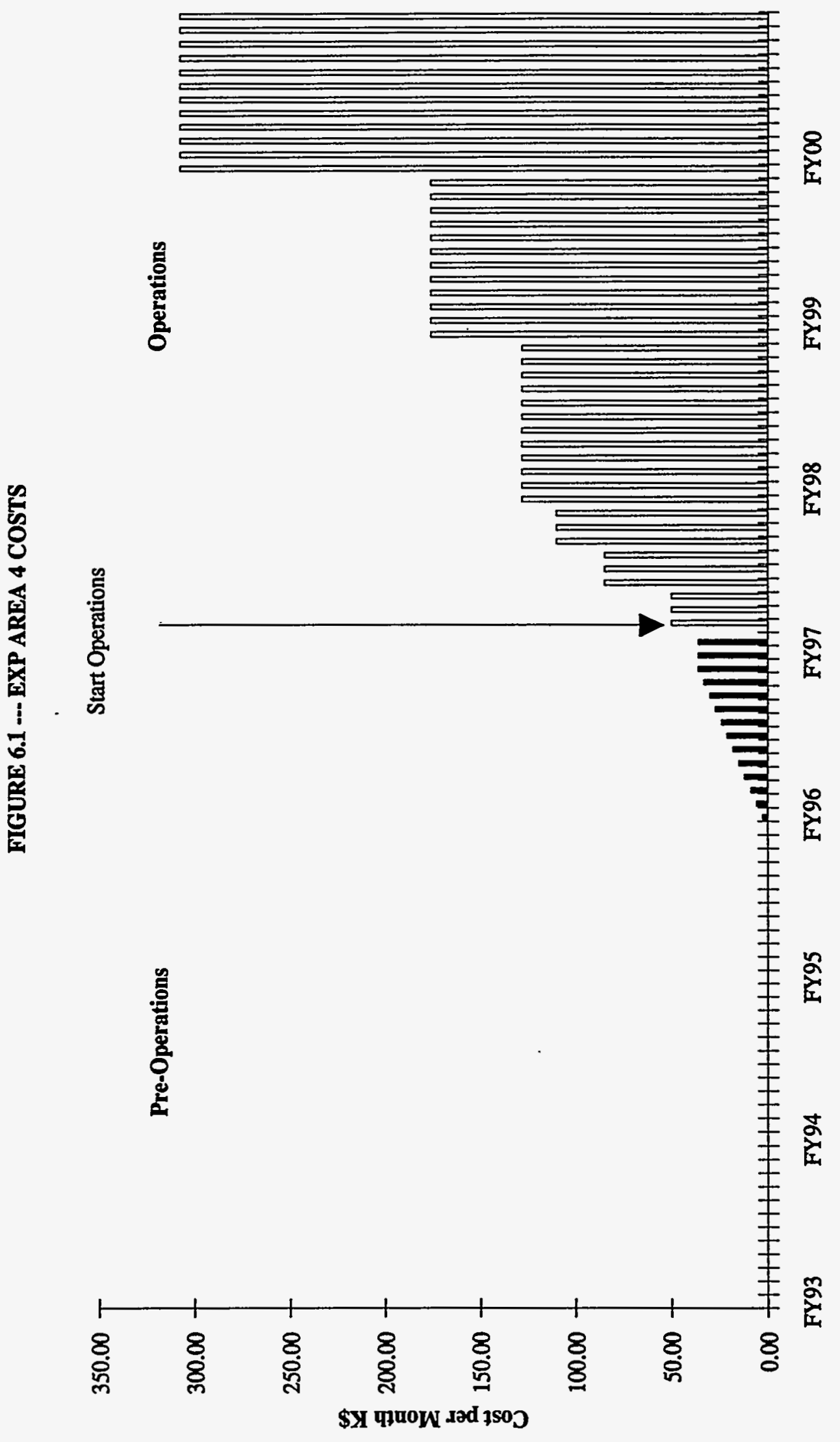




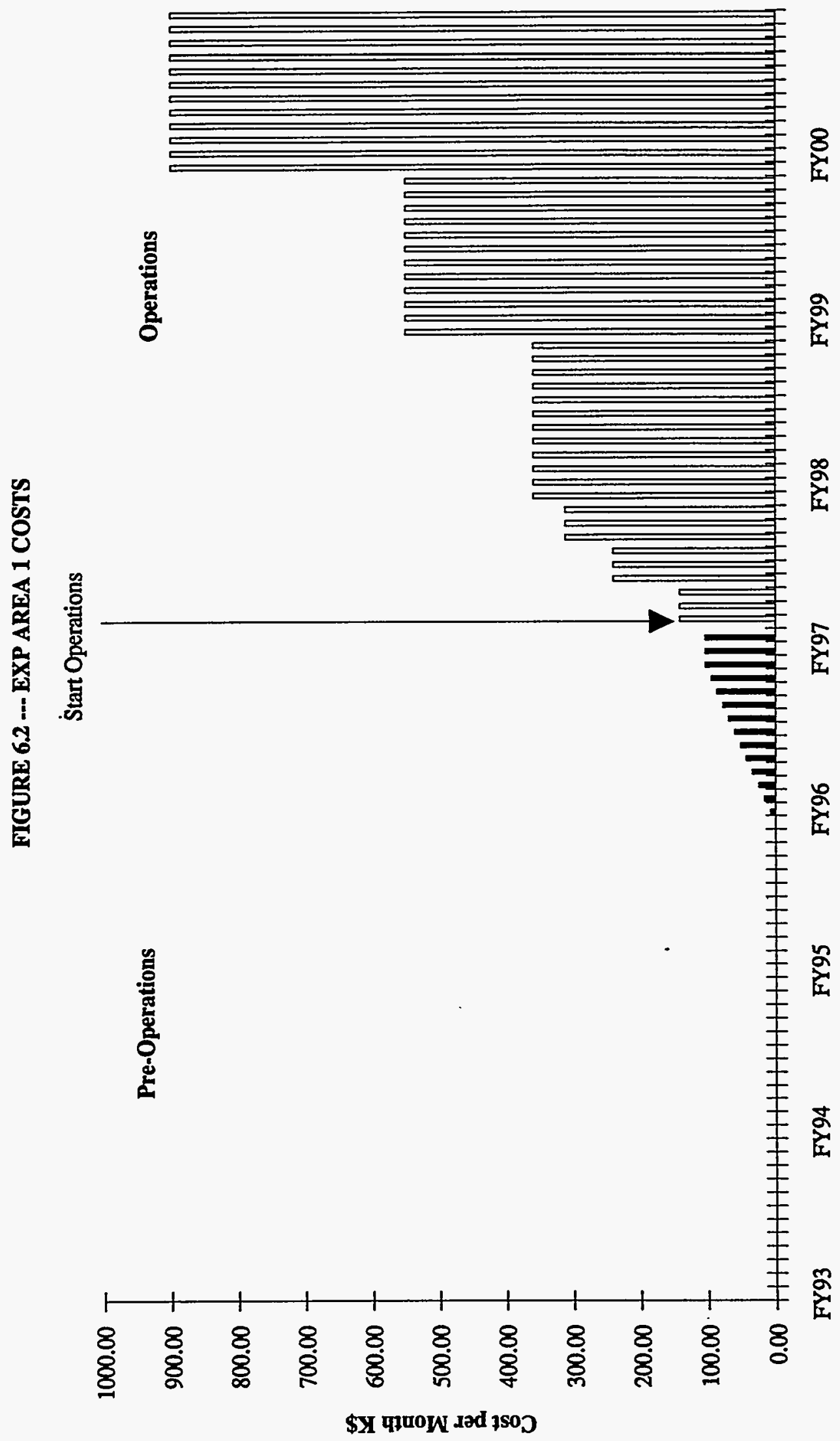




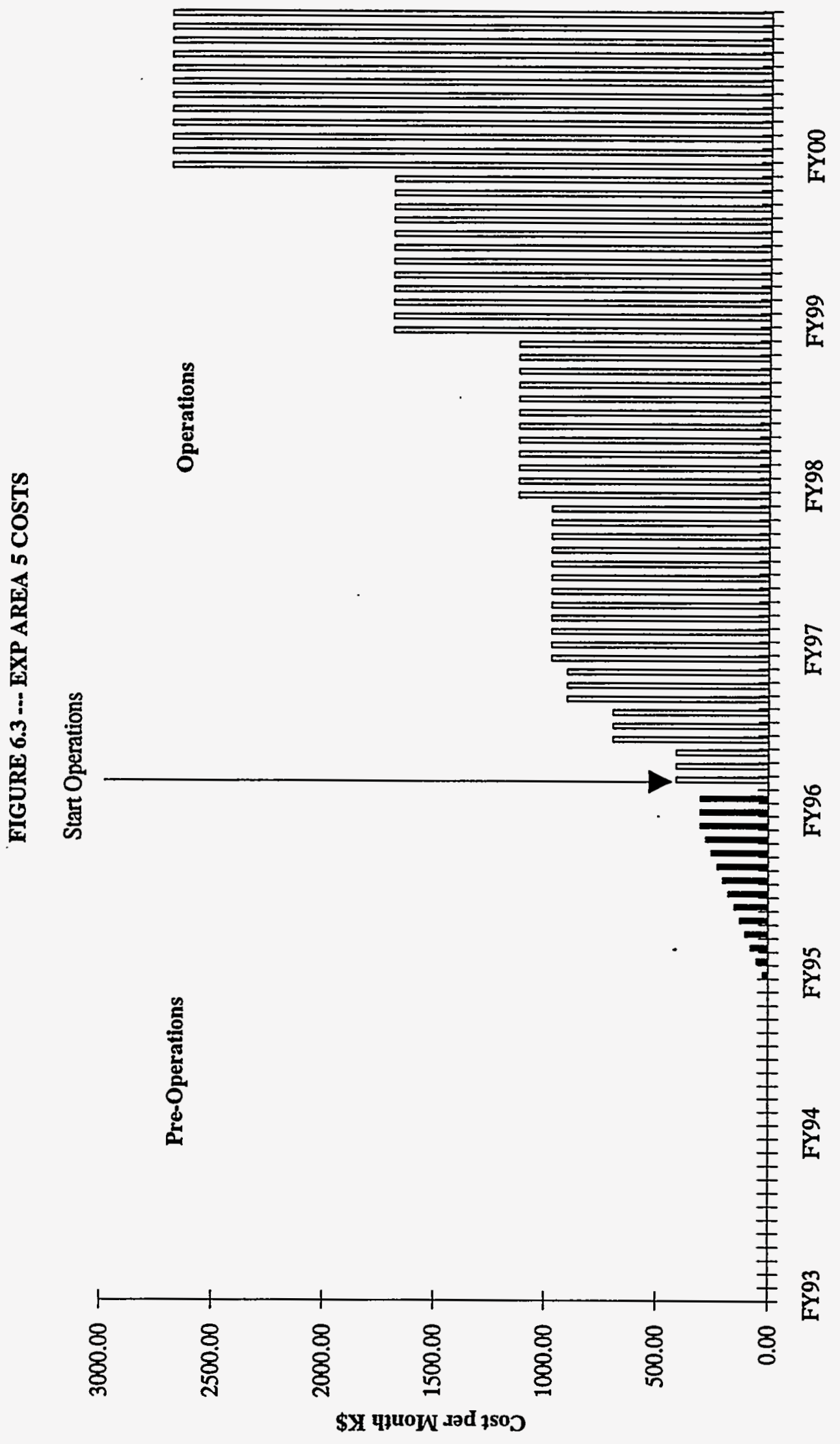




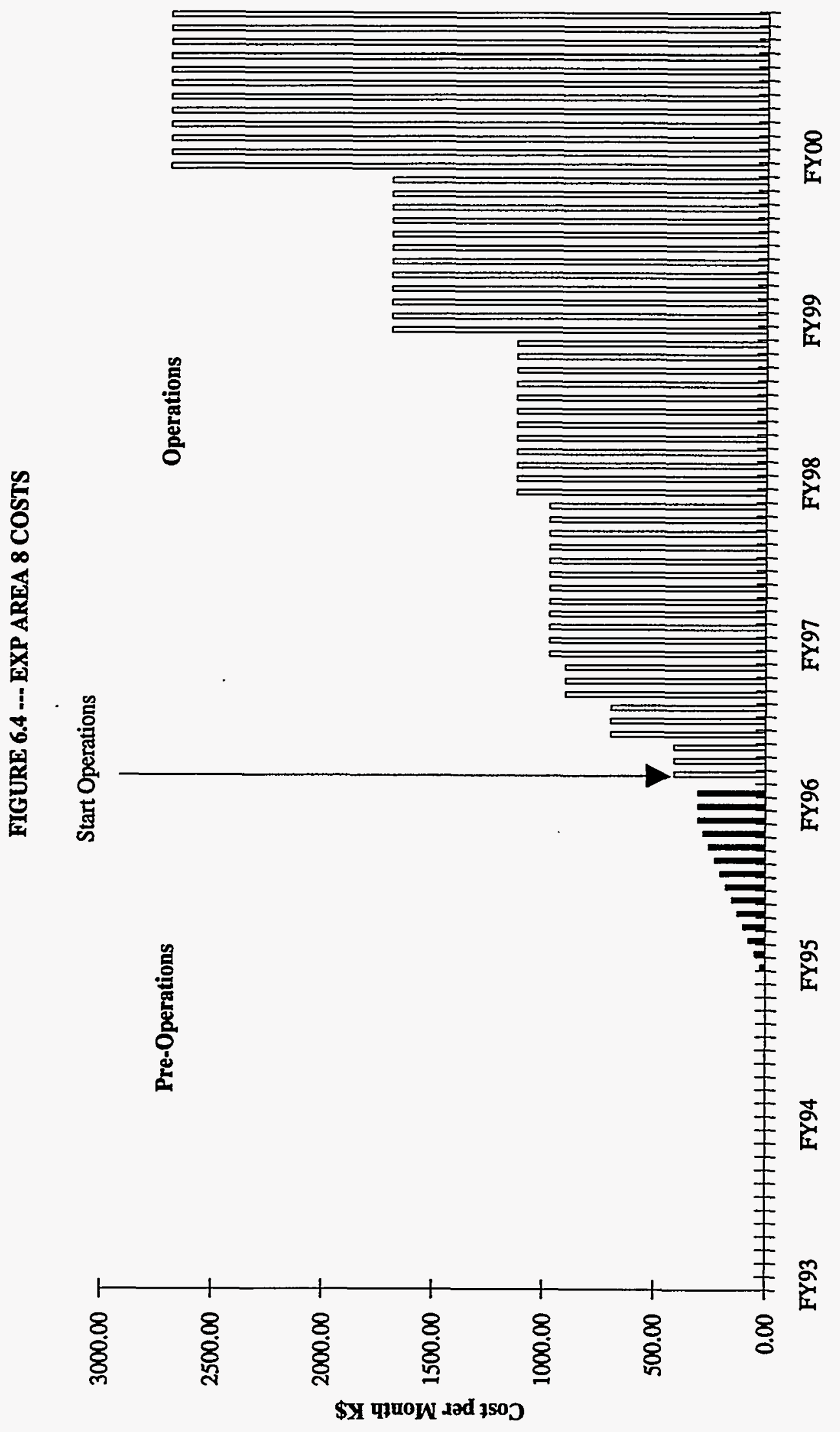




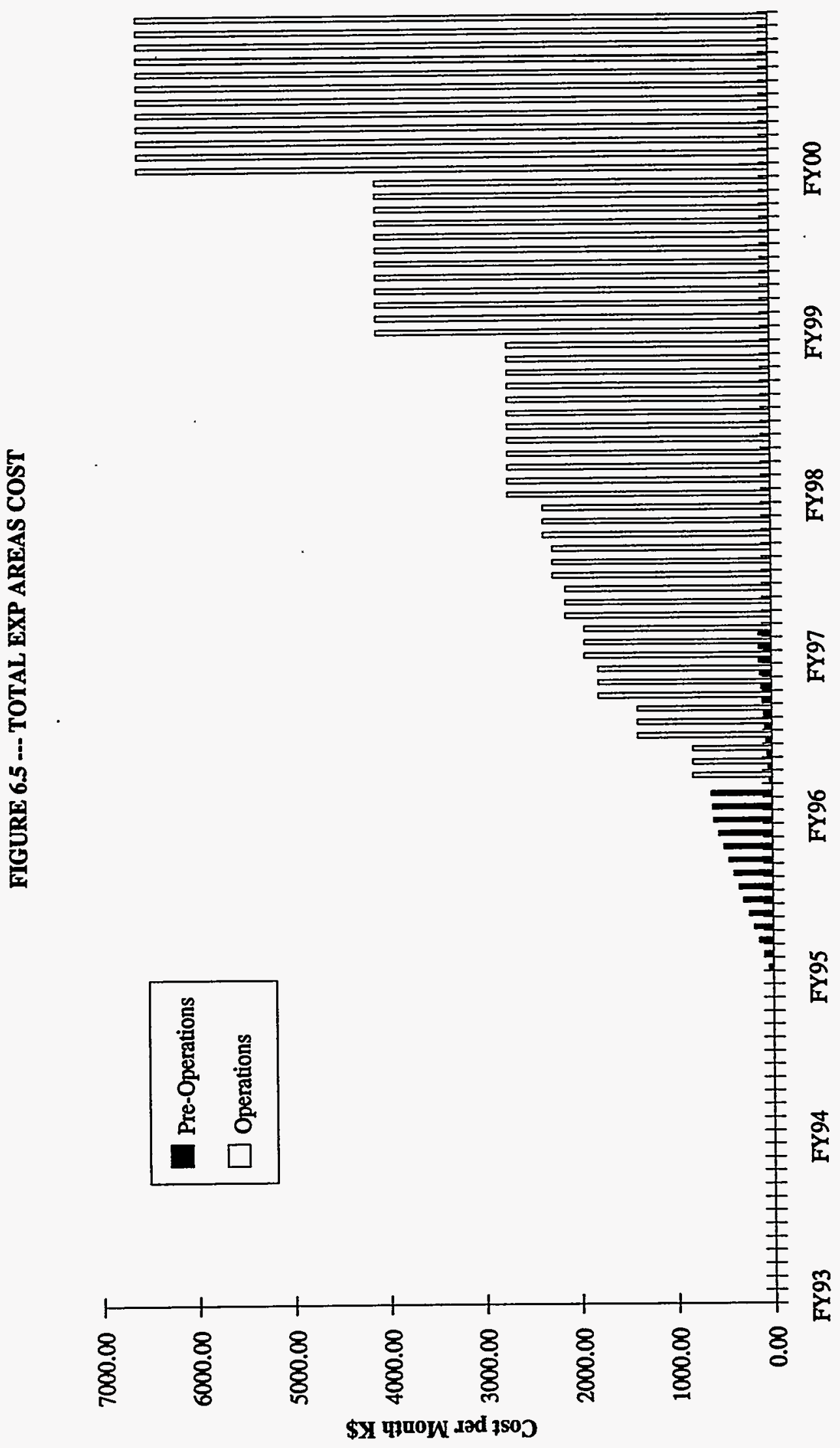




\section{d) Magnet Research Laboratory}

The Magnet Development Laboratory (MDL) and the Magnet Test Laboratory (MTL) have been designed to be research and development facilities for superconducting materials and superconducting magnets. The MDL will provide the SSCL and the physics community with a state-of-the-art facility for ongoing research and development in superconductivity.

When all superconducting magnets for the SSC Collider and HEB have been designed, built and tested, the MDL and MTL facilities will be available for operations support and continued magnet research and development. This includes the design, fabrication, and testing of special purpose magnets that may be required in future operations. Currently the operations program is projected to start in FY 97 and reach an operations support level of 125 FTE in the year 2000. The manpower levels are provided in Table 12.0. The annual costs are provided in Table 13.0 and plotted in Figure 7.0. 
Table 12.0 -.- Magnet Research Laboratory Total Cost

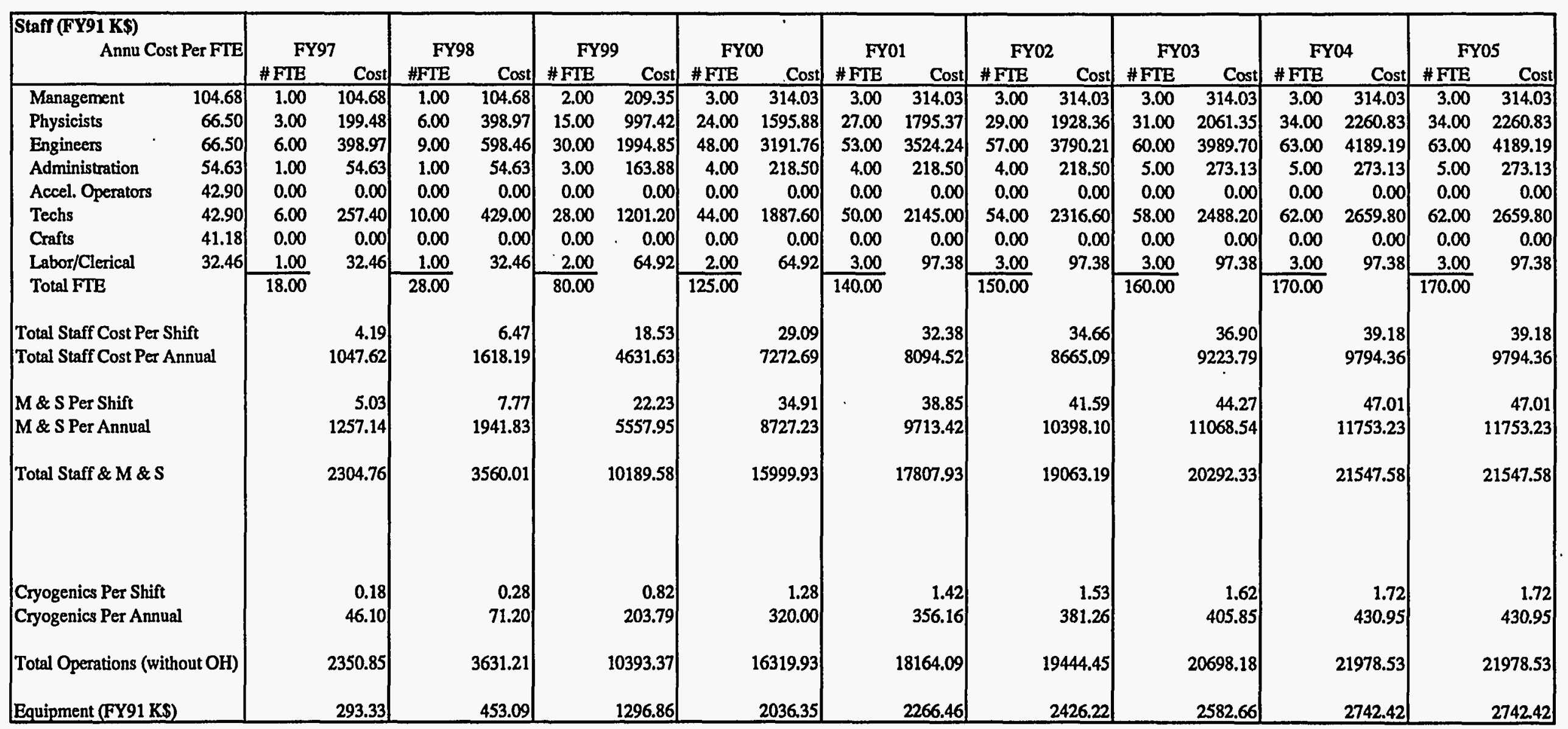


Table 13.0 -..- Magnet Research Costs (FY91 K\$)

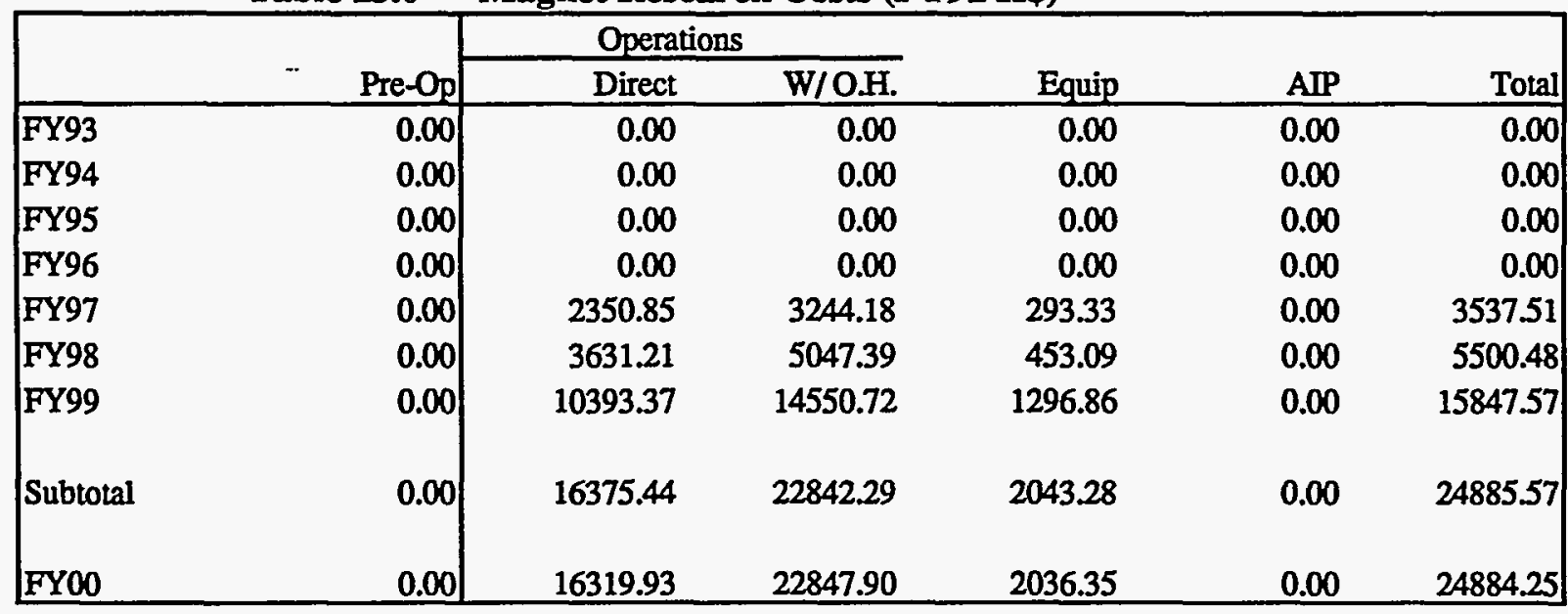




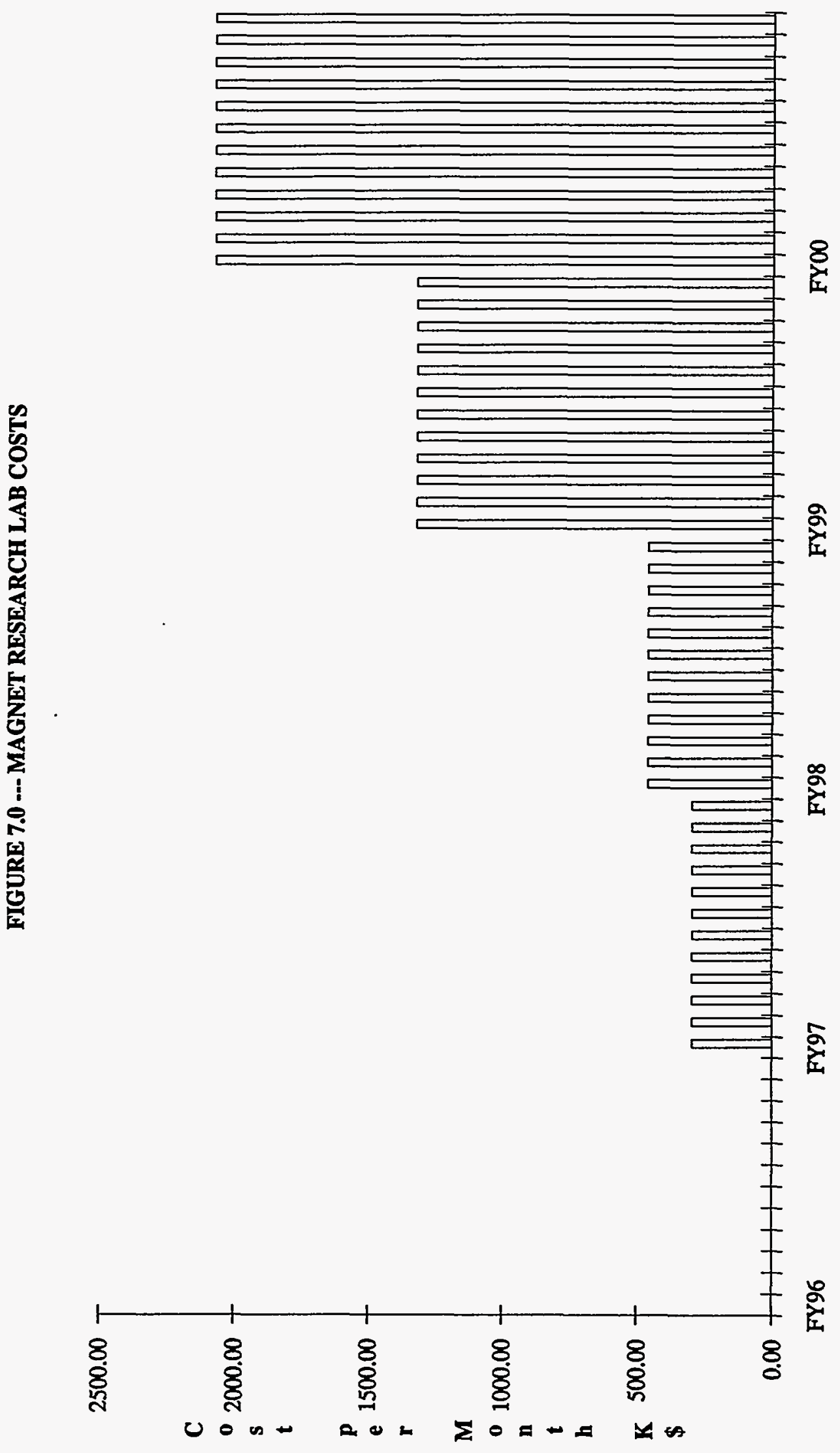




\section{e) Physics Program}

\section{1) Physics Operations}

The SSC Laboratory will be responsible for the operation and maintenance of the detectors through the Physics Research Division. Current plans call for two major detectors and several smaller ones. In particular, the operation of the detectors is a responsibility of the Physics Research Division. There will need to be a smooth transition from the project phase to the operating phase in terms of personnel within the Division. To accomplish this, estimates of scientific staffing were developed based on experience at Fermilab and SLAC in operating and maintaining the present generation of large detectors.

In order to operate the detectors, strong in-house SSCL groups are needed. In particular, 50 to 100 experimental physicists are projected to be in the SSCL collaborating group (out of a collaboration of 500 to 1000 physicists) associated with each major detector. Having about $10 \%$ of the collaboration staff members of the host laboratory is actually smaller than present experience with CDF, D0, and SLD, where $20 \%-25 \%$ has been more typical. It is also assumed that some SSCL physicists will participate in the smaller experiments. Figure 8.0 shows the total number of physicists projected for the experimental program with comparison to the SSCL physics staff. In total, 195 experimental physicists (SSCL staff and paid visitors) are projected in FY 1999 at the start of collider operations

The in-house physics groups at the SSCL will help to expedite the design, construction, and operations of the experimental program. A primary responsibility of this group is to provide the liaison between the detector collaborations and the conventional construction design of the experimental areas. Of particular importance are the design of the interaction halls, assembly buildings, control rooms, and the associated supporting utilities. The SSCL physics group is also expected to carry out a responsible role with respect to the design of beam pipes, IR magnets, and test beam facilities.

SSCL scientific collaborators are expected to be involved in the design, fabrication and installation of many of the subsystems of the large experiments. The level of participation will depend on the size and complexity of the system, as well as the amount of effort required on-site to assemble and install that system. Even those systems that can be delivered complete to the SSC, will require in-house liaison physicists to insure smooth integration with the rest of the detector, and to insure compliance with all SSC requirements.

A strong theoretical physics group is an essential component of a high energy physics laboratory. The theory group not only contributes to research and acts as a host to visiting theorists, but will keep experimentalists at the Laboratory informed of the latest developments in theory. This is of great importance, since the goal of the Laboratory is to explore the nature of fundamental interactions and of matter at energies never probed before, and it is only through the interaction between theory and experiment that this can be fully successful. The input from theory can be used to tailor experiments or the analysis of experiments so as to explore various avenues suggested by theory. A staff of 25 FTE's is projected at the start of collider operations (see Figure 9.0). This includes permanent appointees, term appointees and paid visitors.

In order to achieve the above goals, the overall plan is to have a steady growth over the next eight years and to make a smooth transition from the period of the SSC Project to that of a fully operating laboratory in the year 2000 . The complete program including experimental and theoretical physicists with associated technical and computing support is illustrated in Figure 9. The associated budget details are provided in Table 14.0. The annual budget totals are summarized in Table 15.0 and plotted in Figure 10.0. 


\section{FIGURE 8}

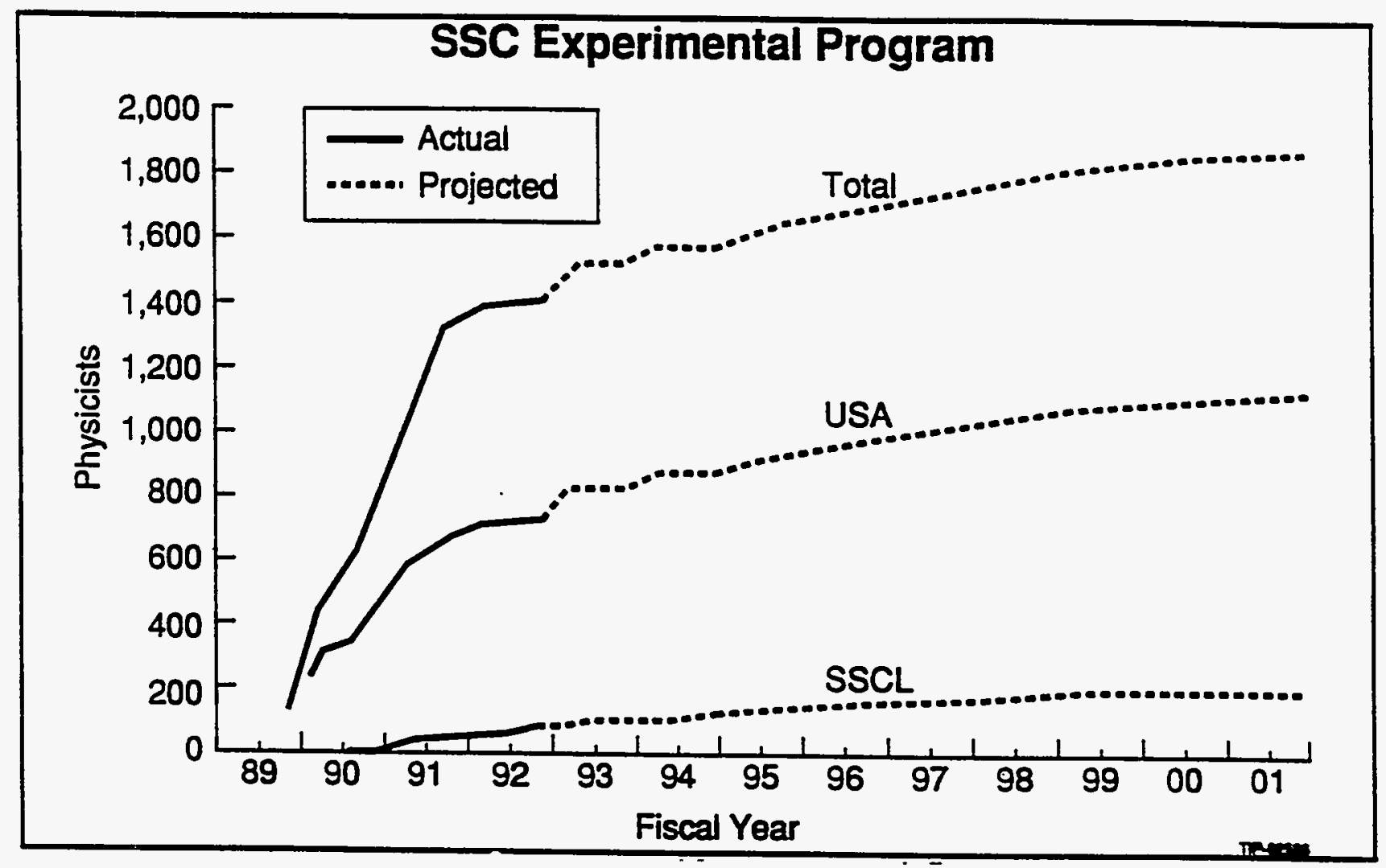


FIGURE 9

SSCL Research Program

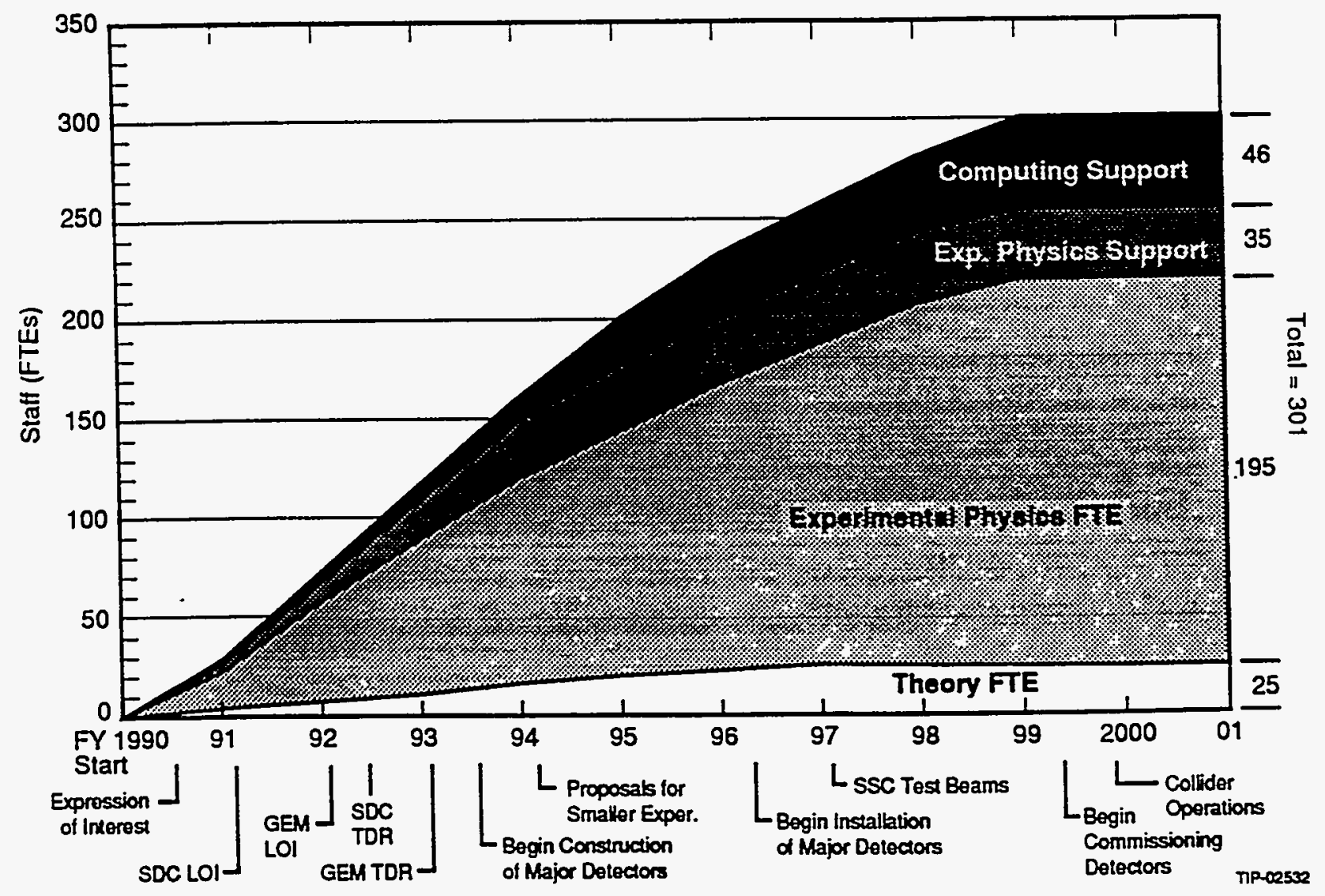




\section{2) Program Support}

There are a number of Physics Division Activities that are included within the TPC through the year FY99. The Physics Division Office, Engineering Resources, Detector and Facilities Coordination and Planning, and support for computing and networking are included in these activities. While there will be some reduction in staff upon completion of the detector fabrications, it is estimated that 150 FTEs are required in FY2000 to support the physics program. Details are provided in a separate report. 
Table 14.0 ... Physics Operations Plan FY91 K\$

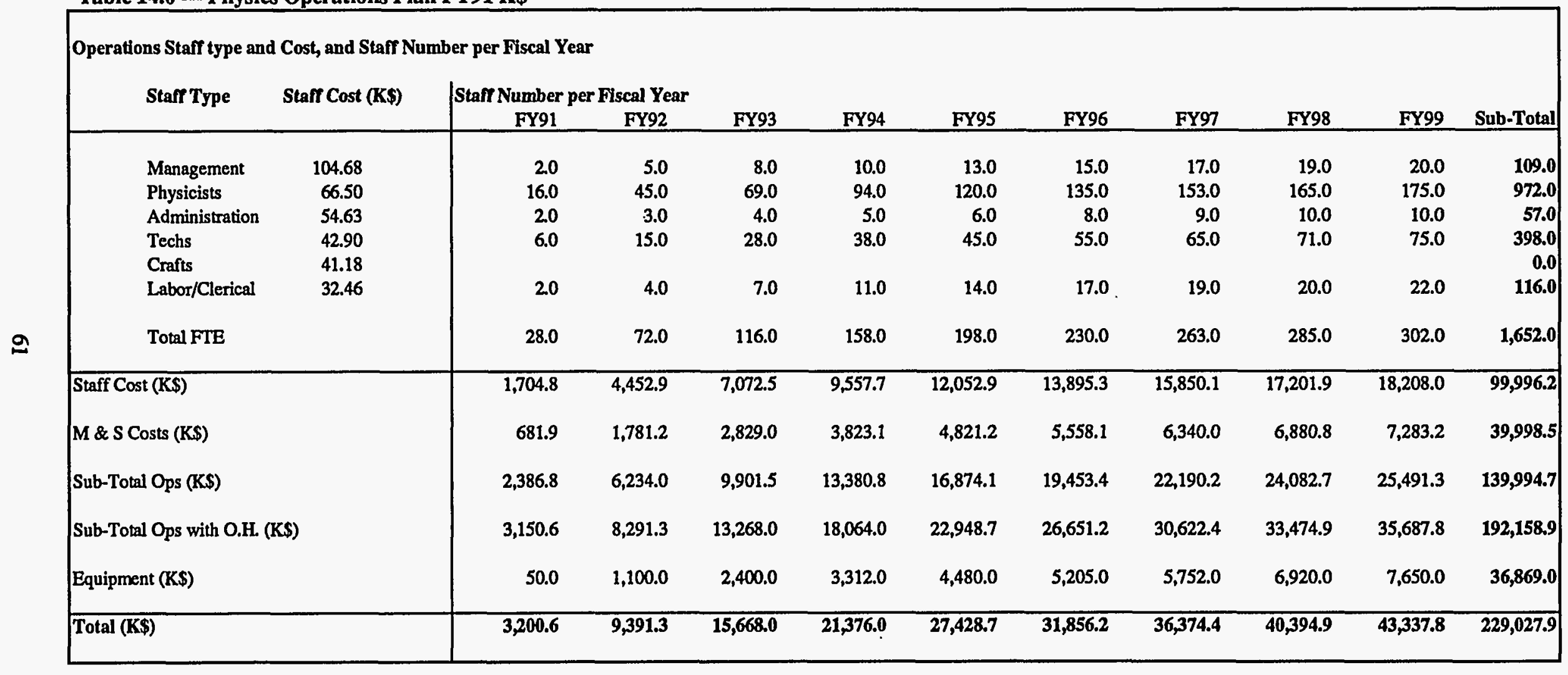


Table 15.0 -..- Physics Operations Cost Summary (FY91 K\$)

\begin{tabular}{|lrrrr|}
\hline & Operation & Op w/OH & Equip & Total \\
\hline FY1991 & $2,386.8$ & $3,150.6$ & 50.0 & $3,200.6$ \\
FY1992 & $6,234.0$ & $8,291.3$ & $1,100.0$ & $9,391.3$ \\
FY1993 & $9,901.5$ & $13,268.0$ & $2,400.0$ & $15,668.0$ \\
FY1994 & $13,380.8$ & $18,064.0$ & $3,312.0$ & $21,376.0$ \\
FY1995 & $16,874.1$ & $22,948.7$ & $4,480.0$ & $27,428.7$ \\
FY1996 & $19,453.4$ & $26,651.2$ & $5,205.0$ & $31,856.2$ \\
FY1997 & $22,190.2$ & $30,622.4$ & $5,752.0$ & $36,374.4$ \\
FY1998 & $24,082.7$ & $33,474.9$ & $6,920.0$ & $40,394.9$ \\
FY1999 & $25,491.3$ & $35,687.8$ & $7,650.0$ & $43,337.8$ \\
& & & & \\
Subtotal & $139,994.7$ & $192,158.9$ & $36,869.0$ & $229,027.9$ \\
& & & & \\
FY2000 & $25,000.0$ & $35,000.0$ & $8,000.0$ & $43,000.0$ \\
\hline
\end{tabular}



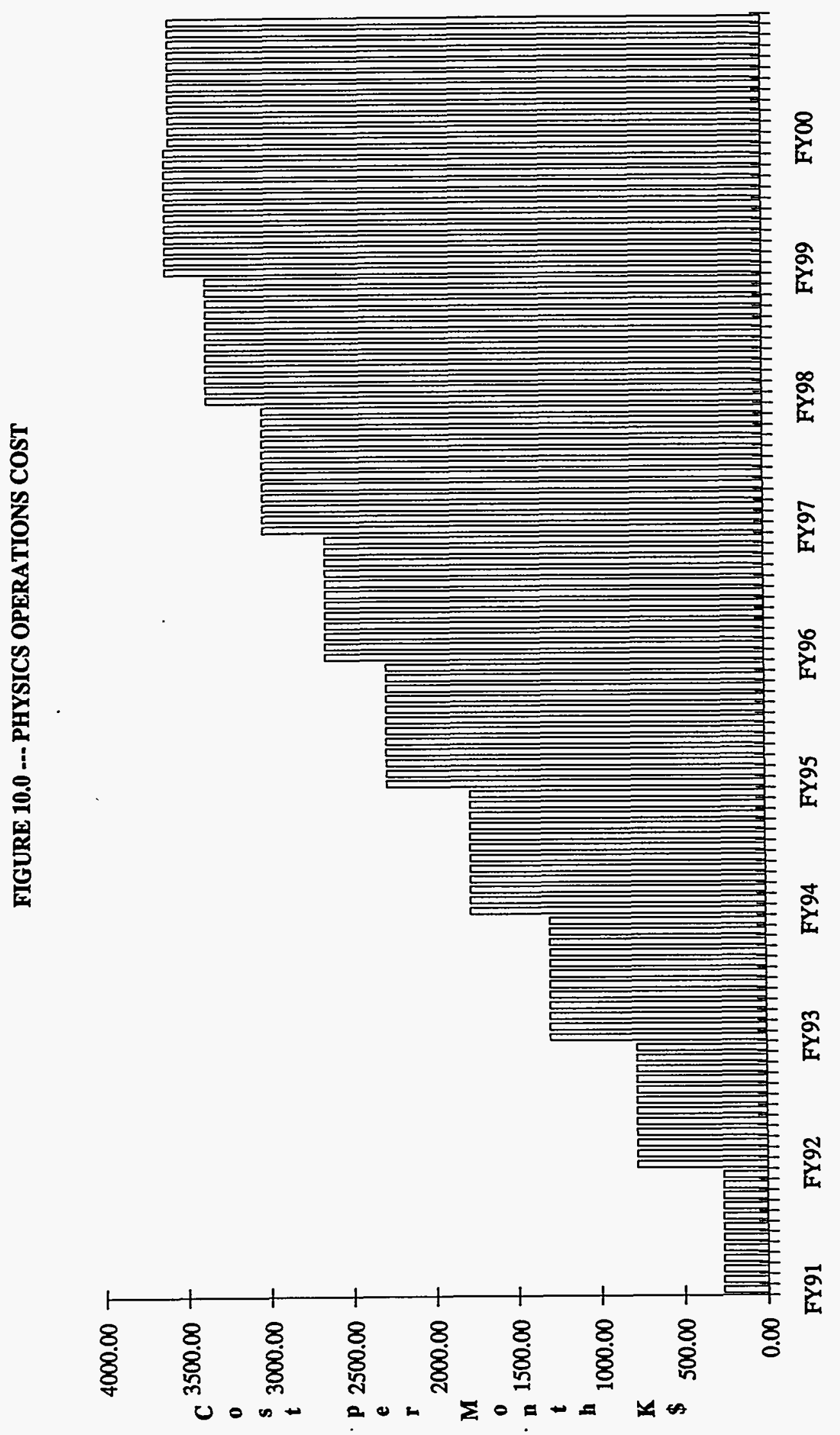


\section{OPERATIONS SUMMARY}

\section{1) Costs}

The projected costs for operations detailed in section B are summarized in this section. This summary includes the costs for operation of the injector accelerators, the test beams, the collider, the magnet research program, and physics research from 1991 through 1999. The results show a total cost of $494 \mathrm{M} \$$ for this period. In the year 2000 , the costs for physics support and GPP are also included resulting in a total annual cost of $300 \mathrm{M} \$$ for the first full year of operations. The information is displayed in Table 16. Table 17 provides the same data distributed by fiscal year. These results are plotted in terms of cost/month and cost/year in Figures $11 \mathrm{~A}$ and $11 \mathrm{~B}$. 
Table 16.0 --- Summary of Integrated Operations Costs (FY 91 M\$)

\begin{tabular}{|c|c|c|c|c|c|c|c|c|c|}
\hline & & INTEGI & L THRC & UGH FY & & & ISCAL Y & $\mathbf{R} 2000$ & \\
\hline & & PRE-OPS * & OPS & EQUIP & AIP & OPS & EQUIP & AIP & GPP \\
\hline LINAC & & 9.73 & 24.37 & 1.46 & 2.93 & 7.22 & 0.43 & 0.86 & \\
\hline LEB & & 8.96 & 20.42 & 1.28 & 2.55 & 7.72 & 0.48 & 0.96 & \\
\hline MEB & & 12.01 & 25.98 & 1.55 & 3.10 & 12.33 & 0.73 & 1.46 & \\
\hline HEB & & 15.95 & 6.46 & 0.33 & 0.65 & 21.04 & 1.07 & 2.13 & \\
\hline TEST BEAMS & & 5.25 & 25.52 & 0.93 & 1.87 & 9.77 & 0.36 & 0.71 & \\
\hline COLLIDER & S1 & 7.96 & 0.00 & 0.00 & 0.00 & 4.48 & 0.37 & 0.64 & \\
\hline & S2 & 7.33 & 0.00 & 0.00 & 0.00 & 4.48 & 0.37 & 0.64 & \\
\hline & S3 & 6.70 & 0.00 & 0.00 & 0.00 & 4.48 & 0.37 & 0.64 & \\
\hline & S4 & 6.07 & 0.00 & 0.00 & 0.00 & 4.48 & 0.37 & 0.64 & \\
\hline & S5 & 5.43 & 0.00 & 0.00 & 0.00 & 4.48 & 0.37 & 0.64 & \\
\hline & S6 & 9.22 & 0.00 & 0.00 & 0.00 & 4.48 & 0.37 & 0.64 & \\
\hline & S7 & 8.28 & 0.00 & 0.00 & 0.00 & 4.48 & 0.37 & 0.64 & \\
\hline & S8 & 7.33 & 0.00 & 0.00 & 0.00 & 4.48 & 0.37 & 0.64 & \\
\hline & S9 & 6.38 & 0.00 & 0.00 & 0.00 & 4.48 & 0.37 & 0.64 & \\
\hline & S10 & 5.43 & 0.00 & 0.00 & 0.00 & 4.48 & 0.37 & 0.64 & \\
\hline EXP & & & & & & & & & \\
\hline FACILITY & Area \#4 & 0.31 & 3.80 & 0.60 & 0.00 & 1.89 & 1.50 & 0.30 & \\
\hline & Area \#1 & 0.89 & 11.30 & 1.70 & 0.00 & 5.30 & 4.50 & 1.00 & \\
\hline & Area \#5 & 2.58 & 44.47 & 7.00 & 0.00 & 15.28 & 14.00 & 3.00 & \\
\hline & Area \#8 & 2.58 & 44.47 & 7.00 & 0.00 & 15.28 & 14.00 & 3.00 & \\
\hline MAGNET & & & & & & & & & \\
\hline FACILITY & & 0.00 & 22.84 & 2.04 & 0.00 & 22.85 & 2.04 & 0.00 & \\
\hline PHYSICS OPS & & 0.00 & 192.16 & 36.87 & 0.00 & 35.00 & 8.00 & 0.00 & \\
\hline DET SUPPORT & & 0.00 & 0.00 & 0.00 & 0.00 & 17.50 & 4.00 & 0.00 & \\
\hline GPP & & & & & & & & & 10.00 \\
\hline TOTAL & & 128.39 & $\stackrel{421.77}{\lfloor}$ & 60.76 & 11.10 & 216.02 & ${ }^{54.75}$ & 19.82 & 10.00 \\
\hline
\end{tabular}

* Pre-operations costs are within the TPC 


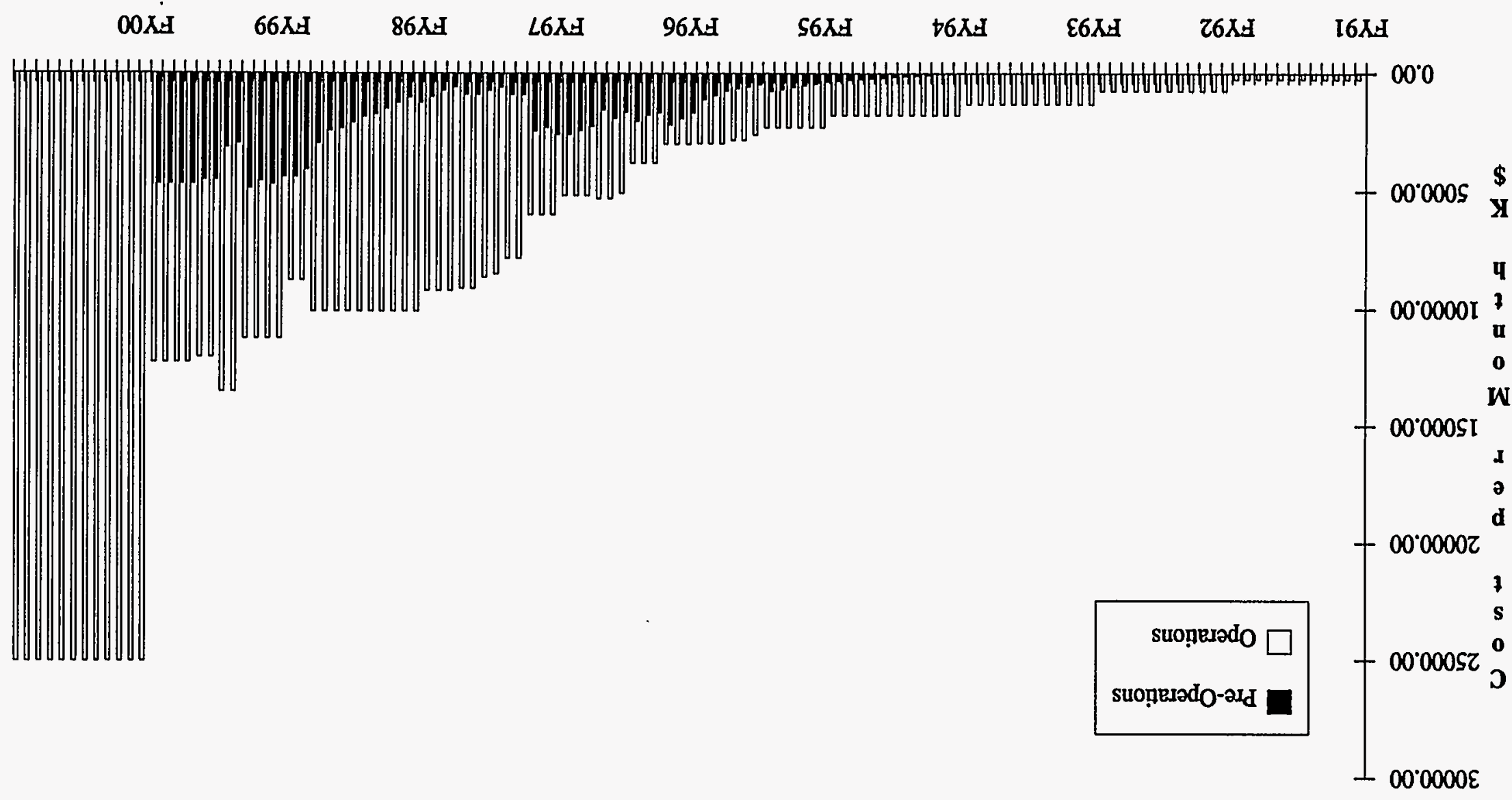

SISOD SNOILVAGdO TVLOL TOSS --- V0'II G\&ODIA 


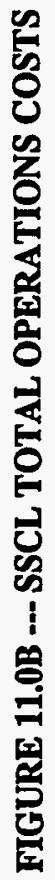

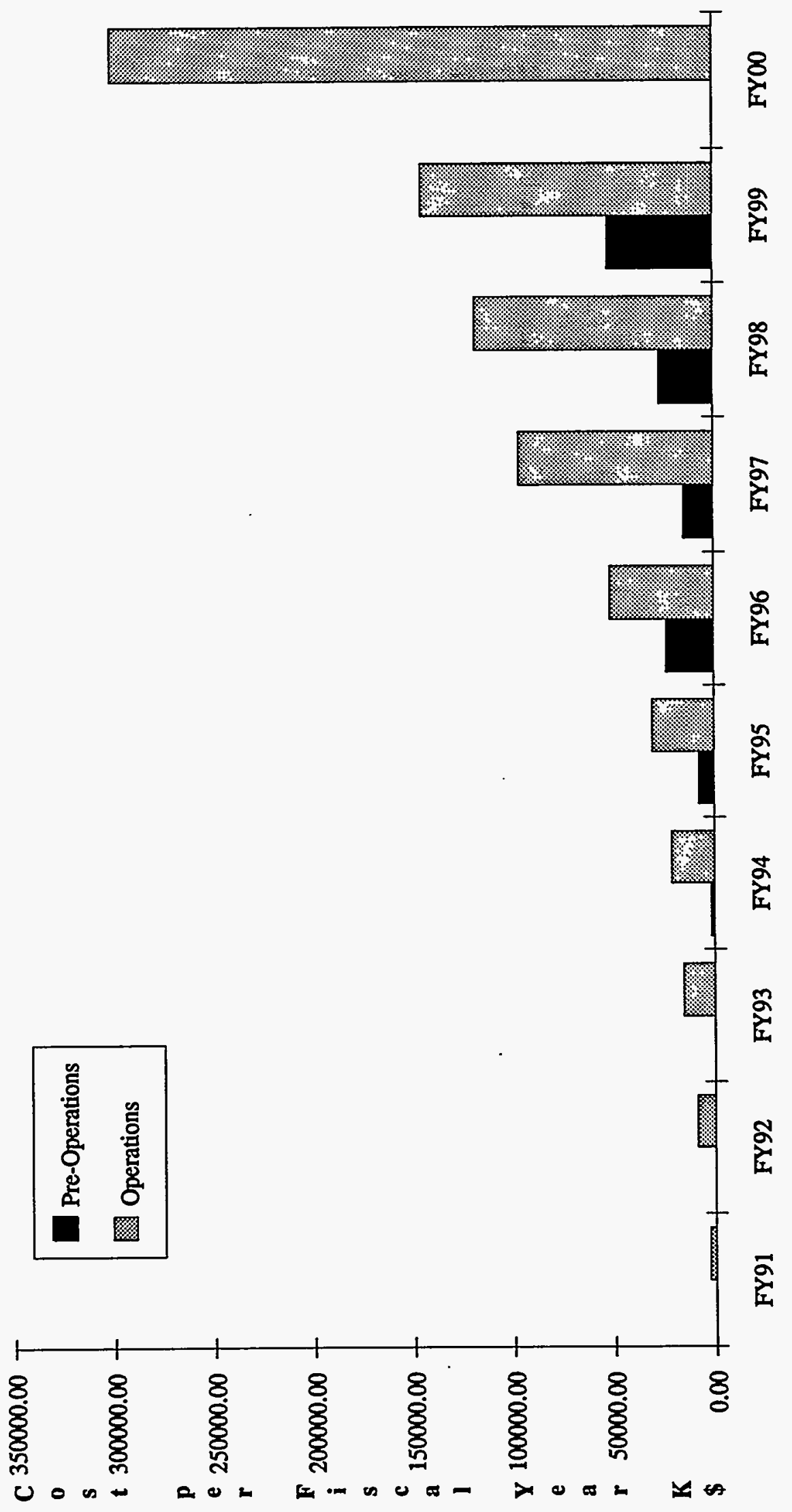


Table 17.0 --- SSCL Total Cost Summary (FY91 K\$)

\begin{tabular}{|lr|rrrrr|} 
& & \multicolumn{3}{|c|}{ Operations } & & \\
\cline { 3 - 7 } & Pre-Op & Direct & W/O.H. & Equip & AIP & Total \\
\hline FY91 & 0.00 & 2386.78 & 3150.56 & 50.00 & 0.00 & 3200.56 \\
FY92 & 0.00 & 6234.03 & 8291.26 & 1100.00 & 0.00 & 9391.26 \\
FY93 & 0.00 & 9901.49 & 13268.00 & 2400.00 & 0.00 & 15668.00 \\
FY94 & 2074.12 & 13380.77 & 18064.04 & 3312.00 & 0.00 & 21376.04 \\
FY95 & 8126.47 & 1919.59 & 25879.22 & 4658.38 & 356.76 & 30894.36 \\
FY96 & 23765.65 & 33410.57 & 45336.05 & 5612.09 & 814.18 & 51762.32 \\
FY97 & 14865.85 & 63741.86 & 85532.12 & 8513.97 & 2937.28 & 96983.38 \\
FY98 & 27004.59 & 76767.37 & 102602.26 & 12530.42 & 3714.66 & 118847.35 \\
FY99 & 52551.41 & 90818.57 & 119650.23 & 22585.29 & 3276.87 & 145512.39 \\
& & & & & & \\
Subtotal & 128388.09 & 315761.03 & 421773.74 & 60762.16 & 11099.75 & 493635.64 \\
& & & & & & \\
FY00 & 0.00 & 167008.47 & 216023.01 & 54750.97 & 19815.54 & 300589.52 \\
\hline
\end{tabular}




\section{2) Manpower}

The manpower associated with the above operations categories are summarized by fiscal year in Table 18. For the year 2000, the population of the component labor categories is provided in Table 19. The total direct staff indicated is 1386 FTE. The associated indirect staff is estimated at approximately 800 FTE for a total SSCL staff of about 2200 FTE in the year 2000. This is exclusive of visiting scientists which are estimated to number about 500 .

From the above data one can compare the "accelerator operations" staff with FNAL. Figure 12 makes a comparison of both the SSC Injector Operations staff as well as the Injector plus Collider staff with the FNAL operations staff at two stages of FNAL development. The projection for SSC injector operations is comparable with the FY91 FNAL operations. Figure 13 provides a comparison of component labor categories for the SSC (Injector and Collider) with the equivalent FY91 FNAL operations. Again a reasonable correspondence is evident between the SSC model and the actual FNAL staff. 
Table 18.0

SSCL DIRECT TECHNICAL STAFF (FTE's)

\begin{tabular}{|c|c|c|c|c|c|c|c|c|c|c|c|c|c|c|}
\hline & Linac & LEB & MEB & HEB & $\begin{array}{r}\text { Test } \\
\text { Beams }\end{array}$ & Collider & $\begin{array}{r}\text { Exp Fac } \\
\# 4\end{array}$ & $\begin{array}{r}\text { Pac } \\
\# 1\end{array}$ & $\begin{array}{r}\text { Exp Fac } \\
\# 5\end{array}$ & $\begin{array}{r}\text { Exp Fac } \\
\# 8\end{array}$ & $\begin{array}{c}\text { Magnet } \\
\text { Lab }\end{array}$ & $\begin{array}{l}\text { Physics } \\
\text { Research }\end{array}$ & $\begin{array}{l}\text { Physies } \\
\text { Support }\end{array}$ & Total \\
\hline$\overline{\text { FY91 }}$ & 0.00 & 0.00 & 0.00 & 0.00 & $\overline{0.00}$ & 0.00 & 0.00 & 0.00 & $\overline{0.00}$ & 0.00 & 0.00 & 28.00 & 0.00 & 28.00 \\
\hline FY92 & 0.00 & 0.00 & 0.00 & 0.00 & 0.00 & 0.00 & 0.00 & 0.00 & 0.00 & 0.00 & 0.00 & 72.00 & 0.00 & 72.00 \\
\hline FY93 & 0.00 & 0.00 & 0.00 & 0.00 & 0.00 & 0.00 & 0.00 & 0.00 & 0.00 & 0.00 & 0.00 & 116.00 & 0.00 & 116.00 \\
\hline FY94 & 22.92 & 0.00 & 0.00 & 0.00 & 0.00 & 0.00 & 0.00 & 0.00 & 0.00 & 0.00 & 0.00 & 158.00 & 0.00 & 180.92 \\
\hline FY95 & 47.92 & 25.67 & 1.83 & 0.00 & 0.29 & 0.00 & 0.00 & 0.00 & 19.25 & 19.25 & 0.00 & 198.00 & 0.00 & 312.21 \\
\hline FY96 & 75.63 & 61.37 & 60.50 & 0.00 & 25.96 & 46.20 & 2.29 & 6.42 & 61.95 & 61.95 & 0.00 & 230.00 & 0.00 & 632.26 \\
\hline FY97 & 61.88 & 69.30 & 82.13 & 0.88 & 38.85 & 64.68 & 7.38 & 20.65 & 92.40 & 92.40 & 18.00 & 263.00 & 0.00 & 811.54 \\
\hline FY98 & 59.58 & 66.73 & 104.87 & 77.88 & 46.20 & 107.80 & 11.00 & 30.80 & 92.40 & 92.40 & 28.00 & 285.00 & 0.00 & 1002.66 \\
\hline FY99 & 77.92 & 87.27 & 137.13 & 148.58 & 46.20 & 181.72 & 11.00 & 30.80 & 92.40 & 92.40 & 80.00 & 302.00 & 0.00 & 1287.41 \\
\hline FY2000 & 55.00 & 61.60 & 96.80 & 138.60 & 46.20 & 184.80 & 11.00 & 30.80 & 92.40 & 92.40 & 125.00 & 302.00 & 150.00 & 1386.60 \\
\hline
\end{tabular}

Table 19.0

SSCL DIRECT STAFF CATEGORIES FOR FY2000 (FTE's)

\begin{tabular}{|c|c|c|c|c|c|c|c|c|c|c|c|c|c|c|c|}
\hline & & Linac & LEB & MEB & HEB & $\begin{array}{r}\text { Test } \\
\text { Beams }\end{array}$ & Colllder & $\begin{array}{r}\text { Exp Fac } \\
\# 4 \\
\end{array}$ & $\begin{array}{r}\text { Exp Fac } \\
\# 1 \\
\end{array}$ & $\begin{array}{r}\text { Exp Fac } \\
\# 5\end{array}$ & $\begin{array}{r}\text { Exp Fac } \\
\# 8 \\
\end{array}$ & $\begin{array}{r}\text { Magnet } \\
\text { Lab }\end{array}$ & $\begin{array}{r}\text { Physics } \\
\text { Research }\end{array}$ & $\begin{array}{r}\text { Physics } \\
\text { Support }\end{array}$ & Total \\
\hline Management & $\overline{E 3}$ & 2.20 & 2.20 & 2.20 & 2.20 & 2.20 & 4.40 & 0.44 & 1.10 & 2.20 & 2.20 & 3.00 & 20.00 & 10.00 & 54.34 \\
\hline Physicists & E2 & 6.60 & 6.60 & 11.00 & 17.60 & 4.40 & 11.00 & 2.20 & 4.40 & 11.00 & 11.00 & 24.00 & 175.00 & 60.00 & 344.80 \\
\hline Engineers & E2 & 8.80 & 11.00 & 15.40 & 26.40 & 6.60 & 33.00 & 2.20 & 6.60 & 19.80 & 19.80 & 48.00 & 0.00 & 27.00 & 224.60 \\
\hline Administration & $(\mathrm{E} 1+\mathrm{E} 2) / 2$ & 2.20 & 2.20 & 2.20 & 4.40 & 2.20 & 4.40 & 0.44 & 1.10 & 2.20 & 2.20 & 4.00 & 10.00 & 5.00 & 42.54 \\
\hline Accel. Operators & E1 & 6.60 & 6.60 & 8.80 & 11.00 & 4.40 & 11.00 & 0.00 & 0.00 & 0.00 & 0.00 & 0.00 & 0.00 & 0.00 & 48.40 \\
\hline Techs & E1 & 22.00 & 26.40 & 44.00 & 61.60 & 19.80 & 88.00 & 3.96 & 11.00 & 33.00 & 33.00 & 44.00 & 75.00 & 30.00 & 491.76 \\
\hline Crafts & N3 & 4.40 & 4.40 & 8.80 & 11.00 & 4.40 & 22.00 & 1.10 & 4.40 & 15.40 & 15.40 & 0.00 & 0.00 & 7.00 & 98.30 \\
\hline Labor/Clerical & N2 & 2.20 & 2.20 & 4.40 & 4.40 & 2.20 & 11.00 & 0.66 & 2.20 & 8.80 & 8.80 & 2.00 & 22.00 & 11.00 & 81.86 \\
\hline Total FTE & - & 55.00 & 61.60 & 96.80 & 138.60 & 46.20 & 184.80 & 11.00 & 30.80 & 92.40 & 92.40 & 125.00 & 302.00 & 150.00 & 1386.60 \\
\hline
\end{tabular}


Figure 12.0

\section{Acclerator Operations Manpower Total SSCL and FNAL}

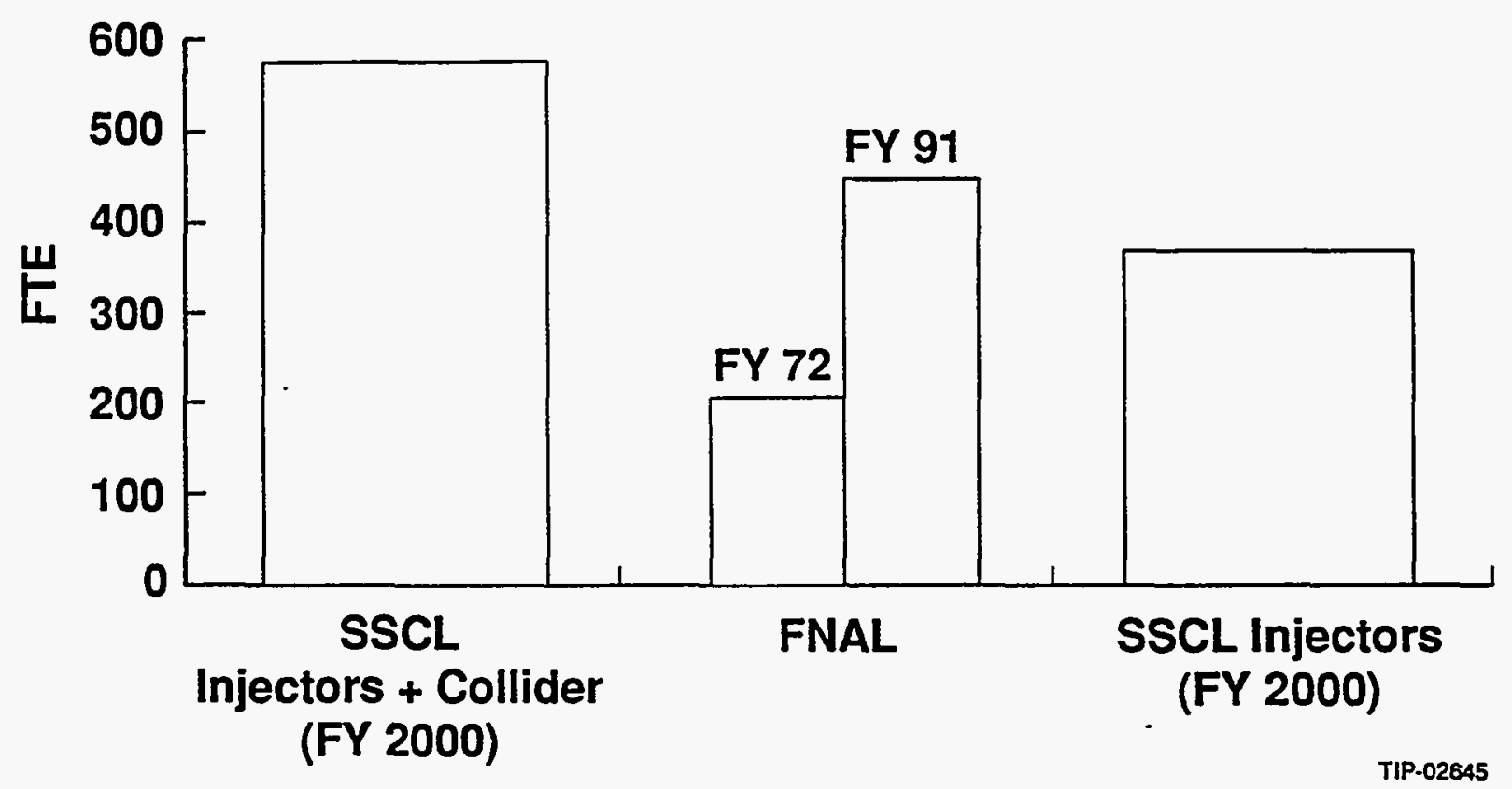




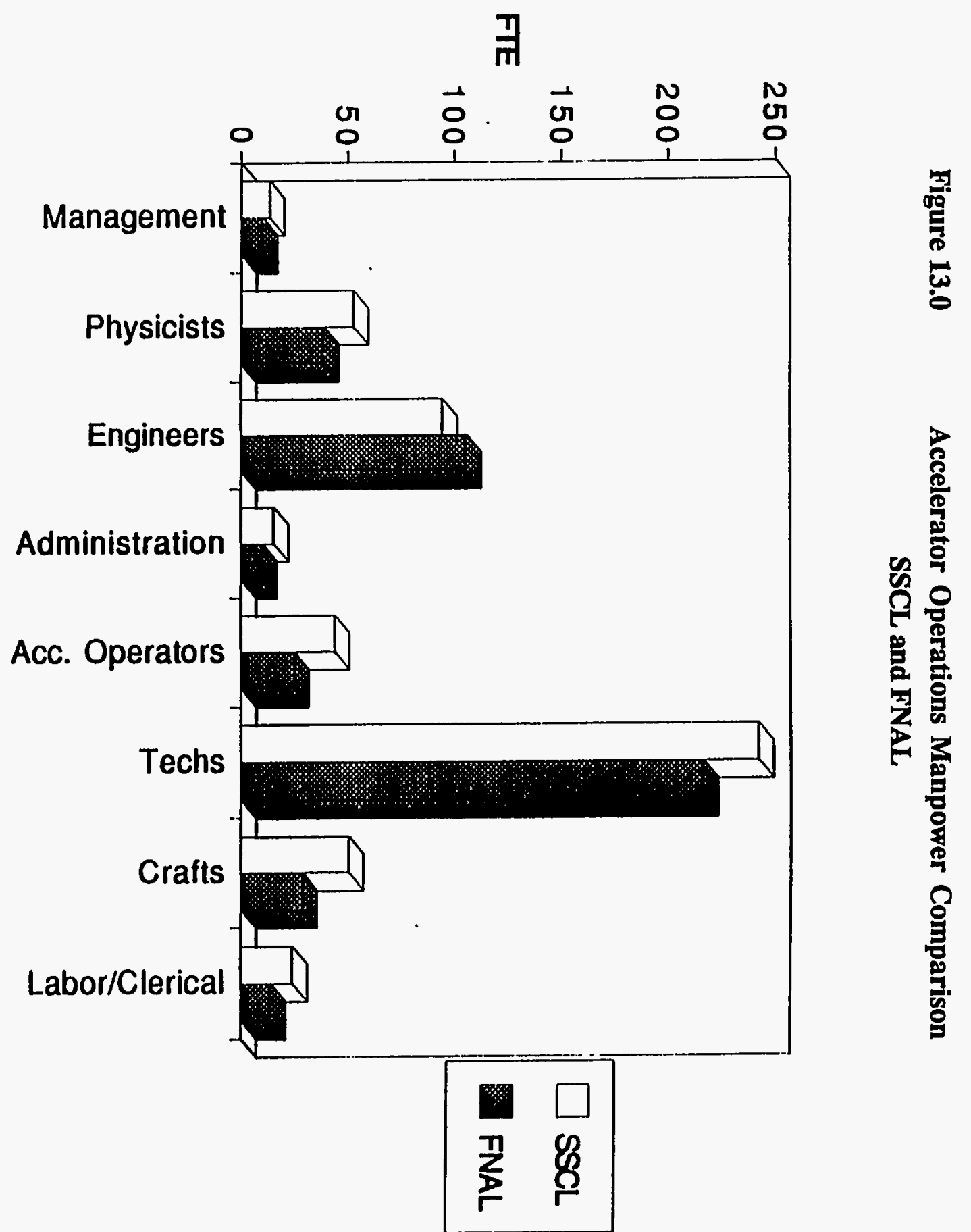

